\title{
INEEL BNCT Research Program Annual Report, CY-2000
}

(Parts 1 and 2)

March 2001

Idaho National Engineering and Environmental Laboratory Bechtel BWXT Idaho, LLC 



\section{INEEL BNCT Research Program Annual Report, CY-2000}

\section{Part 1}

Edited by

J. R. Venhuizen

Published March 2001

Idaho National Engineering and Environmental Laboratory

Idaho Falls, Idaho 83415

Prepared for the

US Department of Energy

Office of Science

Under DOE Idaho Operations Office

Contract DE-AC07-99ID13727 


\begin{abstract}
This report is a summary of the activities conducted in conjunction with the Idaho National Engineering and Environmental Laboratory (INEEL) Boron Neutron Capture Therapy (BNCT) Research Program for calendar year 2000. Applications of supportive research and development, as well as technology deployment in the fields of chemistry, radiation physics and dosimetry, neutron source design and demonstration, and support the Department of Energy's (DOE) National BNCT Program goals are the goals of this Program. Contributions from the individual contributors about their projects are included, specifically described are the following, chemistry: analysis of biological samples and an infrared blood-boron analyzer, and physics: progress in the patient treatment planning software, measurement of neutron spectra for the Argentina RA-6 reactor, and recalculation of the Finnish research reactor FiR 1 neutron spectra, BNCT accelerator technology, and modification to the research reactor at Washington State University for an epithermal-neutron beam.
\end{abstract}




\section{CONTENTS}

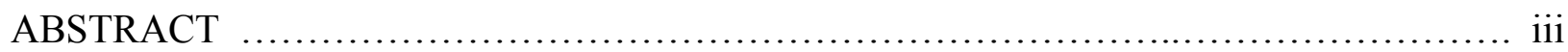

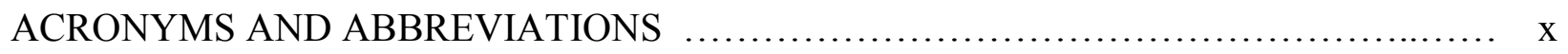

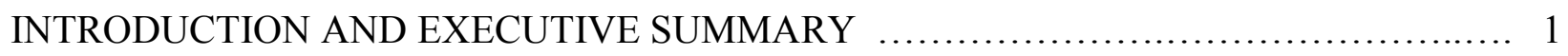

ANALYTICAL CHEMISTRY

W. L. Bauer

DEVELOPMENT OF A BORON ANALYZER BASED UPON INFRARED

SPECTROSCOPY

W. L Bauer, C. Jeffery, J. K. Partin ............................................. 5

RADIATION TREATMENT PLANNING SOFTWARE DEVELOPMENT

AND DEPLOYMENT

D. E. Wessol, C. A. Wemple, F. J. Wheeler, J. J. Cogliati, D. Lyle, G. J. Harkin............. 15

SERAEGS - A DEMONSTRATION CODE

C. A. Wemple, D. W. Nigg.

CONSTRUCTION PROGRESS OF AN EPITHERMAL NEUTRON BEAM FOR

PRECLINICAL BNCT RESEARCH AT WASHINGTON STATE UNIVERSITY

J. R. Venhuizen, D. W. Nigg, C. A. Wemple, G. E. Tripard, S. Sharp, P. R. Gavin .......... 32

IMPROVED EVALUATION OF THE FREE-BEAM SPECTRUM OF THE FiR 1

CLINICAL EPITHERMAL-NEUTRON BEAM FACILITY FOR BNCT

D. W. Nigg, C. A. Wemple, T. Serén, T. Seppälä, I. Auterinen ............................ 53

COLLABORATIVE NEUTRONIC PERFORMANCE CHARACTERIZATION OF

THE CNEA EPITHERMAL-NEUTRON BEAM FACILITY FOR BNCT

D. W. Nigg, H. Blaumann, O. Calzetta Larrieu, J. Longhino, C. A. Wemple,

S. Ribeiro

ADVANCED PROOF-OF-PRINCIPAL EXPERIMENTS FOR FILTERED

EPITHERMAL PHOTONEUTRON BEAMS

D. W. Nigg, W. Scates, Y. D. Harker, C. A. Wemple, F. Harmon

RELEASE OF FREE IONS BY FLUENTALTM MATERIAL IMMERSED IN WATER

D. D. Siemer, D. W. Nigg, P. Hiismäki, S. Autry-Conwell ............................. 90

Appendix A - VTT Leach Test Documentation .............................. 97 


\section{FIGURES}

\section{DEVELOPMENT OF A BORON ANALYZER BASED UPON INFRARED SPECTROSCOPY}

Figure 1. Elimination curve from a dog administered boron as sodium mercaptoundecahydrododecaborate

Figure 2. Single beam infrared spectra acquired with a cell set to a $60 \mu \mathrm{m}$ pathlength with $\mathrm{CaF}_{2}$ windows 6

Figure 3. Schematic of proposed infrared boron analyzer using the infrared LEDs

Figure 4. (a) Effect of water on B analysis by ATR-FTIR spectroscopy,

(b) comparison to transmission cell set to a $60 \mu \mathrm{m}$ pathlength

Figure 5. (a) Calibration curve for ${ }^{10} \mathrm{~B}$ as GB-10 and (b) representative spectra from the calibration curve depicted in (a) 10

Figure 6. Comparison of the IR spectra of GB-10 and BSH in comparison with the emission band from the IR LED and the filter used to eliminate errors caused by the absorption of $\mathrm{CO}_{2}$

Figure 7. Calibration curve obtained from a simple photometric setup employing a $4.2 \mu \mathrm{m}$ IR LED as a source and an ATR multireflection sample cell

\section{RADIATION TREATMENT PLANNING SOFTWARE DEVELOPMENT AND DEPLOYMENT}

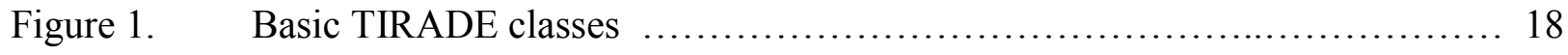

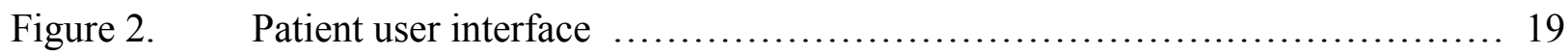

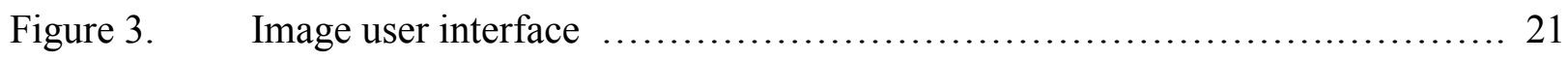

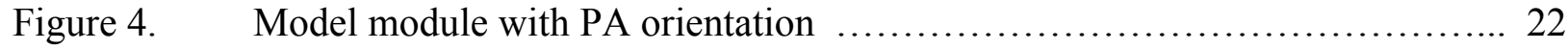

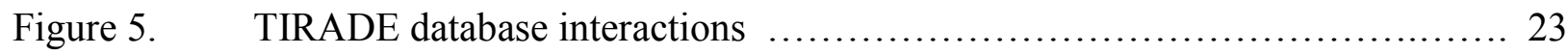




\section{FIGURES (Continued)}

\section{SERAEGS - A DEMONSTRATION CODE}

Figure 1. Dose-depth profile at phantom centerline for large cubic water phantom ..... 28

Figure 2. $\quad$ Dose-depth profile at $(3.5,0)$ for large cubic water phantom ................ 28

Figure 3. Dose-depth profile at $(3.5,3.5)$ for large cubic water phantom $\ldots . \ldots \ldots \ldots . . .29$

Figure 4. Dose-depth profile at phantom centerline for large cubic water phantom, $10 \mathrm{MeV}$ beam .......................................... 29

Figure 5. Dose-depth profile at $(3.5,0)$ for large cubic water phantom, $10 \mathrm{MeV}$ beam .... 30

Figure 6. Dose-depth profile at $(3.5,3.5)$ for large cubic water phantom, $10 \mathrm{MeV}$ beam

Figure 7. Dose-depth profile at phantom centerline for INEEL cylindrical phantom, $10 \mathrm{MeV}$ source

CONSTRUCTION PROGRESS OF AN EPITHERMAL NEUTRON BEAM FOR PRECLINICAL BNCT RESEARCH AT WASHINGTON STATE UNIVERSITY

Figure 1. Elevation plan of the WSU TRIGA reactor facility $\ldots \ldots \ldots \ldots \ldots \ldots \ldots \ldots \ldots \ldots$

Figure 2. Final thermal column shield and adjacent floor area at the WSU TRIGA

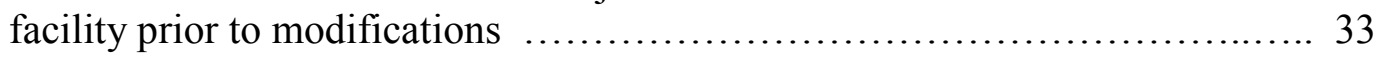

Figure 3. WSU column assembly, with epithermal neutron filter in place ............. 34

Figure 4. Approximate WSU beam stop and treatment room arrangement ............ 34

Figure 5. WSU thermal column with the original graphite and water shielding wall removed

Figure 6. Thermocouple installation in the upstream gamma shielding region of the WSU thermal column cone 36

Figure 7. Partially completed WSU filter-moderator assembly, showing the $\mathrm{AlF}_{3}$, $\mathrm{Al}_{2} \mathrm{O}_{3}$ blocks and boral backing sheet

Figure 8. Completed WSU filter-moderator assembly $\quad$ C....................... 37

Figure 9. WSU treatment room walls during construction $\ldots \ldots \ldots \ldots \ldots \ldots \ldots \ldots \ldots \ldots \ldots$ 


\section{FIGURES (Continued)}

\section{CONSTRUCTION PROGRESS OF AN EPITHERMAL NEUTRON BEAM FOR PRECLINICAL BNCT RESEARCH AT WASHINGTON STATE UNIVERSITY (Continued)}

Figure 10. Cadmium thermal neutron shield and bismuth-lead gamma shield during installation at WSU ................................................ 38

Figure 11. Completed gamma shield assembly at WSU ............................ 39

Figure 12. Bismuth collimator 39

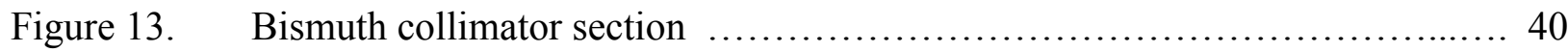

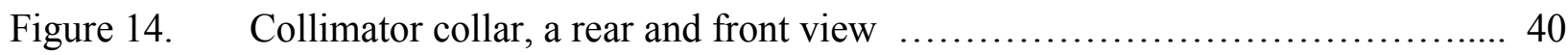

Figure 15. Mockup of the polyethylene-bismuth-lead from inside-out $\ldots \ldots \ldots \ldots \ldots \ldots \ldots 41$

Figure 16. Mockup of the polyethylene-bismuth-lead looking in from the aperture opening

Figure 17. Cut-away cross section of the collimator section, bismuth shield, and

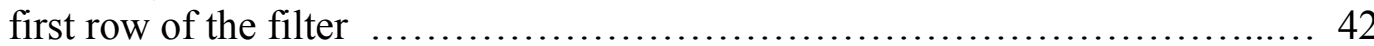

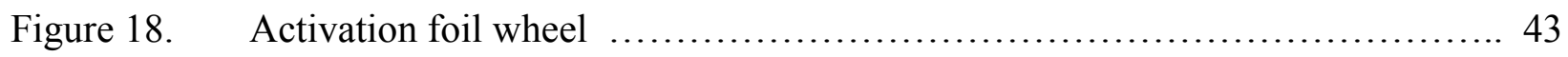

Figure 19. Activation foil packages positioned on the bismuth shield face at WSU ...... 44

Figure 20. Boron sphere used to suppress low-energy neutron flux $\ldots \ldots \ldots \ldots \ldots \ldots \ldots . \ldots 5$

Figure 21. Unfolded free beam neutron spectrum at the downstream bismuth shield face obtained by direct fitting for the WSU epithermal neutron beam facility

\section{IMPROVED EVALUATION OF THE FREE-BEAM SPECTRUM OF THE FiR 1 CLINICAL EPITHERMAL-NEUTRON BEAM FACILITY FOR BNCT}

Figure 1. FiR 1 core and filter/moderator/collimator arrangement (FiR(K63)) as installed since autumn 1997

Figure 2. Foil wheel in position in the 14-cm aperture plane of the FiR 1

epithermal neutron beam 56

Figure 3. Boron sphere used to suppress low-energy neutron flux 56 


\section{FIGURES (Continued)}

\section{IMPROVED EVALUATION OF THE FREE-BEAM SPECTRUM OF THE FIR 1 CLINICAL EPITHERMAL-NEUTRON BEAM FACILITY FOR BNCT}

(Continued)

Figure 4. Unfolded free-beam neutron spectrum obtained by direct least-square fitting for the FiR 1 epithermal neutron beam facility $(14 \mathrm{~cm}$ aperture) $\ldots \ldots \ldots \ldots \ldots .64$

Figure 5. Measured free-beam neutron spectrum obtained by iterative adjustment for the FiR 1 epithermal neutron beam facility (14 $\mathrm{cm}$ aperture) 66

Figure 6. Measured pointwise free-beam neutron flux values (14 cm aperture) obtained at various energy points of interest across the epithermal spectrum by analysis of the stacked foil packages individually $\ldots \ldots \ldots \ldots \ldots \ldots 67$

\section{COLLABORATIVE NEUTRONIC PERFORMANCE CHARACTERIZATION OF THE CNEA EPITHERMAL-NEUTRON BEAM FACILITY FOR BNCT}

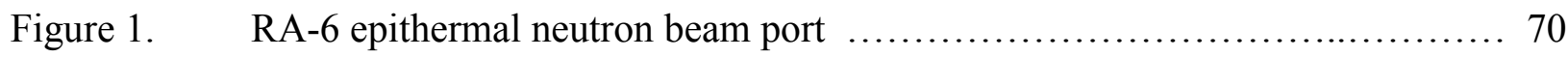

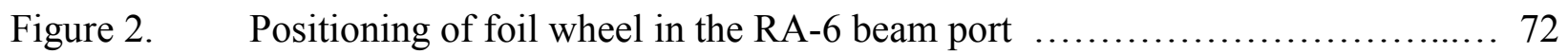

Figure 3. Boron sphere used to suppress low-energy neutron flux $\ldots \ldots \ldots \ldots \ldots \ldots \ldots . \ldots 73$

Figure 4. Unfolded free beam neutron spectrum obtained by direct fitting for the CNEA RA-6 epithermal neutron beam facility

Figure 5. Unfolded free beam neutron spectrum obtained by iterative adjustment for the CNEA RA-6 epithermal neutron beam facility

Figure 6. Anthropomorphic phantom constructed by CNEA for neutron capture therapy research

ADVANCED PROOF-OF-PRINCIPAL EXPERIMENTS FOR FILTERED EPITHERMAL PHOTONEUTRON BEAMS

Figure 1. Epithermal photoneutron source concept for BNCT $\quad \ldots \ldots \ldots \ldots \ldots \ldots \ldots \ldots . \ldots 4$

Figure 2. Early apparatus for filtered photoneutron source experiments $\quad \ldots \ldots \ldots \ldots \ldots . . .65$

Figure 3. L-band electron LINAC at the Idaho Accelerator Center $\ldots \ldots \ldots \ldots \ldots \ldots \ldots . . . . .66$

Figure 4. Partially-assembled neutron production and filtering assembly at the Idaho Accelerator Center L-band LINAC facility 
Figure 5. Completed neuron filtering assembly for photoneutron source experiments $\quad \ldots .88$

\section{TABLES}

\section{SERAEGS - A DEMONSTRATION CODE}

Table 1. Computation times (minutes) for the simple geometry test cases

26

CONSTRUCTION PROGRESS OF AN EPITHERMAL NEUTRON BEAM FOR PRECLINICAL BNCT RESEARCH AT WASHINGTON STATE UNIVERSITY

Table 1. Activation interactions and foils used for the INEEL/WSU preliminary epithermal-neutron beam measurements

\section{IMPROVED EVALUATION OF THE FREE-BEAM SPECTRUM OF THE FiR 1 CLINICAL EPITHERMAL-NEUTRON BEAM FACILITY FOR BNCT}

Table 1. Activation interactions used in the INEEL/VTT FiR 1 epithermal-neutron beam measurements

Table 2. Foil activation rates for the FiR 1 free-beam spectrum measurements

Table 3. Integral neutronic parameters for the FiR 1 free beam (14 $\mathrm{cm}$ aperture) at $250 \mathrm{~kW}$

Table 4. Assumed tissue composition used for Fir beam dosimetry 67

\section{COLLABORATIVE NEUTRONIC PERFORMANCE CHARACTERIZATION OF THE CNEA EPITHERMAL-NEUTRON BEAM FACILITY FOR BNCT}

Table 1. Activation interactions and foils used in the INEEL/CNEA epithermal-neutron beam measurements

Table 2. Saturation activities for the foils used in the RA-6 free beam spectrum Measurements 74

Table 3. Calculated and measured integral flux parameters for the CNEA RA-6 epithermal neutron beam facility

\section{RELEASE OF FREE IONS BY FLUENTAL ${ }^{\mathrm{TM}}$ MATERIAL IMMERSED IN WATER}

Table 1. Raw leach data for FLUENTAL specimens

Table 2. Effective mobilities of fluoride, lithium, and aluminum ions based upon total initial makeup values 
Table 3 Conductivity of the fifth-interval leachates as a function of time 


\section{ACRONYMS AND ABBREVIATIONS}

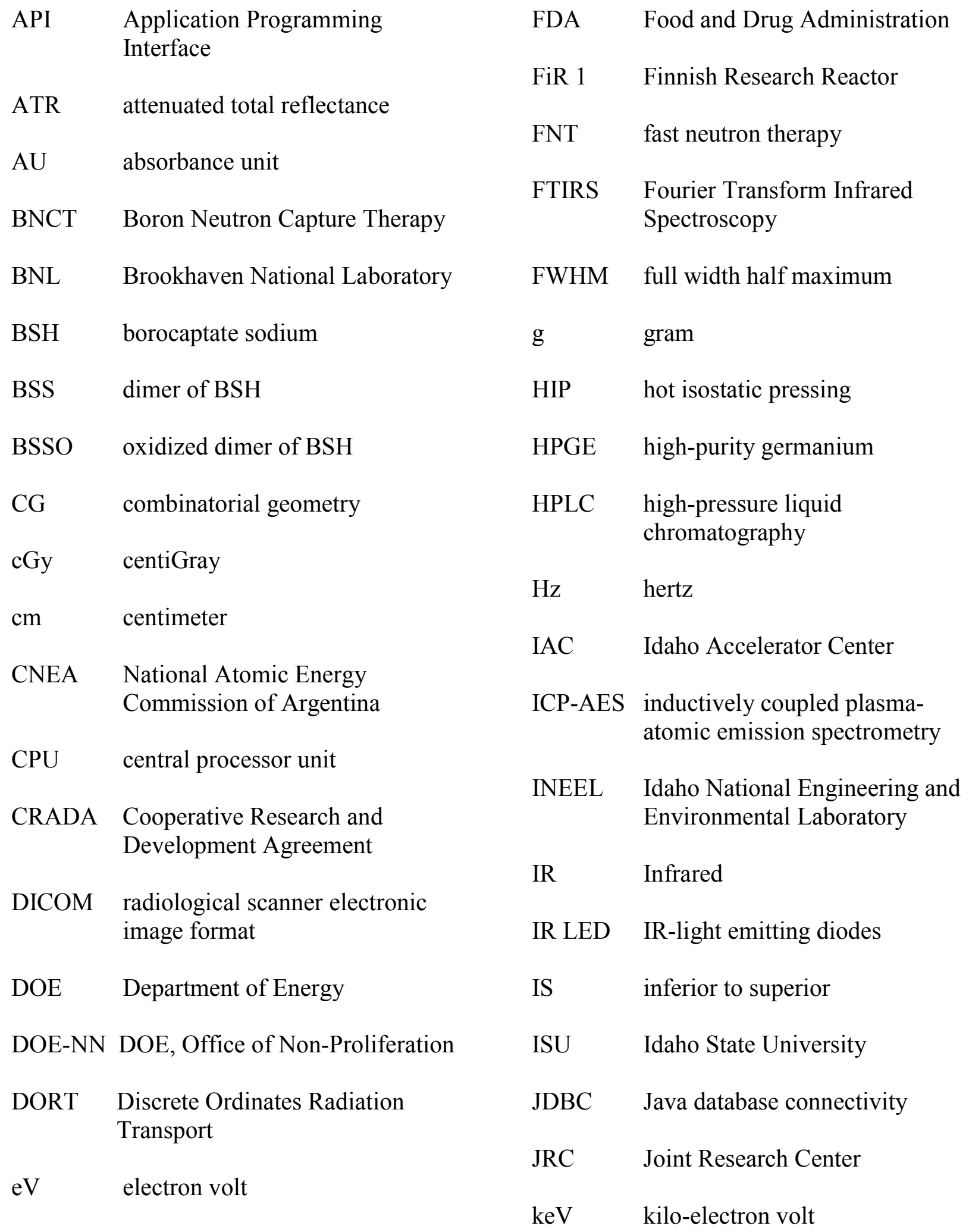




\begin{tabular}{|c|c|c|c|}
\hline $\mathrm{kW}$ & kilowatt & $\mathrm{ppm}$ & parts per million \\
\hline LDRD & $\begin{array}{l}\text { Laboratory Directed Research } \\
\text { and Development }\end{array}$ & $\mathrm{QA} / \mathrm{QC}$ & quality assurance/quality control \\
\hline & & QCL & quantum cascade layers \\
\hline LINAC & linear accelerator & QSH & standard electronic image format \\
\hline LLNL & $\begin{array}{l}\text { Lawrence Livermore National } \\
\text { Laboratory }\end{array}$ & RL & right to left \\
\hline $\mathrm{MC}$ & Monte Carlo & Rtpe & $\begin{array}{l}\text { Radiation treatment planning } \\
\text { environment }\end{array}$ \\
\hline MCNP & Monte Carlo N-Particle & $\mathrm{s}$ & second \\
\hline $\mathrm{MeV}$ & Million-electron volt & $\mathrm{SC}$ & Office of Science \\
\hline $\mathrm{MHz}$ & Megahertz & SERA & $\begin{array}{l}\text { Simulation Environment for } \\
\text { Radiotherapy Applications }\end{array}$ \\
\hline MSU & Montana State University & $\mathrm{S} / \mathrm{N}$ & signal to noise \\
\hline $\mathrm{mm}$ & millimeter & SWT & Southwest Texas State \\
\hline MW & Megawatt & $\mathrm{TE}$ & thermoelectric \\
\hline $\mathrm{mW}$ & milliwatt & & \\
\hline NCI & National Cancer Institute & TIRADE & $\begin{array}{l}\text { Transport Independent } \\
\text { Radiotherapy Environment }\end{array}$ \\
\hline NCT & neutron capture therapy & TRIGA & $\begin{array}{l}\text { Transient Reactor Irradiator- } \\
\text { General Atomics }\end{array}$ \\
\hline NIR & near infrared spectrometer & & \\
\hline NIST & $\begin{array}{l}\text { National Institute of Standards } \\
\text { and Technology }\end{array}$ & UCLA & $\begin{array}{l}\text { University of California, Los } \\
\text { Angeles }\end{array}$ \\
\hline NTL & $\begin{array}{l}\text { Neutron Therapies, Limited } \\
\text { Liability Company }\end{array}$ & UML & unified modeling language \\
\hline ODBC & Open database connectivity & UV & univel geometry \\
\hline OSU & Ohio State University & UW & University of Washington \\
\hline PA & posterior to anterior & VTT & $\begin{array}{l}\text { Valtion Teknillinen } \\
\text { Tutkimuskeskus (Technical }\end{array}$ \\
\hline PET & positron emission tomography & & Research Centre of Finland) \\
\hline PI & principal investigator & WSU & Washington State University \\
\hline
\end{tabular}




$\begin{array}{llll}\text { 3D } & \text { three-dimensional } & \mu \mathrm{s} & \text { microsecond } \\ \mu \mathrm{g} & \text { microgram } & \mu \mathrm{S} & \text { microSiemens } \\ \mu \mathrm{J} & \text { microJoules } & \mu \mathrm{W} & \text { microwatt } \\ \mu \mathrm{m} & \text { micron or micrometer } & & \end{array}$





\section{INEEL BNCT RESEARCH PROGRAM ANNUAL REPORT 2000}

\section{INTRODUCTION AND EXECUTIVE SUMMARY}

The Idaho National Engineering and Environmental Laboratory (INEEL) Boron Neutron Capture Therapy (BNCT) Research Program completed its $14^{\text {th }}$ year under the sponsorship of the United States Department of Energy (DOE), Office of Science (SC). The primary program goal has been and continues to be participation in the establishment of BNCT as a clinically-useful innovative radiotherapy in and of itself, or as an adjunct to fast-neutron therapy. This goal is accomplished through applications of supportive research and development, as well as technology deployment, in the fields of chemistry, radiation physics and dosimetry, and neutron source design and demonstration. These activities have been performed under the auspices of the DOE-SC in close collaboration with several major domestic BNCT and fast-neutron therapy research projects. Where a benefit to the US BNCT effort is realized, the INEEL also maintains formal cooperative arrangements with certain foreign collaborators, specifically in The Netherlands, Finland and Sweden. In late 2000, DOE-NN (Office of Non-Proliferation) requested the participation of the INEEL, in collaboration with the National Atomic Energy Commission of Argentina (CNEA), to conduct some basic neutron measurement studies in the RA-6 facility in San Carlos de Bariloche. Finally, in light of the stated goals of DOE for technology transfer and commercialization, the Program has operated, and continues to operate, in partnership with private US industry through a Cooperative Research and Development Agreement (CRADA), as well as, more recently, through several technology licensing agreements. These arrangements have resulted in substantial leveraging of DOE-SC funding, especially in the important area of advanced boron agent development.

INEEL activities in the field of boron chemistry during 2000 included a continuation of the historical INEEL role as a clearinghouse for quantitative boron analysis. In excess of 1,100 biological samples submitted by DOE-supported BNCT research organizations were analyzed for boron content. In addition, an ongoing borocaptate sodium (BSH) shelf life monitoring study for Ohio State University (OSU) continued throughout the year. Work continued on a real-time infrared blood-boron analyzer that will be able to sample the boron content of a patient's blood by infrared absorption spectrum techniques, since the absorption spectrum contains a feature common to all boron hydride compounds.

The internationally-recognized INEEL SERA (Simulation Environment for Radiotherapy Applications) computational dosimetry and treatment planning software system continued to be supported during the year. The initial release of SERA occurred in 1998, and considerable refinement and additional feature development took place in 1999. The participation of BNCT research centers worldwide serve as benchmarking and testing institutions for SERA, providing extremely valuable feedback and suggestions for improvement. Work has begun on a new targeted radiotherapy treatment planning tool. This tool will take advantage of the many benefits of using the Java programming language to store the data and display the results. It is anticipated that the INEEL researchers will work closely with Lawrence Livermore National Laboratory (LLNL) to incorporate their photon radiotherapy planning tool. 
With the completion of the DOE-sponsored epithermal-neutron BNCT clinical trials at Brookhaven National Laboratory (BNL), INEEL attention has shifted toward the development of new technologies useful for BNCT-augmented Fast Neutron Therapy (FNT), and toward additional basic research focused on the clinical introduction of improved boron agents. This has been done in connection with a longstanding relationship established with a CRADA partner, Neutron Therapies, Limited Liability Company (NTL), as well as under separate collaborations with the University of Washington (UW) fast-neutron radiotherapy program, and with DOEsponsored radiobiological research efforts conducted by the Washington State University (WSU) School of Veterinary Medicine. Human biodistribution studies of one alternate boron agent continued through most of 2000 at UW under a Food and Drug Administration (FDA) approved protocol, with in-kind technical support from the INEEL. These studies are in preparation for the possible initiation in 2001 of privately-funded human trials of BNCT-enhanced FNT for certain lung tumors and high-grade brain tumors using the UW clinical fast-neutron facility. Furthermore, construction of a new epithermal neutron beam facility for preclinical research at WSU continued during the year, in a collaborative effort of INEEL and WSU, with a significant funding component from internal WSU sources.

Detailed articles describing the key 2000 INEEL activities and accomplishments summarized here are presented in the remainder of this report. References to further information are included at the end of each section for that particular section.

Finally, in addition to the baseline BNCT activities supported directly at the INEEL by DOE-SC, further supportive, but separate, BNCT-related university research is sponsored by the INEEL Laboratory Directed Research and Development (LDRD) Program and the Idaho Accelerator Alliance. Two university BNCT projects are currently ongoing under this type of sponsorship. These are: 1) development by INEEL and Idaho State University of an interesting concept for an electron accelerator based epithermal-neutron source for BNCT; and, 2) investigation, by the University of Tennessee, of the application of Positron Emission Tomography (PET) to the quantitative imaging of boron agents in vivo, with incorporation of the resulting information into the treatment planning process via the SERA system. 


\section{ANALYTICAL CHEMISTRY}

\section{W.F. Bauer}

Idaho National Engineering and Environmental Laboratory, Idaho Falls, ID

\section{INTRODUCTION}

There were three basic analytical chemistry related functions during 2000. The first of these functions was simply the determination of boron in a variety of biologically related samples using inductively coupled plasma atomic emission spectroscopy (ICP-AES). The second function was to continue with the quality assurance/quality control (QA/QC) of borocaptate sodium (BSH) for use in clinical trials. The third function was to initiate a task to examine the feasibility of using novel infrared devices to create a device to measure blood boron as boron hydrides in vivo. This device is described in the next article, Development of a Boron Analyzer based upon Infrared Spectroscopy.

\section{Determination of Boron in Biological Samples}

During 2000, only 859 samples were received for analysis. With samples from FY 1999, the total samples analyzed came to 1135. Of the samples received, 653 were from dogs and/or rodents from the Boron Neutron Capture Therapy (BNCT) related programs in Dr. P. Gavin's group at Washington State University (WSU), 73 were of stock solutions to be sent to WSU and assorted other preparations from Dr. F. Hawthorne's group at University of California, Los Angeles (UCLA), 1 was from Dr. D. Feakes at Southwest Texas State University (SWT), 129 were from the trials being done in conjunction with Neutron Therapies, LLC (NTL) at the University of Washington, and 3 were from NTL. The anticipated level of samples from WSU never materialized in 2000 for various reasons. As the neutron beam comes on line, the anticipated number of samples from WSU will increase dramatically. During 2001, samples are expected from UCLA, WSU, UW, SWT, and George Kabalka at the University of Tennessee.

\section{QA/QC Analyses of BSH}

The QA/QC analyses of BSH during 2000 were related to the effort at The Ohio State University (OSU) to evaluate BSH in a Phase I clinical trial. The BSH was natural abundance boron, and originally purchased by OSU from Centronics, Ltd. Shelf-life studies on the final forms packaged by Iowa State University were initiated in 1996 and were continued throughout 2000. The studies consisted of the use of high-pressure liquid chromatography (HPLC) to determine the changes in the $\mathrm{BSH}$ dimer (BSS) and oxidized dimer (BSSO) in samples of the BSH in its final packaged form stored at $4^{\circ} \mathrm{C}$. As of this time, no significant increase of the BSS and BSSO concentrations has been noted. The initial results of the clinical trial were published in the journal Neurosurgery by OSU. ${ }^{1}$ 


\section{REFERENCE}

1. Goodman, J. H.; Yang, W. L.; Barth, R. F.; Gao, Z. X.; Boesel, C. P.; Staubus, A. E.; Gupta, N.; Gahbauer, R. A.; Adams, D. M.; Gibson, C. R.; Ferketich, A. K.; Moeschberger, M. L.; Soloway, A. H.; Carpenter, D. E.; Albertson, B. J.; Bauer, W. F.; Zhang, M. Z.; Wang, C. C., "Boron neutron capture therapy of brain tumors: Biodistribution, pharmacokinetics, and radiation dosimetry of sodium borocaptate in patients with gliomas," Neurosurgery, 47, 2000, 608-621. 


\title{
DEVELOPMENT OF A BORON ANALYZER BASED UPON INFRARED SPECTROSCOPY
}

\author{
W.F. Bauer, C. Jeffery, and J.K. Partin \\ Idaho National Engineering and Environmental Laboratory, Idaho Falls, ID
}

\section{INTRODUCTION}

Real-time, or near real-time, measurement of boron concentrations would be a useful tool in many aspects in the development and practice of Boron Neutron Capture Therapy (BNCT). Rapid turnaround and screening of samples in pharmacokinetic studies would be a significant enhancement of these studies. Direct monitoring of "blood" boron concentrations during neutron irradiation would also be a valuable contribution to BNCT. For example, Figure 1 is the boron elimination curve from a dog in an irradiation experiment where a target dose was to be achieved. The boron elimination from this dog was atypical during the actual irradiation time, as the elimination was expected to follow the line. The ability to monitor the boron elimination "on-the-fly" would have resulted in much more precise control over the radiation dose delivered.

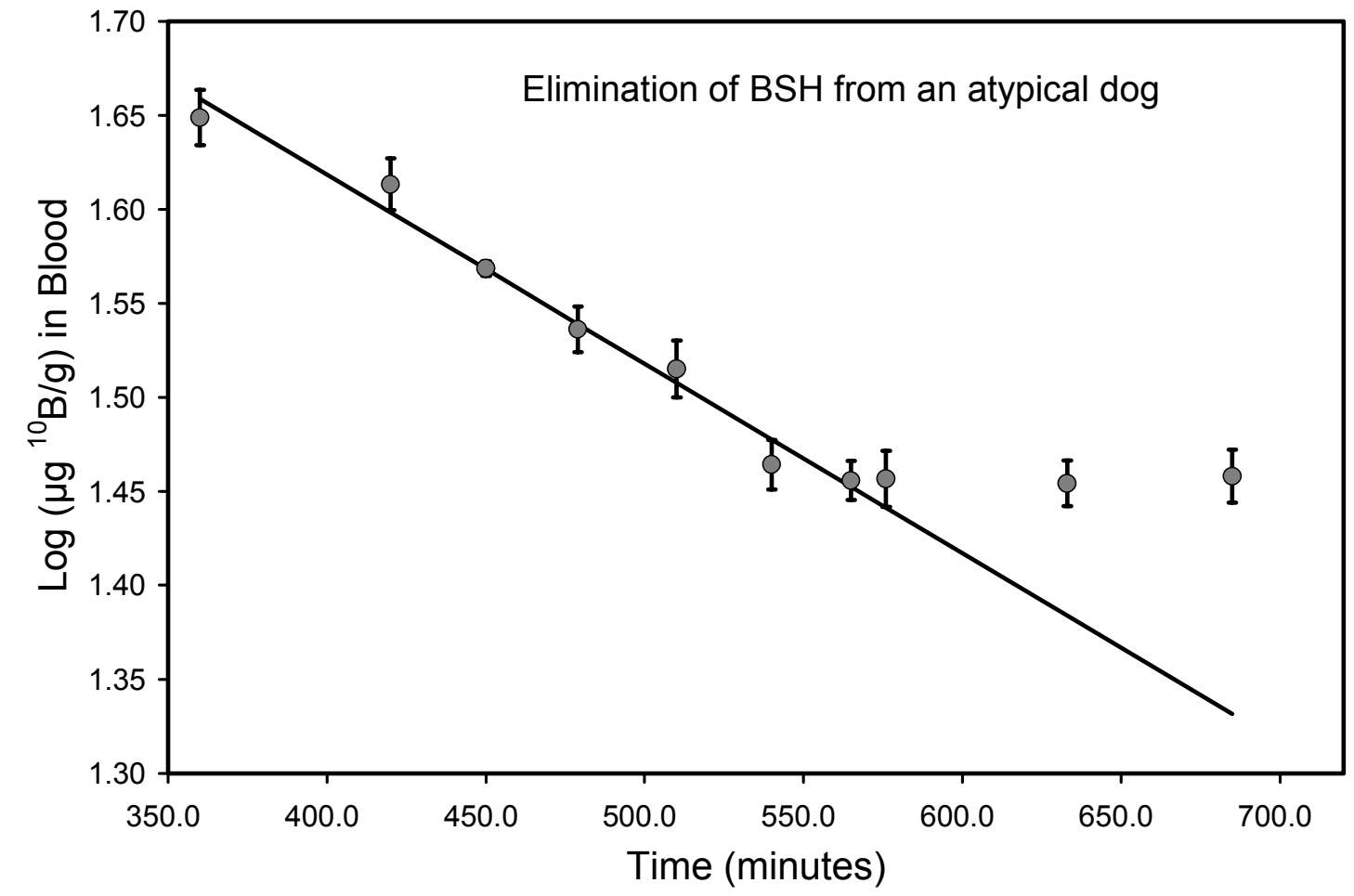

Figure 1. Elimination curve ${ }^{1}$ from a dog administered boron as sodium mercaptoundecahydrododecaborate (BSH). Blood boron concentration was expected to follow the concentrations predicted by the line. 
In addition to the need for a real- to near real-time boron measurement for adjusting irradiation times, a simple laboratory tool for boron determinations would significantly reduce lost time and costs associated with boron analyses. Sample turnaround times for most experiments could be reduced from days or months to minutes if a simple laboratory instrument were available to determine boron concentrations.

Infrared (IR) spectroscopy has been suggested as a potential tool for boron determinations in BNCT related studies because many of the boron delivery agents being considered for BNCT are polyhedral borane derivatives ${ }^{2-6}$. The B-H stretch for these compounds generally occurs at $2400-2650 \mathrm{~cm}^{-1}$. Using this spectral region, detection limits as low as $2.5-5 \mu \mathrm{g} \mathrm{B} / \mathrm{g}$ in blood plasma have been reported ${ }^{2,3,5}$. Infrared analysis for B is rapid; however, it is limited by the achievable detection limits due to the strong absorbance by water throughout most of the mid-infrared spectral region and limitations imposed by the sample cell.

Boron concentration can be determined with infrared spectroscopy because the absorbance of the B-H bond at 2400-2650 $\mathrm{cm}^{-1}$ follows Beer's law,

$$
\mathrm{A}=\varepsilon b C,
$$

where $\mathrm{A}$ is absorbance $\left(\mathrm{A}=-\log \left(\mathrm{I} / \mathrm{I}_{0}\right)\right), \varepsilon$ is the absorptivity coefficient, $\mathrm{b}$ is the pathlength, and $\mathrm{C}$ is the concentration. Absorbance spectroscopy is essentially based upon

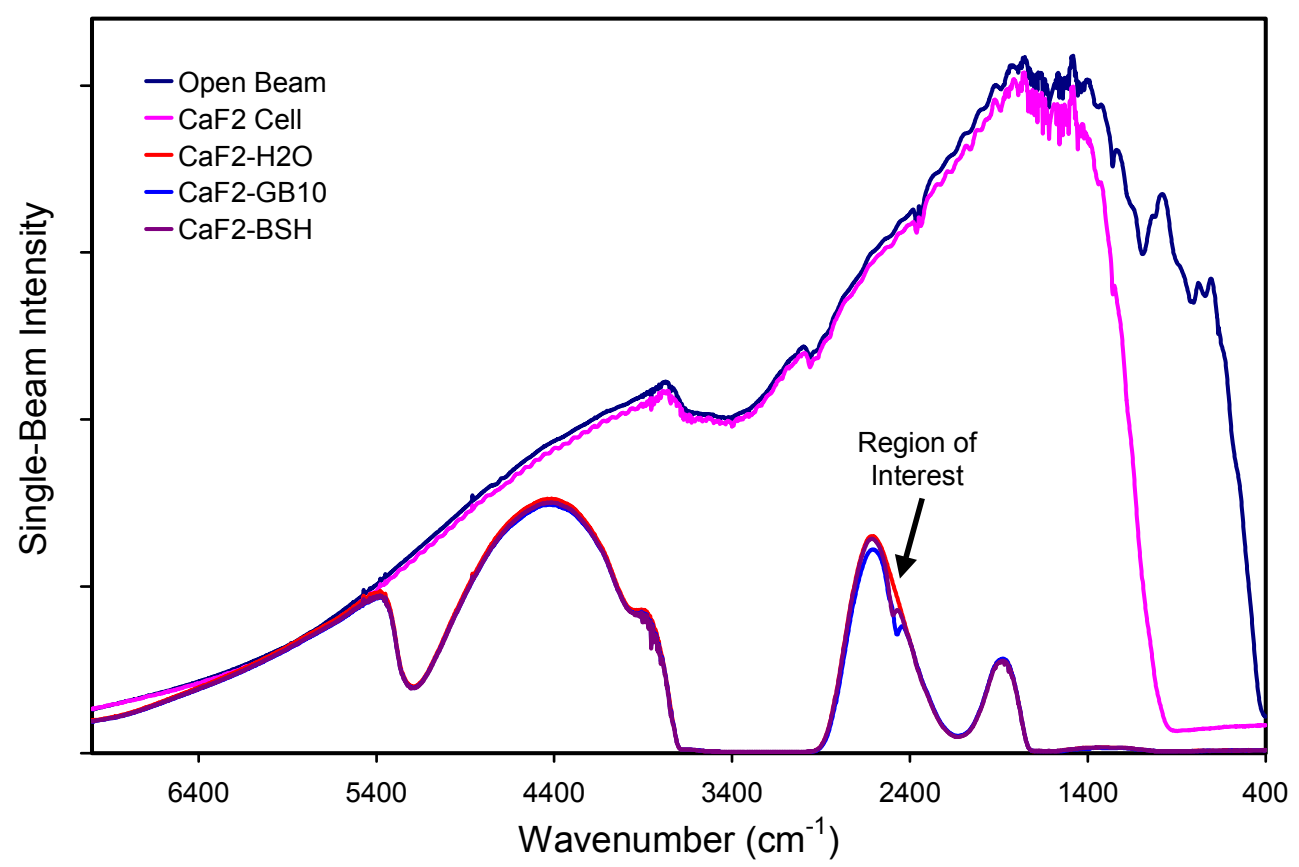

Figure 2. Single beam infrared spectra acquired with a cell set to a $60 \mu \mathrm{m}$ pathlength with $\mathrm{CaF}_{2}$ windows. Water in the cell significantly reduces the light throughput below $\sim 3500 \mathrm{~cm}^{-1}$. 
determining the difference between a large signal with no analyte $\left(\mathrm{I}_{0}\right)$ and a reduced signal when the analyte is present (I). Typically, quantitative analysis is performed at $\leq 1$ absorbance unit $(90 \%$ light absorbed $=1 \mathrm{AU})$. In modern instruments, it is common to have detection limits in the $10^{-4} \mathrm{AU}$ range (measures $\sim 0.023 \%$ of light absorbed). Clearly, decreasing $\mathrm{I}_{0}$ significantly reduces the size of the measured difference relative to the readout range, resulting in an overall increase in noise due to a loss of signal resolution. Figure 2 demonstrates the problems caused by water in infrared absorbance spectroscopy. These single beam spectra were collected with a $60 \mu \mathrm{m}$ pathlength transmission cell with $\mathrm{CaF}_{2}$ windows. The empty cell essentially transmits $100 \%$ of the light to the detector above $1400 \mathrm{~cm}^{-1}$ within the limitations of the other optical components in the system. Filling the cell with water makes most of the spectrum completely unusable. Fortunately, in the case of the polyhedral borane compounds, the absorbance of water is at a local minimum in the spectral region where the primary B-H absorbance band is. In this area $>65 \%$ of the infrared energy is absorbed by water and the few $100+$ ppm of B as GB10 or BSH is barely visible. Use of longer pathlengths would also increase the absorbance of water, further reducing the signal to noise $(\mathrm{S} / \mathrm{N})$ ratio and increasing the detection limits.

One possibility is to have more intense IR sources in the spectral region of concern. The typical source for infrared spectroscopy is a blackbody radiator operating at 1000 $1200^{\circ} \mathrm{C}$. This source produces $<<\mu \mathrm{J}$ of energy in the $2400-2650 \mathrm{~cm}^{-1}$ region of the spectrum. In recent years, infrared light emitting diodes (IR LEDs) and quantum cascade lasers (QCLs) emitting in the infrared region and operating at room temperature have been developed and are now commercially available on a limited basis. Both types of devices are being designed primarily for gas detection systems ${ }^{7-9}$, so limited wavelengths are available. For IR LEDs, the devices generally available emit at 1.8, 2.8 or 3.4, 3.8, 4.2 , or $4.8 \mu \mathrm{m}$ for water, hydrocarbons, $\mathrm{H}_{2} \mathrm{~S}, \mathrm{CO}_{2}$, and $\mathrm{CO}$, respectively. IR LEDs have output energies in the range of a few $\mu \mathrm{W}$ to $\mathrm{mW}$ when operated in continuous and pulsed modes, respectively, with a full width half maximum (FWHM) bandwidth of $\sim 0.5 \mu \mathrm{m}$. At room temperatures, QCLs can produce up to several 10's to 100's of $\mathrm{mW}$ at a single wavelength, and some are tunable over short ranges ${ }^{10}$. Other diode lasers are available but are generally quite expensive, as they must be operated at liquid nitrogen temperature and only operate at $\mu \mathrm{W}-\mathrm{mW}$ outputs.

Even if more intense sources were available to help overcome the limitations posed by the presence of water in the sample by increasing the amount of transmitted light $\left(\mathrm{I}_{0}\right)$, the sample cell would still be a limitation. The accuracy and precision are further reduced in transmission spectroscopy when such short pathlengths $(<60 \mu \mathrm{m})$ are required because of the inherent difficulties in filling and cleaning the sample cell and in reproducing the pathlength accurately in the process. Attenuated total reflectance (ATR) is one method that has been used in IR spectroscopy to overcome the issues associated with nonreproducible pathlengths ${ }^{11}$.

The work reported here describes our first attempts at overcoming the limitations of infrared absorbance spectroscopy described above. We are attempting to use attenuated total reflectance and some novel new infrared sources to build a laboratory instrument 
whose sole purpose is to measure boron from polyhedral borane compounds in biological samples. The instrument to be developed will be capable of analysis in both liquid and solid samples.

\section{EXPERIMENTAL SETUP}

The attenuated total reflectance cell used for the Fourier Transform infrared (FTIR) studies was the Foundation Series Multi-Reflection HATR accessory (Thermo SpectraTech, Shelton, CT) with a ZnSe internal reflection crystal mounted in trough plate for liquid samples. A Wilmad (Buena, NJ) VariPath transmission cell with $\mathrm{CaF}_{2}$ windows was used for the transmission measurements. Infrared spectra were acquired on a BioRad (Hercules, CA) FTS 60 FTIR spectrometer. Scans were acquired at $4 \mathrm{~cm}^{-1}$ resolution and were typically an average of 32 scans.
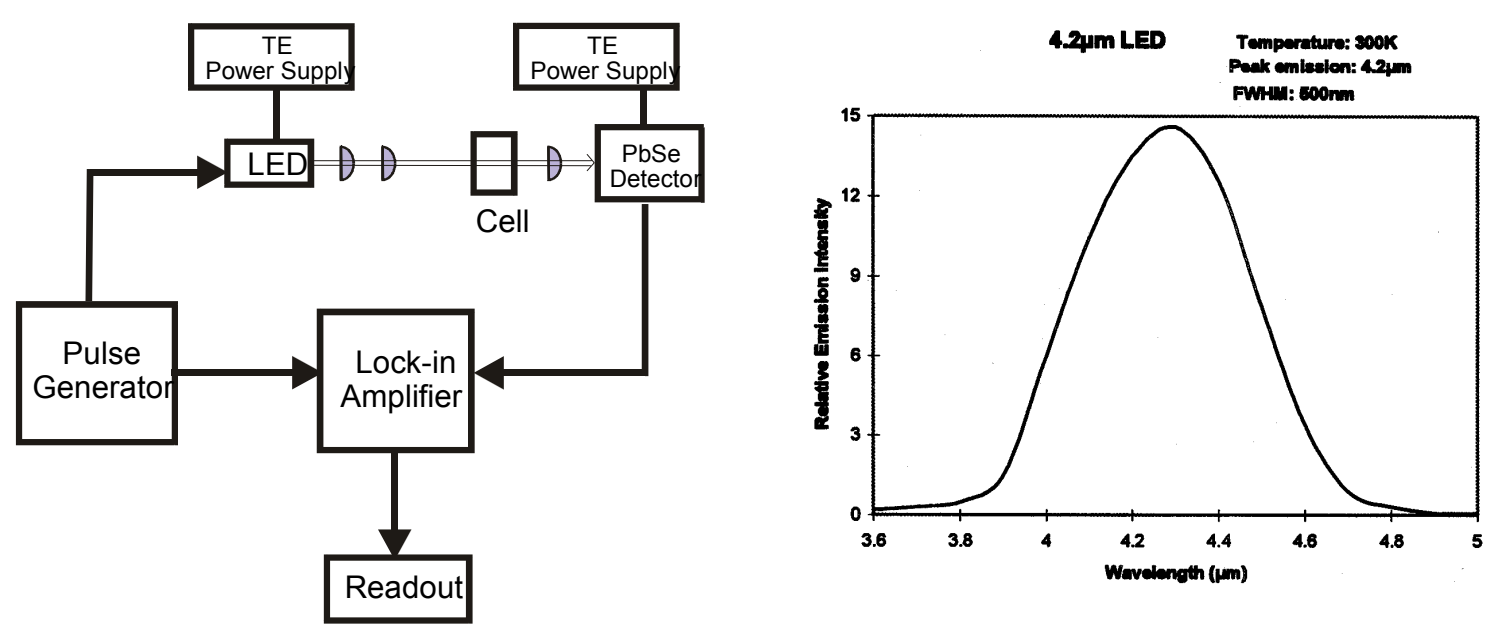

Figure 3. Schematic of proposed infrared boron analyzer using the infrared LEDs. Plot on right shows output of $4.2 \mu \mathrm{m}$ IR LED used in this work.

Figure 3 is a simple schematic of the proposed infrared analyzer for boron analysis in biological samples. The IR LED was from Boston Electronics and was operated in a pulsed mode using a pulse generator from Laser Monitoring Systems, LTD, with power supplied by a HP6216A Power Supply. In pulsed mode, the output power that can be obtained is considerably more than in a continuous mode. In general, a 200-600 $\mu \mathrm{sec}$ pulse with a 10\%-15\% duty cycle seems to work well with the PbSe (Electro-Optical Systems, Inc.) detector used at this time. The IR LED peak emission shifts to a slightly shorter wavelength with a corresponding slight net increase in output when cooled, so the IR LED was cooled to $-30^{\circ} \mathrm{C}$ with the built-in thermoelectric (TE) cooler. The TE cooler on both the IR LED source and the PbSe detector were powered and controlled by power supplies from Electro-Optical Systems, Inc. The IR LED pulses and the detector output were input into a lock-in amplifier. The output from the lock-in amplifier was fed into a 

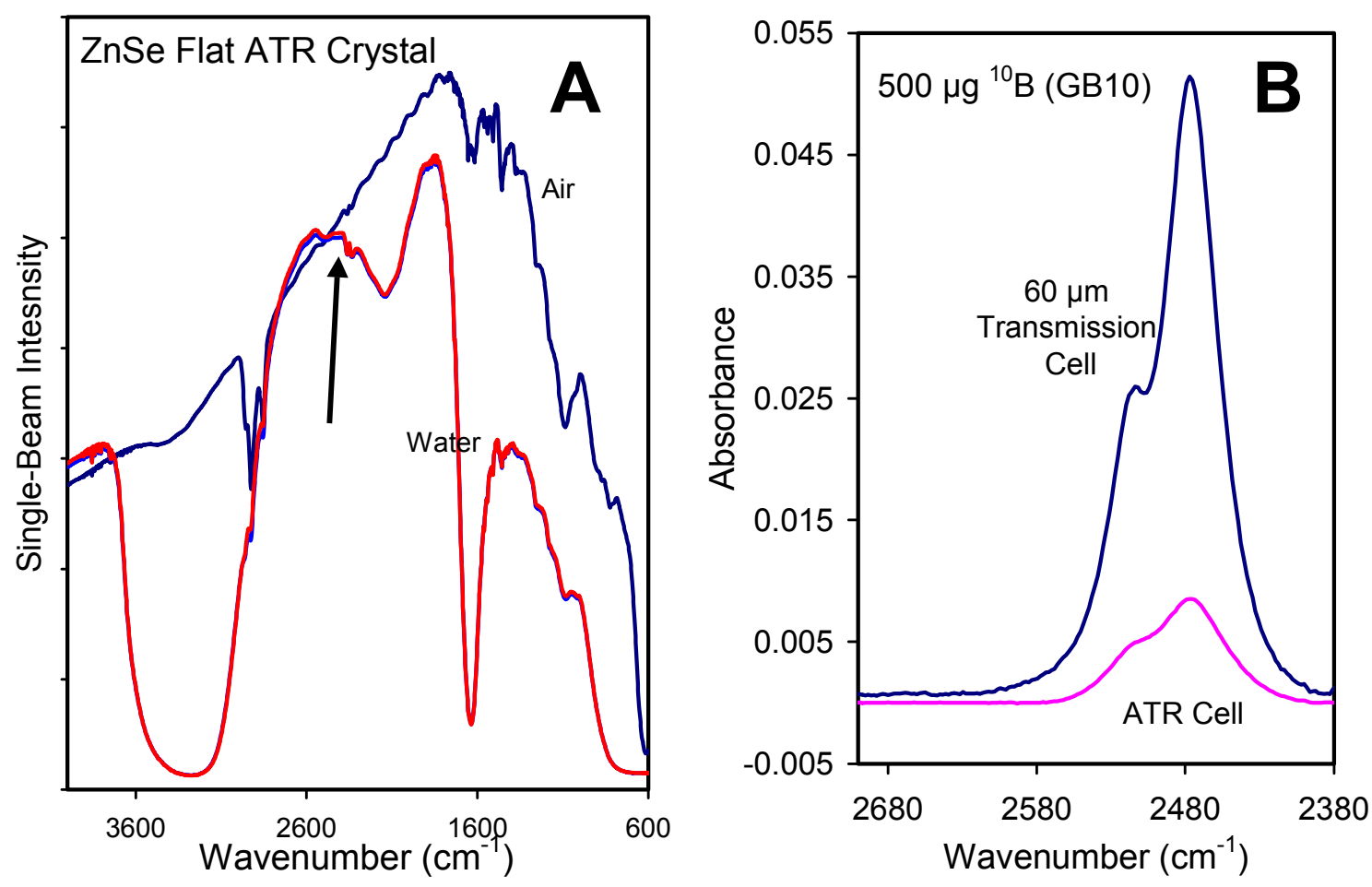

Figure 4. (a) Effect of water of B analysis by ATR-FTIR spectroscopy. (b) comparison to transmission cell set to a $60 \mu$ pathlength. The effective pathlenth for the ATR cell is $10 \mu \mathrm{m}$.

Keithley 194A high speed voltmeter being used as the readout device. Output from the IR LED was collimated through two $\mathrm{BaF}_{2}$ lenses and passed through the sample cell, which was either the transmission or ATR cell described above. A third $\mathrm{BaF}_{2}$ lens was used to focus the light from the cell onto the detector that had a $4 \mu \mathrm{m}$ bandpass filter directly in front of the detector window. The bandpass filter had a nominal $0.15 \mu \mathrm{m}$ bandpass with $88.7 \%$ light transmission at $4 \mu \mathrm{m}$ and $70+\%$ light being transmitted between the approximate range of 3.94-4.06 $\mu \mathrm{m}$. Solutions of GB-10 were prepared by simple dilutions from $10,000 \mu \mathrm{g}{ }^{10} \mathrm{~B} / \mathrm{g}$ as GB-10 stock solutions (Neutron Therapies, Inc.). Solutions of BSH were prepared by weighing the dry salt from an INEEL archive sample and diluting with deionized (18 megaohm) water.

\section{RESULTS AND DISCUSSION}

Initial baseline studies were carried out on the FTIR. Figure 2 shows the dramatic effect that water has on the decrease in available signal in the spectral regions of interest for the determination of boron hydride compounds. Figure 4 a shows the same effect when using the multipass ATR cell. In the region of interest, there is actually very little loss of signal due to water; therefore, somewhat less noise is expected from the absorbance calculation. The net decrease in pathlength is noticeable in Figure $4 \mathrm{~b}$. The ATR cell has an apparent 
pathlength of only $\sim 10 \mu \mathrm{m}$. However, the reproducibility and decrease in overall noise is readily apparent in the calibration curve from the ATR cell shown in Figure 5. The detection limit estimated from the standard deviation of the y-intercept is $\sim 5 \mu \mathrm{g} \mathrm{B} / \mathrm{g}$. Clearly, even with the path length as short as $\sim 10 \mu \mathrm{m}$, detection limits comparable to those achieved in much longer pathlength cells can be obtained. This is primarily the result of more reproducible sampling, but may also be partially attributed to having the same noise level on more intense signals used for the absorbance calculation. It is also readily apparent that the absorbance that needs to be measured accurately to achieve at least this detection limit is quite low, i.e., noise of $\leq 0.0001 \mathrm{AU}$.
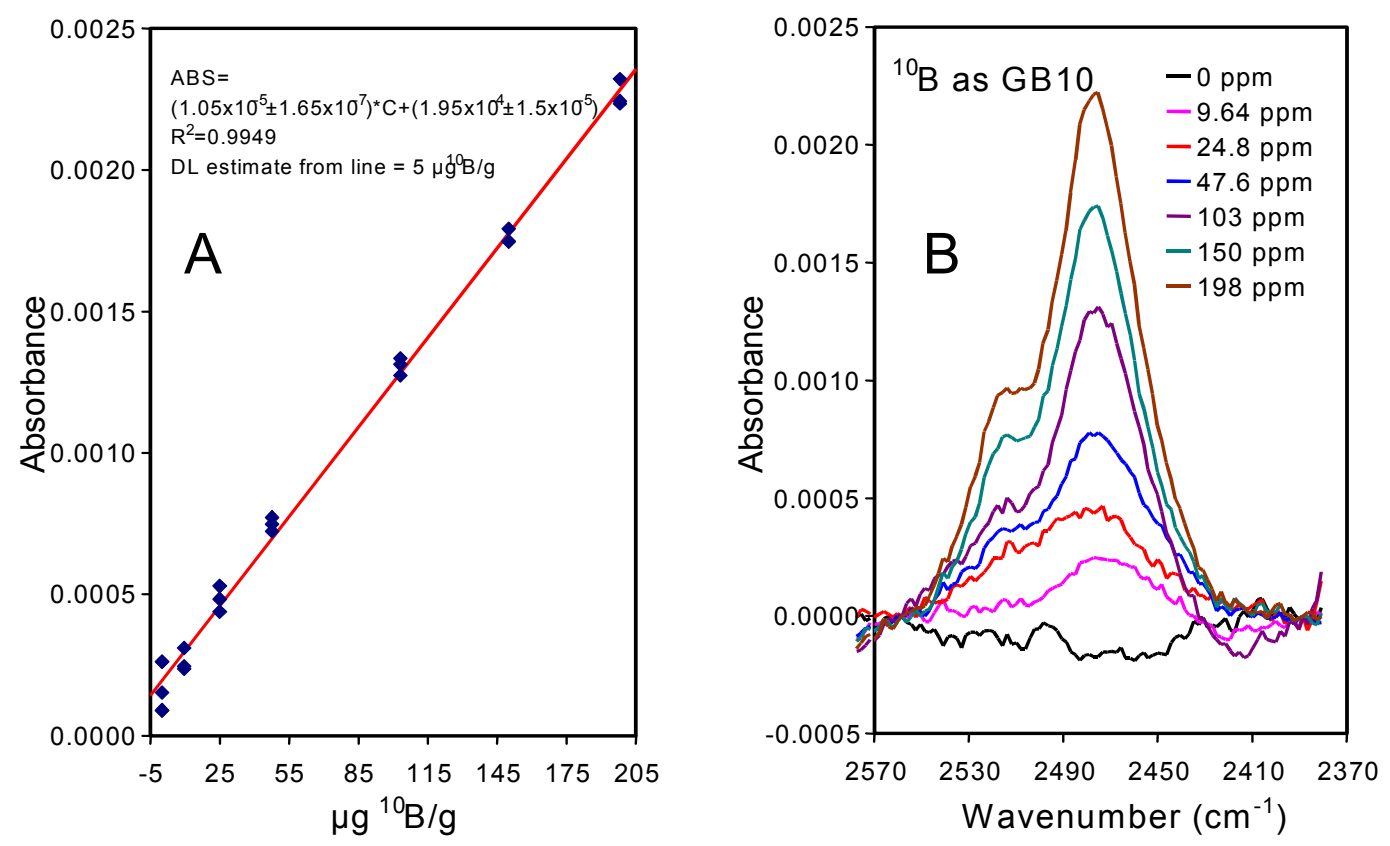

Figure 5. (a) Calibration curve for ${ }^{10} \mathrm{~B}$ as $\mathrm{GB}-10$ (b) representative spectra from the calibration curve depicted in (a).

Short term noise measured with the IR LED system shown in Figure 3 can be as low as $0.0001 \mathrm{AU}$ with only the lenses and an empty transmission cell present. Figure 6 shows the approximate output of the IR LED used superimposed on the absorption spectra of BSH and GB-10. Since the IR LED was optimally designed to measure carbon dioxide, a filter with a bandpass centered on $4 \mu \mathrm{m}\left(2500 \mathrm{~cm}^{-1}\right)$ was purchased to eliminate noise that would arise from air currents causing varying absorbance of carbon dioxide. This filter transmits $\sim 88 \%$ of the light at four microns. The approximate shape of the bandpass of transmitted light is also shown in Figure 6. Overall, the filter transmits only $11 \%-12 \%$ of the total energy output of the IR LED. This is comparable to the total energy that 


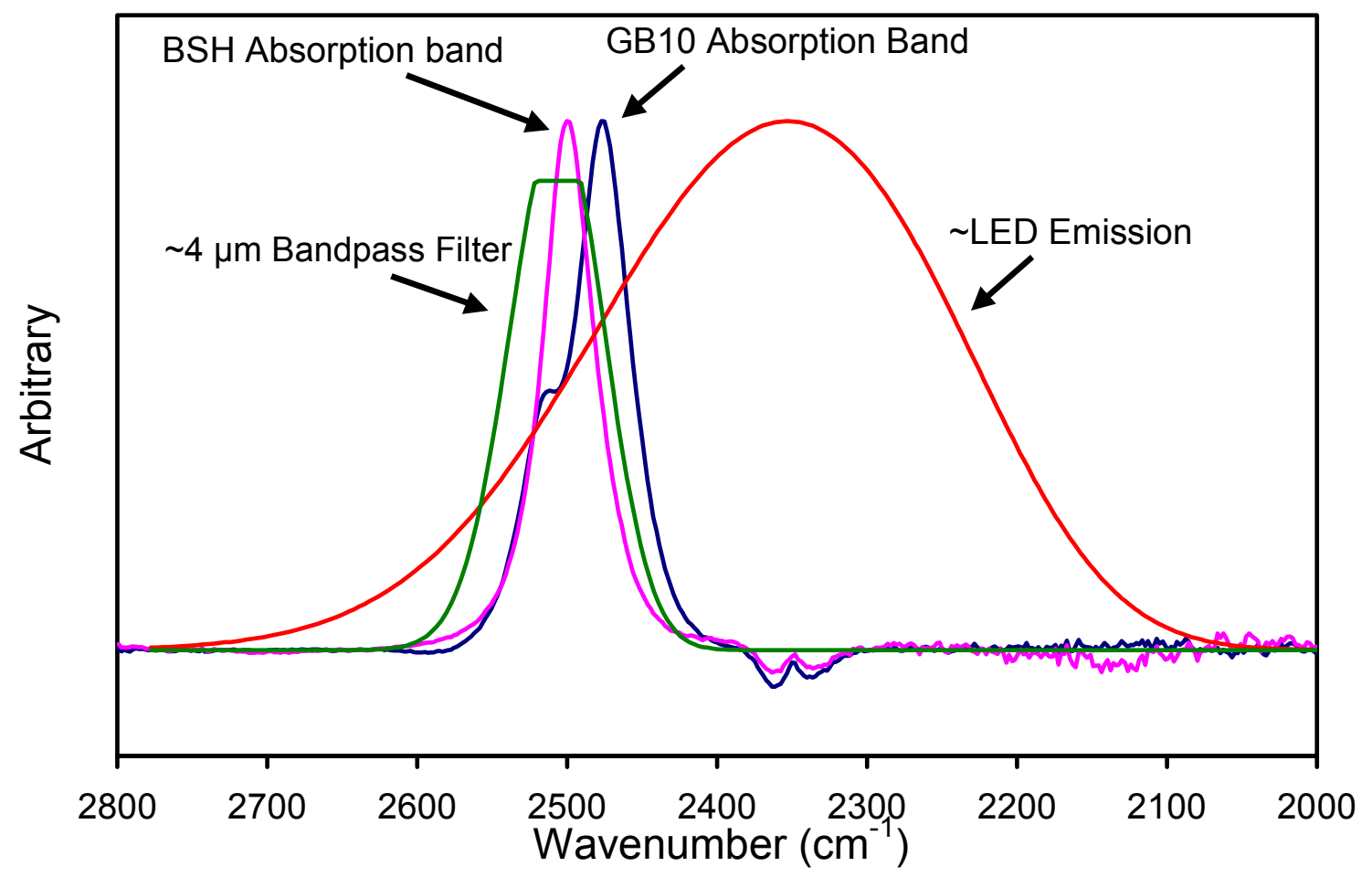

Figure 6. Comparison of the IR spectra of GB-10 and BSH in comparison with the emission band from the IR LED and the filter used to eliminate errors caused by the absorption of $\mathrm{CO}_{2}$.

is available for absorption by the compounds of interest. For BSH, this is an exact match; however, for GB-10, the bandpass of the filter is at a slightly higher frequency than the location of the maximum absorbance, and the sensitivity will be less. When considering the $3 \mathrm{BaF}_{2}$ lenses, the filter, the transmission of the ZnSe ATR cells, and other inefficiencies in the system, with the ATR cell, $<2 \%$ of the energy produced by the LED actually reaches the detector. This is roughly comparable to what can be achieved with a $60 \mu \mathrm{m}$ pathlength transmission cell with water in it. Inefficiencies are related to poor collimation of the beam, a beam too wide for the actual ATR crystal used in the cell, and inadequate focusing of the light that make it through the cell onto the detector.

Even when considering the immense loss of light in the system, calibration curves such as the one shown in Figure 7 can be obtained using the ATR cell. Although this curve is less than optimum for achieving the necessary detection limits, it does demonstrate that the analysis can be performed using a simple filter instrument and an ATR cell. A source that is at least a factor of 10 brighter in the $4 \mu \mathrm{m}$ region will be required to make this instrumentation viable. The major source of error at this time is long-term drift. The signals are so small that drift that would otherwise be nearly unnoticeable has been amplified to the point of being very significant. Utilizing very long time constants (e.g., 30 seconds) is not sufficient to overcome this drift at this time. Increasing the IR LED output by increasing the current to the LED with a corresponding decrease in the pulse 
width and shortening of the duty cycle was also attempted. The limits were not achievable since the PbSe detector and associated time constant in the amplifier were not adequate to detect the necessary short pulses. Detectors capable of this have much smaller active areas and may require liquid nitrogen cooling. It may be necessary to replace the focusing lenses with focusing mirrors to minimize loss and optimize the focus. Attempts to obtain a quantum cascade laser source, which should have more than sufficient output energy, have been unsuccessful due to limited availability and a limited availability of wavelengths. A collaboration is being pursued to obtain one of these devices.

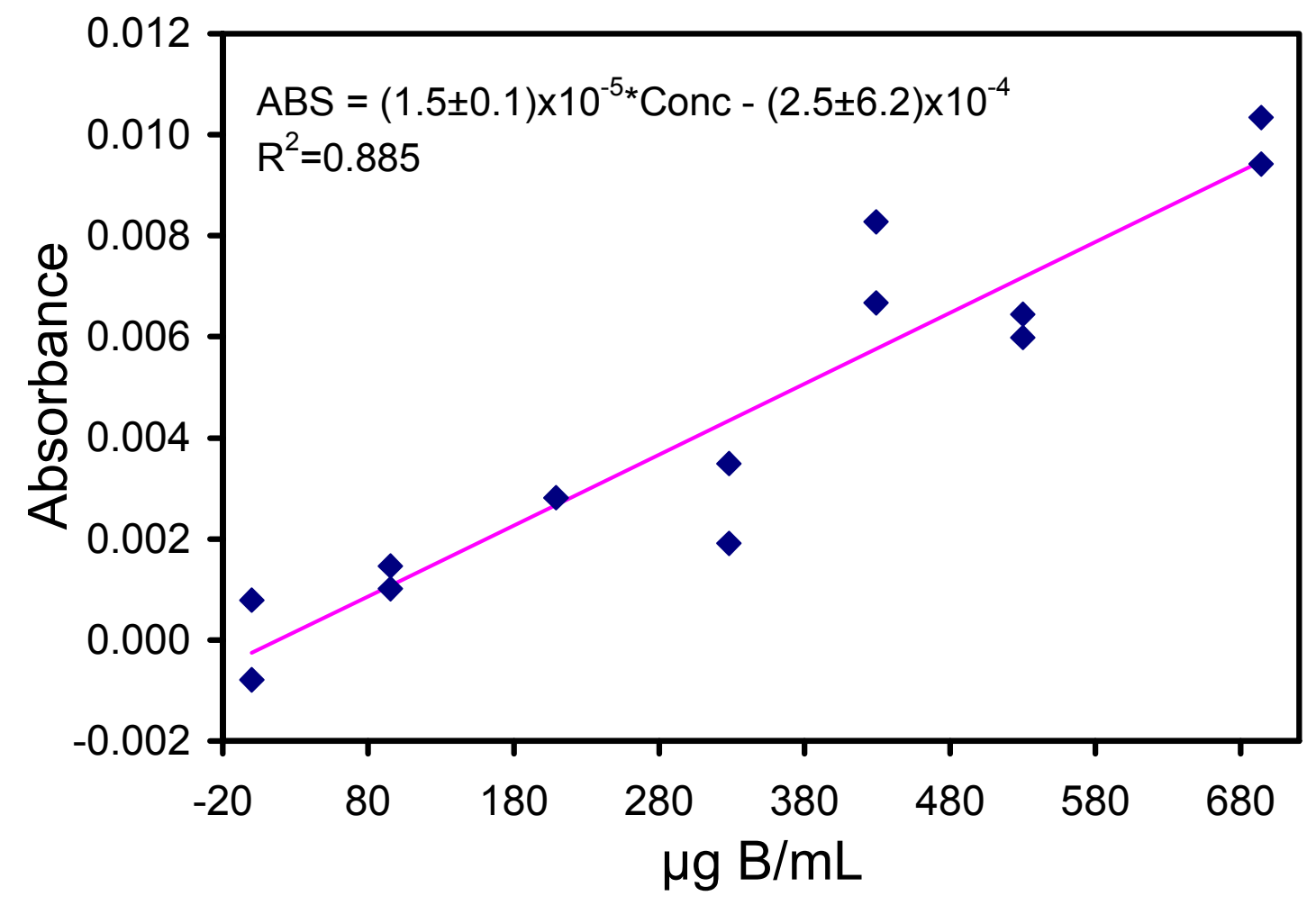

Figure 7. Calibration curve obtained from a simple photometric setup employing a 4.2 $\mu \mathrm{m}$ IR LED as a source and an ATR multireflection sample cell.

\section{CONCLUSIONS/DIRECTIONS}

The ability to determine boron concentrations to a level of $\sim 5 \mu \mathrm{g}{ }^{10} \mathrm{~B} / \mathrm{g}$ using ATR-FTIR has been demonstrated. The feasibility of the filter based instrument for determination of boron levels with and ATR or transmission cell has been demonstrated as well. Unfortunately, the IR LED source does not appear to have sufficient output energy to overcome the light losses in the system to date. Significant improvements will need to be made to increase the light throughput. Most notably, focusing, including focusing with more efficient optical devices such as mirrors, a slightly wider bandpass filter, and a 
faster detector are needed so that shorter, more intense pulses from the IR LED can be measured.

Following are the plans and directions for the near term future:

- Obtain a detector with a fast enough response to allow measurement of shorter pulses so that the IR-LED output characteristics can be fully characterized and the output maximized.

- Optical configurations are being considered, e.g., using mirrors rather than lenses for focusing of the beam.

- Thermal sources have also been ordered for direct comparison to the IR-LED.

- ATR crystals other than $\mathrm{ZnSe}$ are being considered that may improve the throughput.

- Continue the work with the FTIR and the ATR cell to extend the ATR method to samples other than biological fluids. Another absorption band may be utilized as an internal standard.

\section{REFERENCES}

1. Bauer, W. F.; Micca, P. L.; White, B. M. In Advances in Neutron Capture Therapy; Soloway, A. H., Barth, R. F., Carpenter, D. E., Eds.; Plenum Press: New York, 1993, pp 403-8.

2. Saini, P.; Lai, J. C. K.; Lu, D. R., "FT-IR measurement of mercaptoundecahydrododecacarborate in human plasma," Journal of Pharmaceutical and Biomedical Analysis, 12, 1994, 1091-1095.

3. Lu, D. R.; Munro, C., "Quantitative analysis of mercaptoun-decahydrododecaborate by Fourier transform infrared spectroscopy," Pharmacentical Research, 9, 1992, 1199-1202.

4. Moore, D. E.; Setiawan, Y.; Blagojevic, N.; Allen, B. J. In Advances in Neutron Capture Therapy; Soloway, A. H., Barth, R. F., Carpenter, D. E., Eds.; Plenum Press: New York, 1993, pp 413-417.

5. Setiawan, Y.; Rise, T.; Moore, D. E., "Fourier-Transform Infrared (Ftir) Spectrometry for the Assay of Polyhedral Boron-Compounds in Plasma and Pharmaceutical Formulations," Pharmaceutical Research, 11, 1994, 723-727.

6. Moore, D. E., "A Review of Techniques for the Analysis of Boron in the Development of Neutron-Capture Therapy Agents," Journal of Pharmaceutical and Biomedical Analysis, 8, 1990, 547-553.

7. Matveev, B.; Aidaraliev, M.; Gavrilov, G.; Zotova, N.; Karandashov, S.; Sotnikova, C.; Stus, N.; Talalakin, G.; Il'inskaya, N.; Aleksandrov, S., "Room temperature InAs photodiode-InGaAs LED pairs for methane detection in the mid-IR," Sensors and Actuators B-Chemical, 51, 1998, 233-237. 
8. Matveev, B. A.; Gavrilov, G. A.; Evstropov, V. V.; Zotova, N. V.; Karandashov, S. A.; Sotnikova, G. Y.; Stus, N. M.; Talalakin, G. N.; Malinen, J., "Mid-infrared (3-5 mu $\mathrm{m})$ LEDs as sources for gas and liquid sensors," Sensors and Actuators BChemical, 39, 1997, 339-343.

9. Krier, A.; Sherstnev, V. V.; Gao, H. H., "A novel LED module for the detection of H2S at 3.8 mu m," Journal of Physics D-Applied Physics, 33, 2000, 1656-1661.

10. Gmachl, C.; Capasso, F.; Kohler, R.; Tredicucci, A.; Hutchinson, A. L.; Sivco, D. L.; Baillargeon, J. N.; Cho, A. Y., "The sense-ability of semiconductor lasers - Midinfrared tunable quantum cascade lasers for gas-sensing applications," Ieee Circuits \& Devices, 16, 2000, 10-18.

11. Bauer, B., Floyd, T. A., "Monitoring of Glucose in Biological-Fluids by FourierTransform Infrared Spectrometry with a Cylindrical Internal Reflectance Cell," Analytica Chimica Acta, 197, 1987, 295-301. 


\title{
RADIATION TREATMENT PLANNING SOFTWARE DEVELOPMENT AND DEPLOYMENT
}

\author{
D.E. Wessol ${ }^{1}$, C.A. Wemple ${ }^{1}$, F.J. Wheeler ${ }^{1}$, J.J. Cogliati ${ }^{2}$, D. Lyle ${ }^{2}$, G.J. Harkin ${ }^{2}$ \\ 1. Idaho National Engineering and Environmental Laboratory, Idaho Falls, ID \\ 2. Montana State University, Bozeman, MT
}

\section{INTRODUCTION}

The 1999 BNCT annual report ${ }^{1}$ included a brief historical discussion of advanced radiotherapy treatment planning software development at INEEL, beginning with the development of BNCT_rtpe ${ }^{2}$ (Radiation Treatment Planning Environment), continuing with the development of SERA $^{3}$ (Simulation Environment for Radiotherapy Applications) treatment planning software in 1998, and ending with the Transport Independent Radiotherapy Environment (TIRADE) multi-modal treatment planning system, which is currently under development.

Since last year's annual report, SERA has been placed into maintenance mode, and updates are available to licensed users. Design and development for TIRADE, the new multi-modal treatment planning system, is currently underway at INEEL and Montana State University (MSU), with the possibility of future collaborations with Lawrence Livermore National Laboratory (LLNL).

\section{SERA UPDATES DURING 2000}

SERA 1B0 was released in February 2000. As described in the 1998 INEEL BNCT Annual Report ${ }^{4}$, SERA contains a number of independent software modules, including an image formatter, image editor, three-dimensional viewer, dose contouring and plotting tools, transport modeling interface, and a dose post-processing function. Most of the SERA modules have been updated since the $1 \mathrm{~B} 0$ release, and updates can be found at http://www.cs.montana.edu/ bnct. The following subsections describe the changes made to each module since the $1 \mathrm{~B} 0$ release.

\section{seraImage}

DICOM image input was added to seraImage. This support is only for public DICOM keys and, while compatible with DICOM-RT, does not support the output phase of this standard. The update for the seraImage module is identified as seraImage 1B1 for Linux/Solaris on the BNCT web site. This update enables seraImage to read little endian (most significant byte first) images and split byte images. 


\section{seraModel}

The update for the seraModel module is identified as seraModel $1 B 2$ for Linux/Solaris on the BNCT web site. This update fixes problems encountered when loading QSH files containing both image locations and reference location/image spacing. Prior to this fix, the reference location/image spacing was taking precedence over the image locations. Now, the user can choose either the image locations given in the QSH header file, or specify the reference location and image spacing. The update also repairs a problem with incorrectly computed bounding boxes for image slice orientations other than transverse. A help file has been included that describes how the slice orientations are determined.

\section{sera3d}

The update for the sera3d module is identified as sera3d 1B2 for Linux/Solaris on the BNCT web site. In sera3d, the axes were being labeled incorrectly when a slice orientation other than transverse was supplied in the .uvh file. A help file has been included to describe how the slice orientations are determined. Additionally, problems were found when reading the three dimensional (3D) dose contour header file. The problem occurred when the number of planes specified in the dose header file did not match the number of image slices from the QSH data. The user is now warned if this condition occurs, and the dose header file must be corrected before continuing.

\section{seraDose}

The update for the seraDose module is identified as seraDose 1B2 for Linux/Solaris on the BNCT web site. There were problems found with the Apply reference boron button in the dose factor widget, along with the way reference values were reset when changes were made to the dose factor or concentration values. Additionally, problems were found when reading the $3 \mathrm{D}$ dose contour header file. The problem occurred when the number of planes specified in the dose header file did not match the number of image slices from the QSH image file. The user is now warned if this condition occurs, and the dose header file must be corrected before continuing.

\section{$\underline{\text { seraCalc }}$}

The update for the seraCalc module is identified as seraCalc $1 B 2$ for Linux/Solaris on the BNCT web site. These updates corrected two minor bugs. The first corrected a problem with saving the input file when running in Test mode. The second corrected allowed the user to define a ".rst" filename that ended in something other than .rst. This change is important for those using the edit (D) mode of seraMC after combination, or for re-editing a previous run.

\section{$\underline{\text { seraPlan }}$}

The update for the seraPlan module is identified as seraPlan 1B3 for Linux/Solaris on the BNCT web site. Several bugs were fixed in seraPlan, relating to dynamic memory 
allocation, reaction rate edits, the $3 \mathrm{D}$ dose contour files, variable initialization, and the user-defined contour edits. A bug was also fixed in the dose interpolation routine, which gave anomalous results when sparse data were used for the interpolation. Other changes cleaned up the edit output, cleaned up the functioning of the resources file, and made certain that the constraint marker point dose edits were always performed.

\section{seraMC}

The update for the seraMC module is identified as seraMC 1 B6 for Linux/Solaris on the web site. These updates cleared up a few resilient bugs in seraMC. The edit isotope identifiers and atom densities for the new activity edits in seraMC were not being written to the ".rst" file(s) created by seraMC, and two dose component reference dose values were transposed in the $3 \mathrm{D}$ contour file header. A minor bug was fixed in the source routines, which resulted in an insufficient number of source points being generated for problems with several spatial source segments. Also, a long-standing bug was discovered in the combinatorial geometry $(\mathrm{CG})$ routines, which produced errors when converting the RVW body type to the WED body type. The capabilities of the seraMC source file were expanded to accommodate negative directional cosines and rectangular source regions, and reaction cross sections for several foil materials were added to the cross section library.

\section{TIRADE DESIGN AND DEVELOPMENT}

During 2000, design and development was initiated of the $\mathrm{Java}^{5}$ based, threedimensional, multi-modal, transport independent radiotherapy environment (TIRADE). Unlike its predecessors, TIRADE is a patient-centric system that can used for planning several radiotherapy modalities, including standard photon therapy, BNCT, fast neutron therapy, targeted radionuclide therapy, and brachytherapy. In addition, TIRADE is able to employ multi-modal image sets for plan development.

TIRADE will contain the usual number of separate, but interrelated, software modules, including an image formatter, image editor, dose contouring and plotting tools, transport modeling interface, and a dose post-processing function. These modules, when ordered properly, form the treatment planning pipeline. The following subsections discuss the overall draft design and initial module development, which was able to be partially implement during 2000.

\section{TIRADE Design}

The class structure for TIRADE has been developed and tested using a first generation unified modeling language (UML). The class structure is shown in Figure 1, with only the basic classes shown. The class structure follows the treatment planning pipeline. The patient data type was made thread safe to prevent unsynchronized access of data by the various modules. The patient class also keeps track of all other data types that are associated with that patient. All access to these other data types is done via the patient class; thus, the thread safety of the patient class extends to all other data classes. 


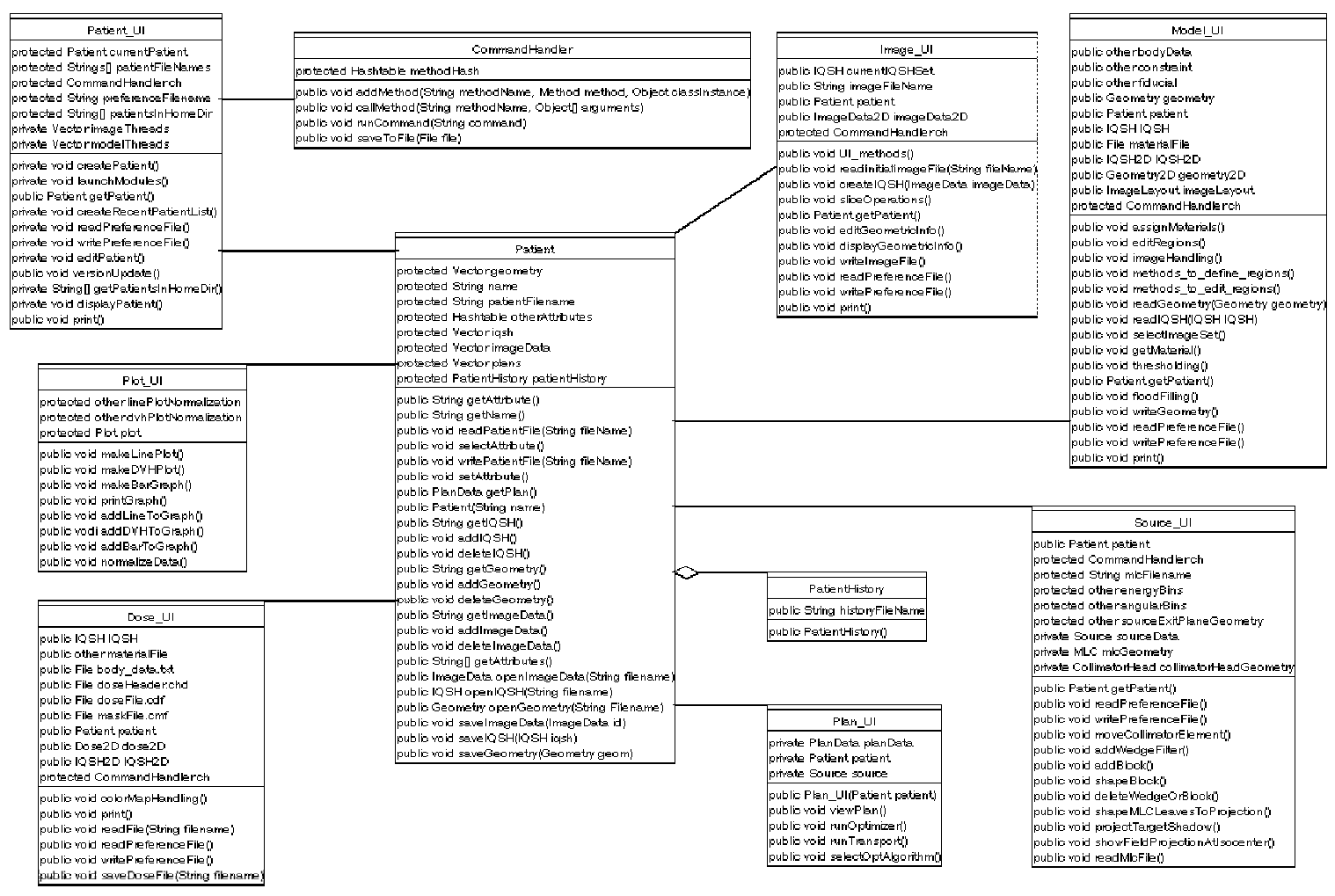

Figure 1. Basic TIRADE classes.

\section{$\underline{\text { Patient Module }}$}

The patient module is the focal point of TIRADE: It manages the entire treatment planning process. In addition to running and managing all of the independent modules, the patient module creates, edits, and retrieves the patient database.

The patient user interface, Patient_UI, allows the user to record, review, and edit patient information. A screen shot of the patient user interface is shown in Figure 2. This information includes some standard fields (name, address, phone, e-mail, date of birth, gender, etc.), but also includes fields that the user can specify. The Patient_UI module also allows the user to see what other data files are associated with a given patient. These files can be dissociated from the patient, as well. The Patient_UI also controls TIRADE by running the TIRADE modules as threads, to manage memory and data files. As the control unit, it can also set and save the user's preferences for the software's behavior and appearance, and maintains a list of the most recently used patient files. 
File Operations
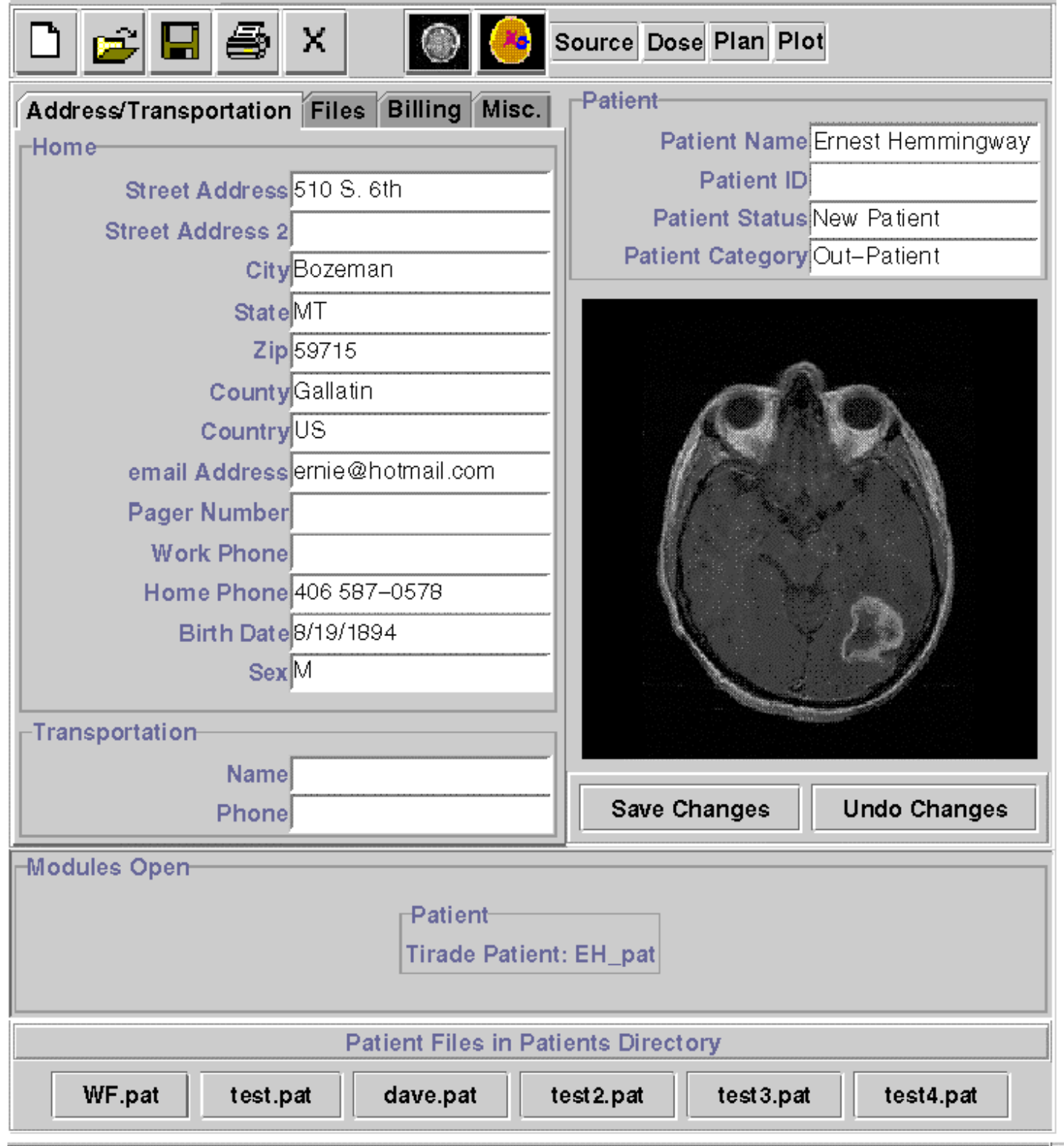

Figure 2. Patient user interface.

\section{Image Module}

The image module prepares the images for use by the other TIRADE modules. It provides the following features:

- Mutual information multi-modal image registration;

- Arbitrary image axis reslicing;

- Assures image spacing uniformity. 
The image user interface module, Image_UI, allows the user to open images in QSH, DICOM3, TIRADE internal, and raw image formats (see Figure 3). Reading of the QSH and raw image format is done by a plugin, and the ability to read other image formats may be included with the development of a plugin for each desired format. Once the image file is opened, the user can edit the images' properties, including, but not limited to, size, rotation, quality, brightness, and location. The images may also be printed.

The user may reslice image sets along different axes and spacings. This is accomplished by generating any missing information using a weighted average, then defining a slice plane (inferior-superior, right-left, or posterior-anterior) and the desired spacing between slices. Once the images have been edited, they can be saved in either the Image Data format or the TIRADE internal (IQSH) format. The Image Data format is used to save edited images that either still require more work, or are not uniformly sliced. The IQSH format is used to save images that are sliced uniformly and are ready for region labeling. Image_UI also allows color model shifting, to facilitate the viewing of different regions in individual images.

A multi-modal image registration system has been designed for, and partially implemented in, the image module. This method is based on mutual image entropy ${ }^{6}$, which allows multi-modal image registration without fiducial markers. 


\section{File Operations}

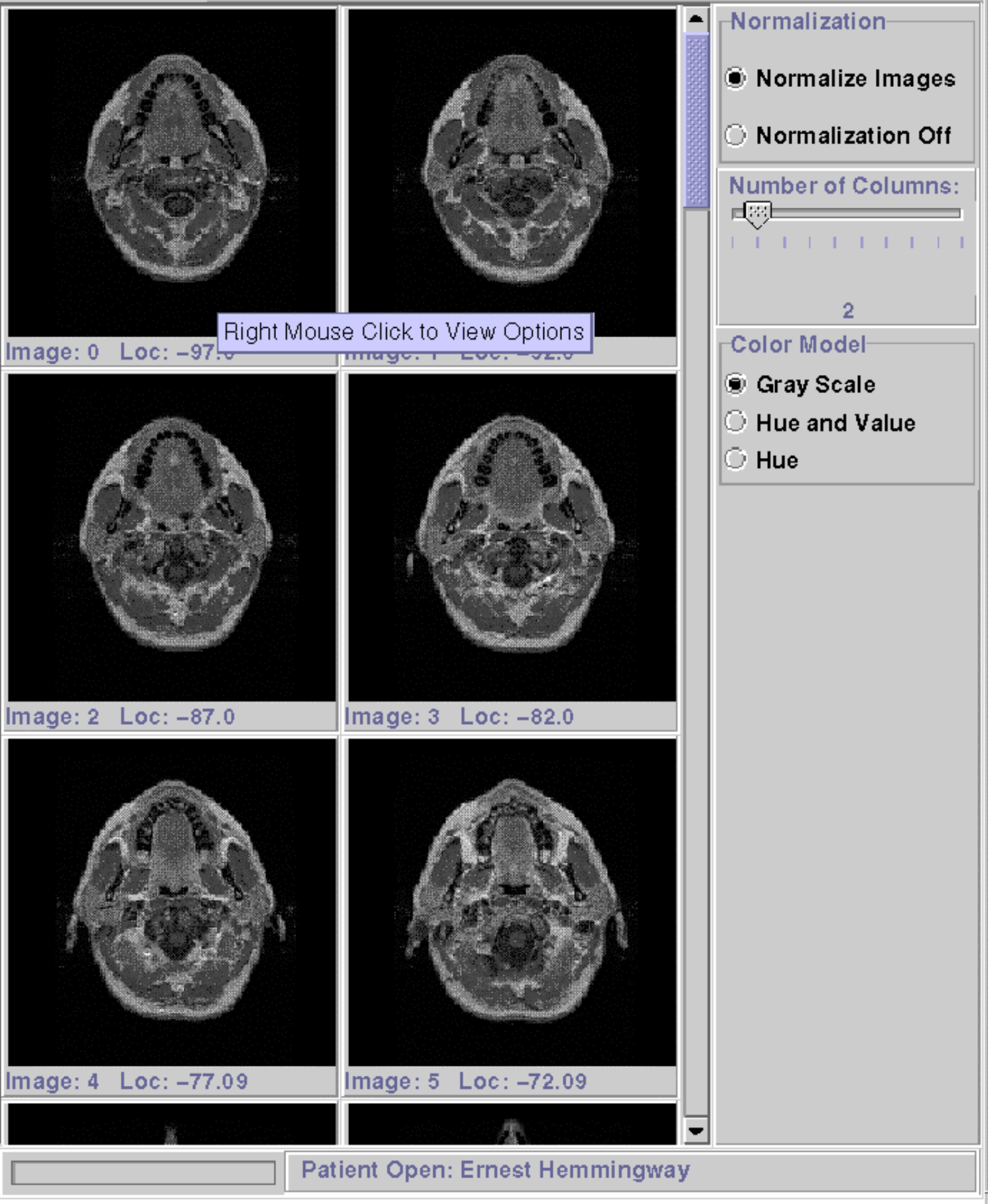

Figure 3. Image user interface. 


\section{Model Module}

The model module creates the geometry of the patient and target based on the image data (see Figure 4). The model module can now be used to create a new univel ${ }^{7}$ body data file. The model module has two new features not found in seraModel. The first is the ability to save the commands given to the program and then replay them at some future time. This allows a file to be precisely recreated from just the image data and the record of commands. The other new feature that has been added is the ability to edit images along any plane. This allows editing along the IS (Inferior to Superior) plane, the RL (Right to Left) plane, and the PA (Posterior to Anterior) plane, no matter the image orientation of the original images. The model user interface is shown in Figure 4 with the images oriented along the PA axis. Other features implemented in the model module are the wand tool and paint brush tool.

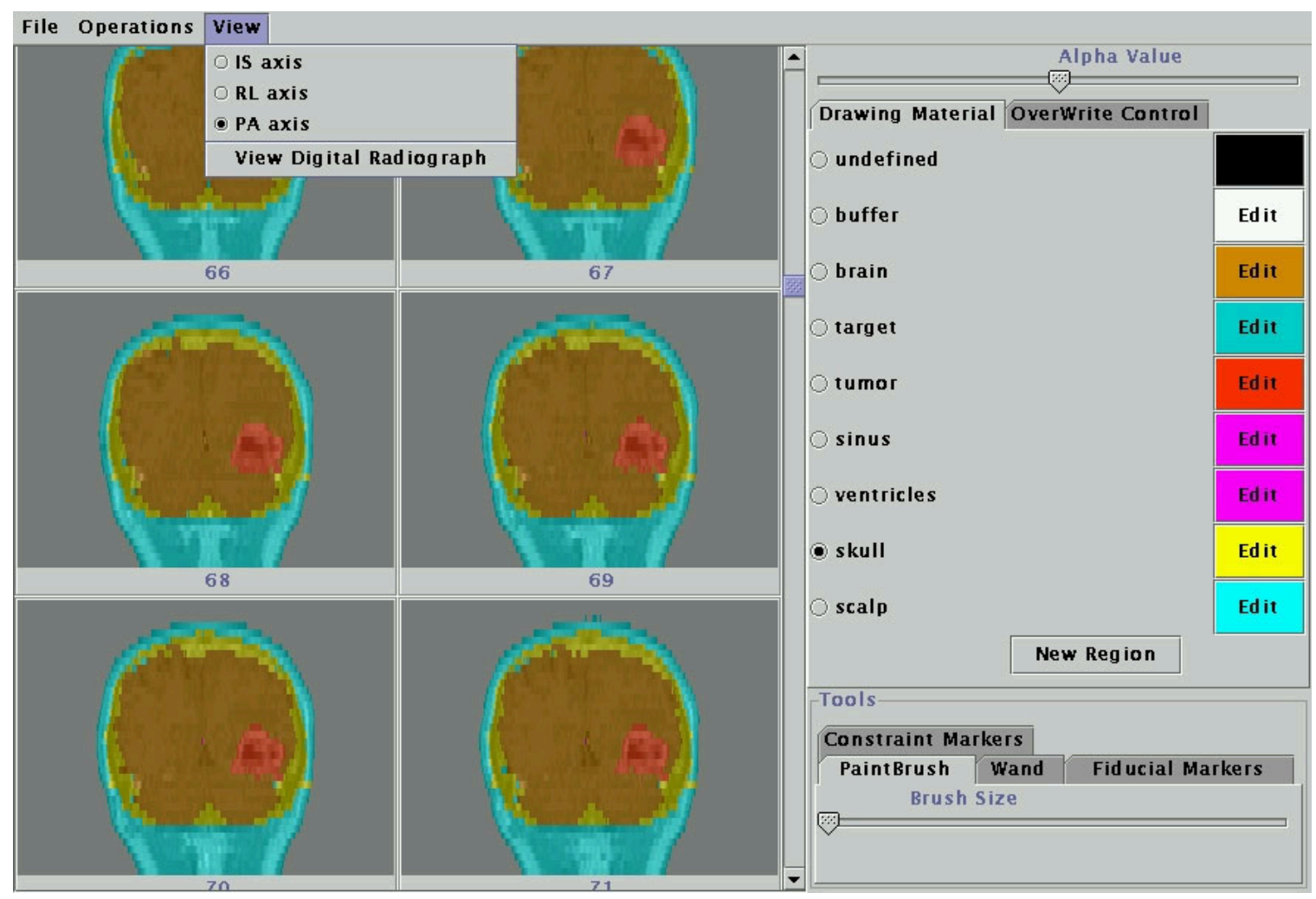

Figure 4. Model module with PA orientation.

\section{Command Handler}

An integral part of the TIRADE is the CommandHandler. The CommandHandler records all commands entered by the user, as described in the model module subsection. This tool is used to implement the module's repeatability features. The command handler can 
also orchestrate several different threads, and receive and write commands back and forth to them.

\section{Data Format}

The most recent addition is the implementation of the Java Database Connectivity Application Programming Interface (JDBC-API) as a means to store and retrieve all TIRADE data files. Files may now be stored locally, or may be saved and accessed remotely in a database, where the data can be accessed and queried by other database applications which conform to the Open Database Connectivity (ODBC) standard. Figure 5 shows the relationship between the TIRADE modules and the database. This choice is made as a preference in the Patient_UI module. The database in use currently is MySQL, but any ODBC database management system can be used. The addition of database connectivity allows multiple users to access the same information from multiple sites. Handling of database interaction is done with the DatabaseSetup class. This class holds both the information necessary to make the connection to the database management system, and the methods for storing, updating, deleting, and querying information in the database. It also closes the connection.

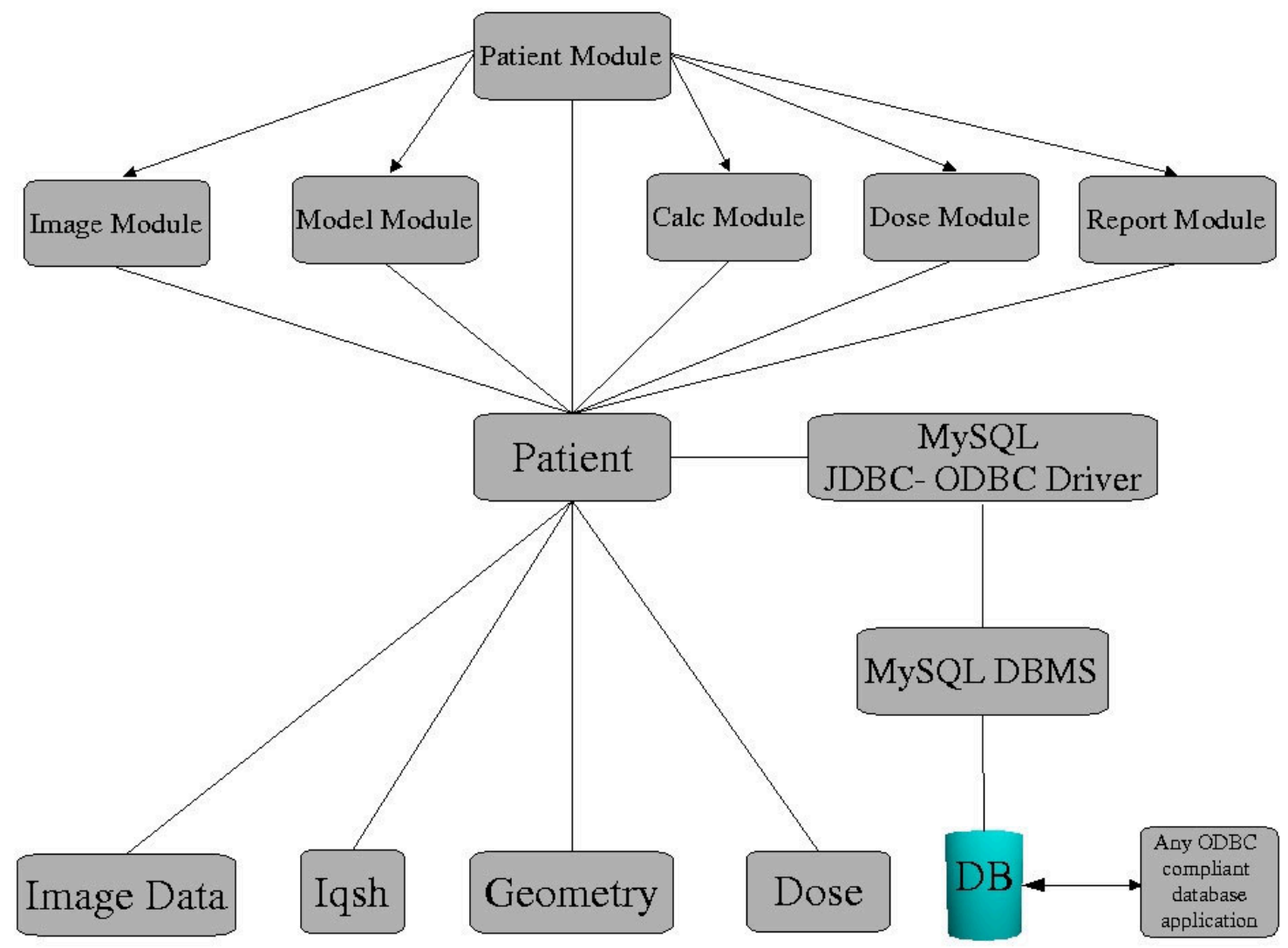

Figure 5. TIRADE database interactions. 


\section{FUTURE DIRECTIONS}

The ultimate objective of the near-term (2000-2001) effort is to assemble a prototype demonstration system with an open multi-modality particle transport interface. Initial therapy modalities to be addressed include the standard photon modalities noted above, as well as neutron therapy and neutron capture therapy. This prototype will be the basis for further development of a refined, generalized, Java-based system that could be introduced into human trials under the co-sponsorship of the National Cancer Institute $(\mathrm{NCI})$, or others, at an appropriate time.

\section{REFERENCES}

1. D.E. Wessol, C.A. Wemple, F.J. Wheeler, M.T. Cohen, M.B. Rossmeier, J.J. Cogliati, G.J. Harkin, J.R. Venhuizen, and D.W. Nigg, "Radiation Treatment Planning Software Development and Deployment," in: J.R. Venhuizen (ed.), "INEEL BNCT Research Program Annual Report 1999," http://id.inel.gov/cart, INEEL External Report 2000-00392, April 2000.

2. D.E. Wessol, R.S. Babcock, F.J. Wheeler, G.J. Harkin, L.L. Voss, M.W. Frandsen, "BNCT_rtpe: BNCT Radiation Treatment Planning Environment Users Manual Version 2.2", http://id.inel.gov/cart/rtpe manual/sec00.html, INEEL External Report, February, 1997.

3. D.E. Wessol, C.A. Wemple, F.J. Wheeler, M.T. Cohen, M.B. Rossmeier, J. Cogliati, "SERA: Simulation Environment for Radiotherapy Applications Users Manual Version 1B0", http://www.cs.montana.edu/ bnct, INEEL External Report, October, 1999.

4. D.E. Wessol, M.W. Frandsen, C.L. Albright, M. T. Cohen, F.J. Wheeler, G.J. Harkin, M.B. Rossmeier, C.A. Wemple, and D.W. Nigg, "BNCT Radiation Treatment Planning Software Development " in: J.R. Venhuizen (ed.), "INEEL BNCT Research Program Annual Report 1998," INEEL External Report Ext-99-00293, April 1999.

5. James Gosling, Bill Joy, and Guy Steele, The Java Language Specification, AddisonWesley, ISBN:0201634511, September 1996.

6. Paul Viola and William M. Wells, "Alignment by Maximization of Mutual Information," International Journal of Computer Vision, 24(2), pp 137-154, 1997.

7. M.W. Frandsen, D.E. Wessol, F.J. Wheeler, D. Starkey, "Rapid Geometry Interrogation for Uniform Volume Element-Based BNCT Monte Carlo Particle Transport Simulation", Proceedings of the Eighth International Symposium on Neutron Capture Therapy, Plenum Press, New York. 


\section{SERAEGS - A DEMONSTRATION CODE}

\section{C.A. Wemple, D.W. Nigg}

Idaho National Engineering and Environmental Laboratory, Idaho Falls, ID

\section{INTRODUCTION}

As a preliminary step in the development of a new, generalized, multi-particle transport code for medical applications, a demonstration of the ability to merge the univel geometry methodology ${ }^{1}$ with full, coupled photon-electron transport was necessary. Since the EGS $\operatorname{code}^{2}$ is the international gold standard for photon-electron transport, it was decided to merge the univel geometry and subelement mesh editing of the seraMC code with EGS. The EGSnrc version ${ }^{2}$ was chosen, as this incorporates all the latest capabilities and bug fixes.

\section{CODE MODIFICATIONS}

The EGSnrc code is written in a high-level computer language called MORTRAN, which is a macro translator to FORTRAN. It requires the user to supply four routines, preferably written in MORTRAN - a driver routine (MAIN), two distance to boundary routines (HOWFAR and HOWNEAR), and a tally routine (AUSGAB). All communication between the user routines and the bulk of EGS takes place through four subroutines - HATCH, which performs initialization of EGS variables and common blocks; SHOWER, which performs the photon-electron transport; and the user routines HOWFAR and AUSGAB. The HOWFAR routine computes distance to boundary along the particle flight path, while the HOWNEAR routine computes the distance to the nearest boundary in any direction. For our purposes, the HOWFAR routine was implemented as a call to the univel routines for identifying the present region and determining distance to boundary. HOWNEAR was entered as a constant approximating the dimension of a univel; this gave a basic attempt at a multiple scattering approach for electron transport, without investing a great deal of time or effort. AUSGAB invoked the seraMC subelement mesh tally capabilities by calling the tally_g routine without revision.

One additional routine, written in MORTRAN, was necessary to serve as a driver for the electron-gamma cascade calculation. This routine, ETRACK, performed the loops over the number of batches and number of particles per batch, calling the EGS routine SHOWER for each starting (source) particle. It also calculated the region balance edits, and dumped the incremental tally results to bulk storage. All other functions necessary (input processing, editing, output, source routines, etc.) were performed by existing seraMC routines, largely without modification.

In order to preserve the energy balance in the tallies, some minor modifications to the base seraMC coding were required. This mainly entailed changing the tally and bulk 
storage arrays from single-precision to double-precision. This was needed because the total energy deposition in a cell is on the order of $\mathrm{MeV}$, but the incremental energy deposition from a particle can be several orders of magnitude lower, which can result in accumulation/truncation errors. This modification was performed in all legacy seraMC routines.

\section{TESTING}

Three simple geometry test cases were run with seraEGS, MCNP, and seraMC. Two sets of runs were made with seraEGS: one to determine CPU times for a fixed number of particles; and the other to calculate well-converged tallies. This was necessary, as seraEGS computes dose, and the other codes calculate KERMA. Dose converges much more slowly than KERMA, as it is based on collisions, not track length through space.

The three test cases were: 1 ) a 30 -cm cubic water phantom with a $1 \mathrm{MeV}$ photon beam impinging on the free surface; 2) the same phantom with a $10 \mathrm{MeV}$ photon beam; and 3) a $6.35-\mathrm{cm}$ diameter, $18.1-\mathrm{cm}$ height cylindrical water phantom with a $10 \mathrm{MeV}$ photon beam impinging on the flat free surface. Each test case was demonstrated using four different methodologies: standard MCNP geometry; SeraEGS with combinatorial geometry (CG); SeraEGS with univel geometry (UV); and seraMC with CG. All photon beams were monoenergetic and monodirectional. Timing cases were run for 100,000 histories, while the converged tally cases in seraEGS were run for 2,000,000 histories. The timing results are shown in Table 1, and the tally results for seraEGS and MCNP are shown in Figures 1-7. The timing results for seraEGS and MCNP are comparable, considering the simplicity of the multiple scattering approach employed in seraEGS. The extremely short runtimes for seraMC reflect the lack of electron transport in the calculation, which makes remarkably little difference in the tally results for these simple test cases.

Table 1. Computation times (minutes) for the simple geometry test cases. All cases run for 100,000 histories.

\begin{tabular}{|l|c|c|c|c|}
\hline & MCNP & SeraEGS CG & SeraEGS UV & seraMC \\
\hline $1 \mathrm{MeV}$ cube & 7.34 & 12.22 & 12.76 & 0.33 \\
\hline $10 \mathrm{MeV}$ cube & 20.51 & 61.93 & 62.98 & 0.25 \\
\hline $1 \mathrm{MeV}$ cylinder & 12.09 & 40.7 & 39.89 & 0.22 \\
\hline
\end{tabular}

Note that the converged tally results, as shown in Figures 1-7, display the expected discrepancy between dose and KERMA - the seraEGS results show a buildup of dose at the beam entry, while the KERMA results only show attenuation with depth. However, after sufficient penetration, both results converge to the same solution.

These results demonstrate that the univel geometry, initially developed and tested only for coupled neutron-gamma transport, will work equally well for photon-electron transport calculations. The speed and accuracy of the univel geometry methods, when 
properly coupled to a multiple scattering approach, can provide a means to greatly improve the computational speed of photon-electron transport for complex geometries.

\section{REFERENCES}

1. Frandsen, M.W., "Rapid Geometry Interrogation for a Uniform Volume ElementBased Monte Carlo Particle Transport Simulation," M.S. Thesis, Department of Computer Science, Montana State University, April 1998, http://www.cs.montana.edu/ bnct/publications/mike/thesis3.html.

2. Kawrakow, I. and Rogers, D.W.O, "The EGSnrc Code System: Monte Carlo Simulation of Electron and Photon Transport," NRCC Report PIRS-701, National Research Council of Canada, April 2000. 


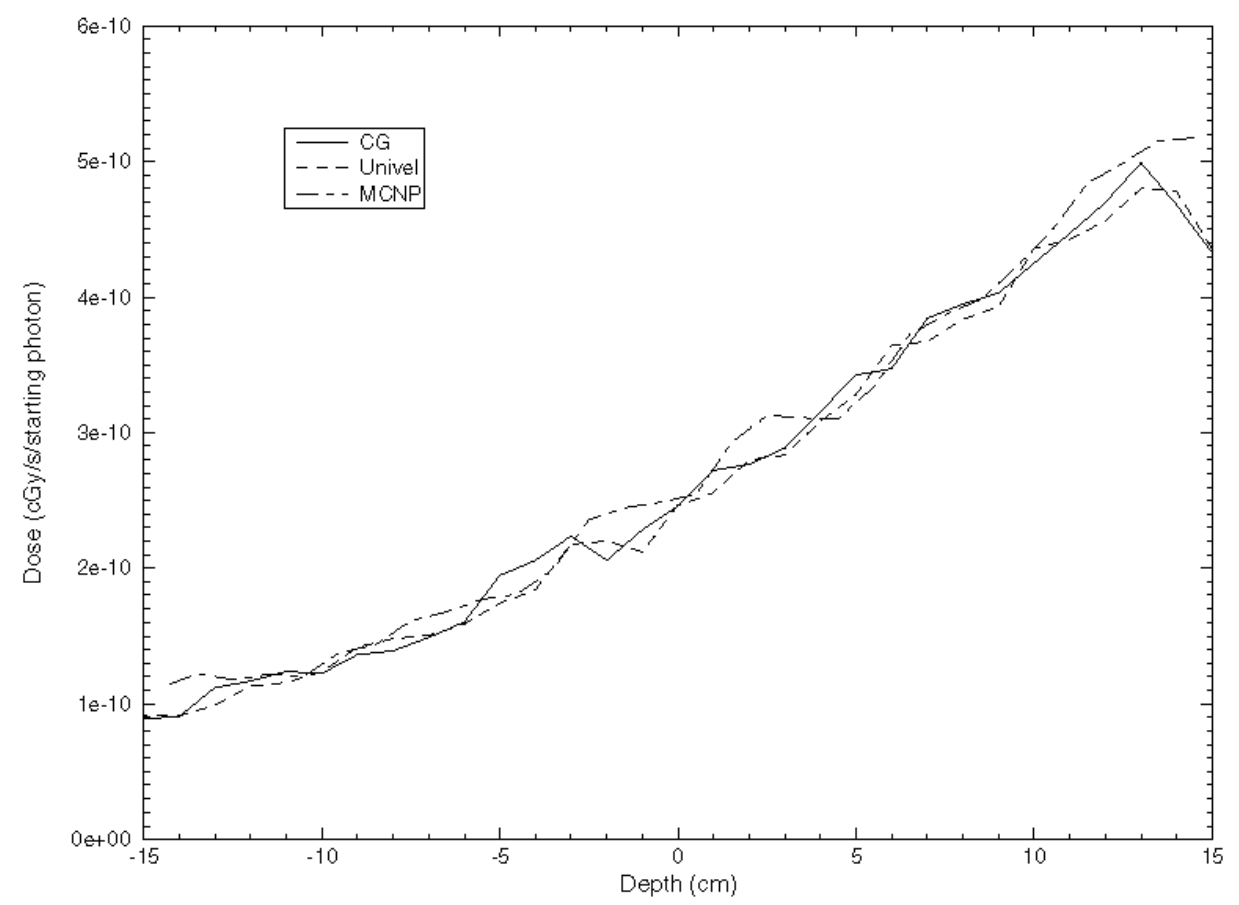

Figure 1. Dose-depth profile at phantom centerline for large cubic water phantom.

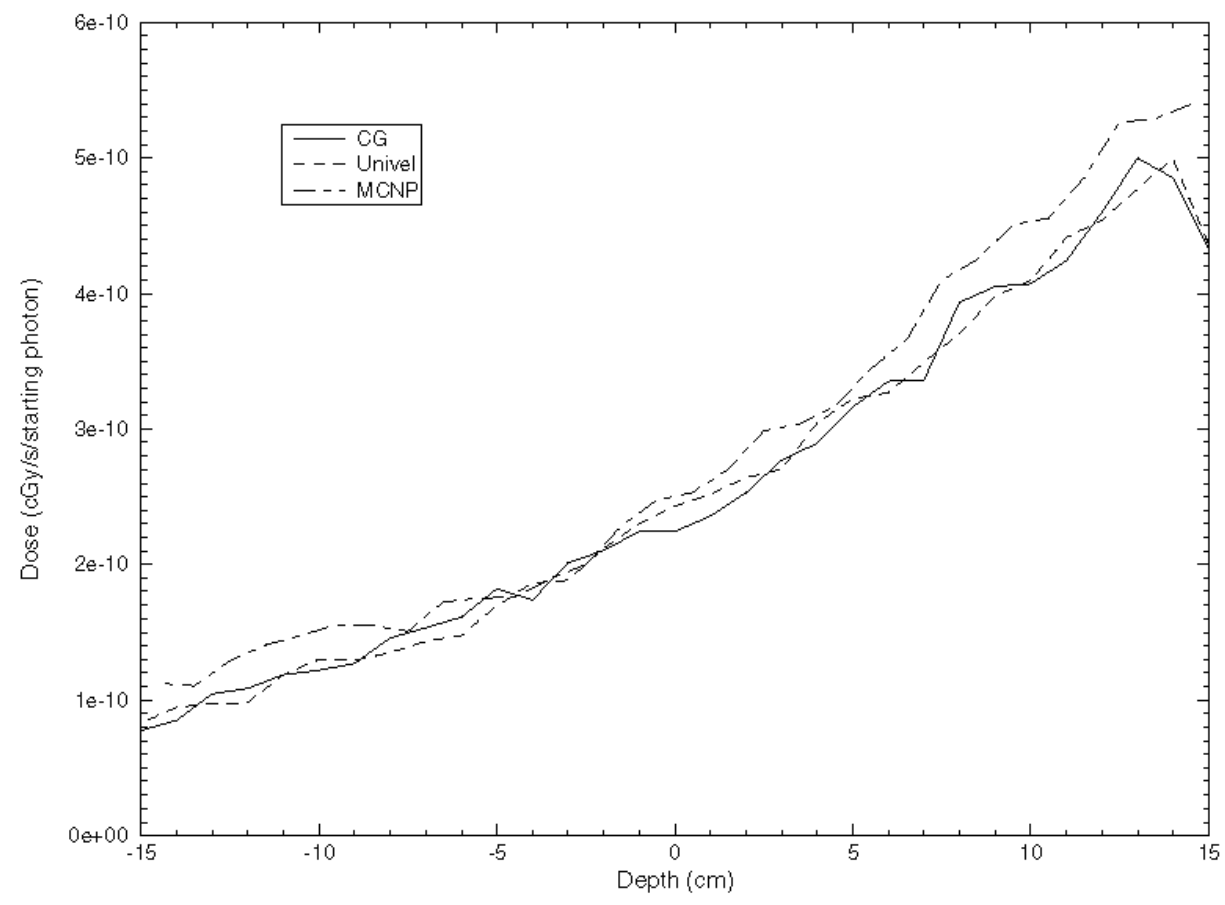

Figure 2. Dose-depth profile at $(3.5,0)$ for large cubic water phantom. 


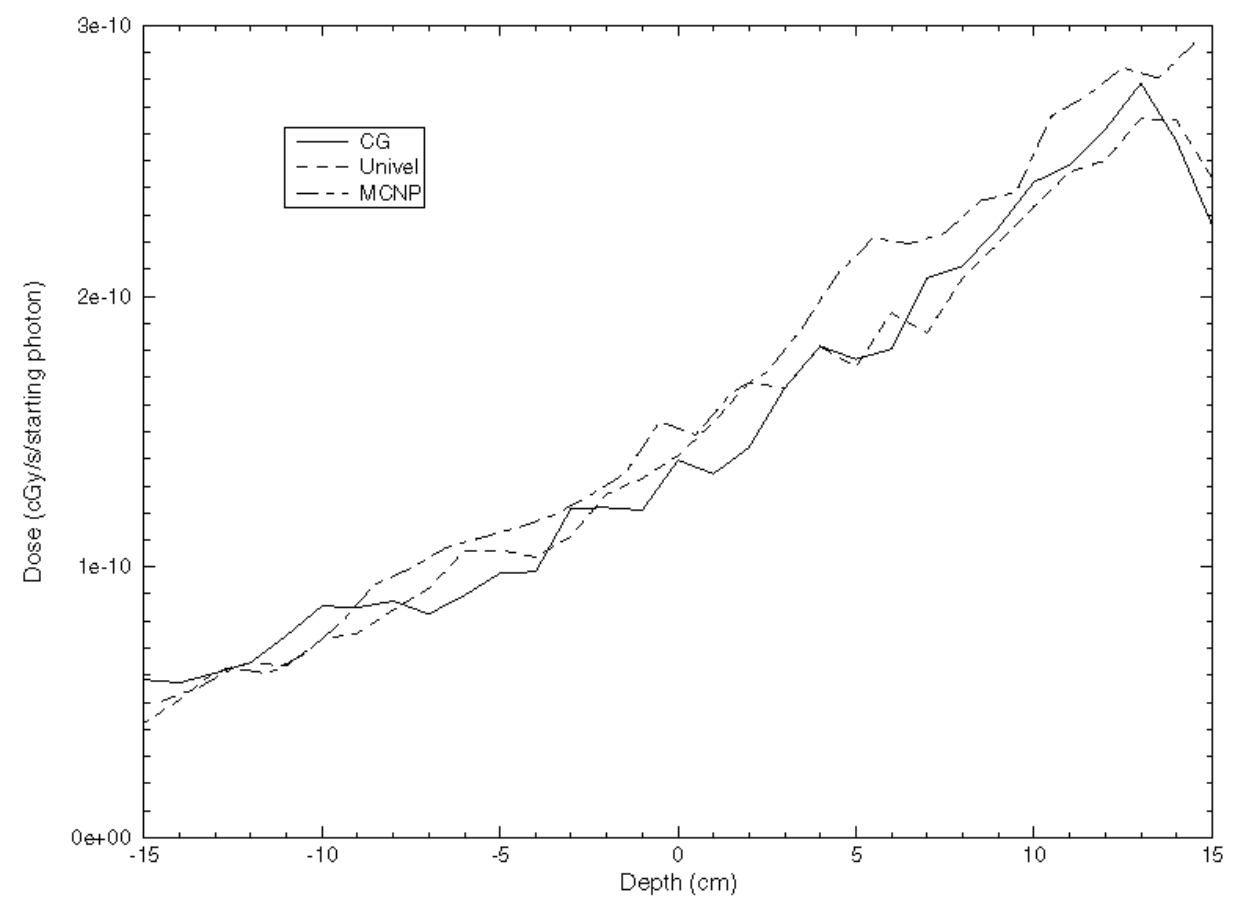

Figure 3. Dose-depth profile at $(3.5,3.5)$ for large cubic water phantom.

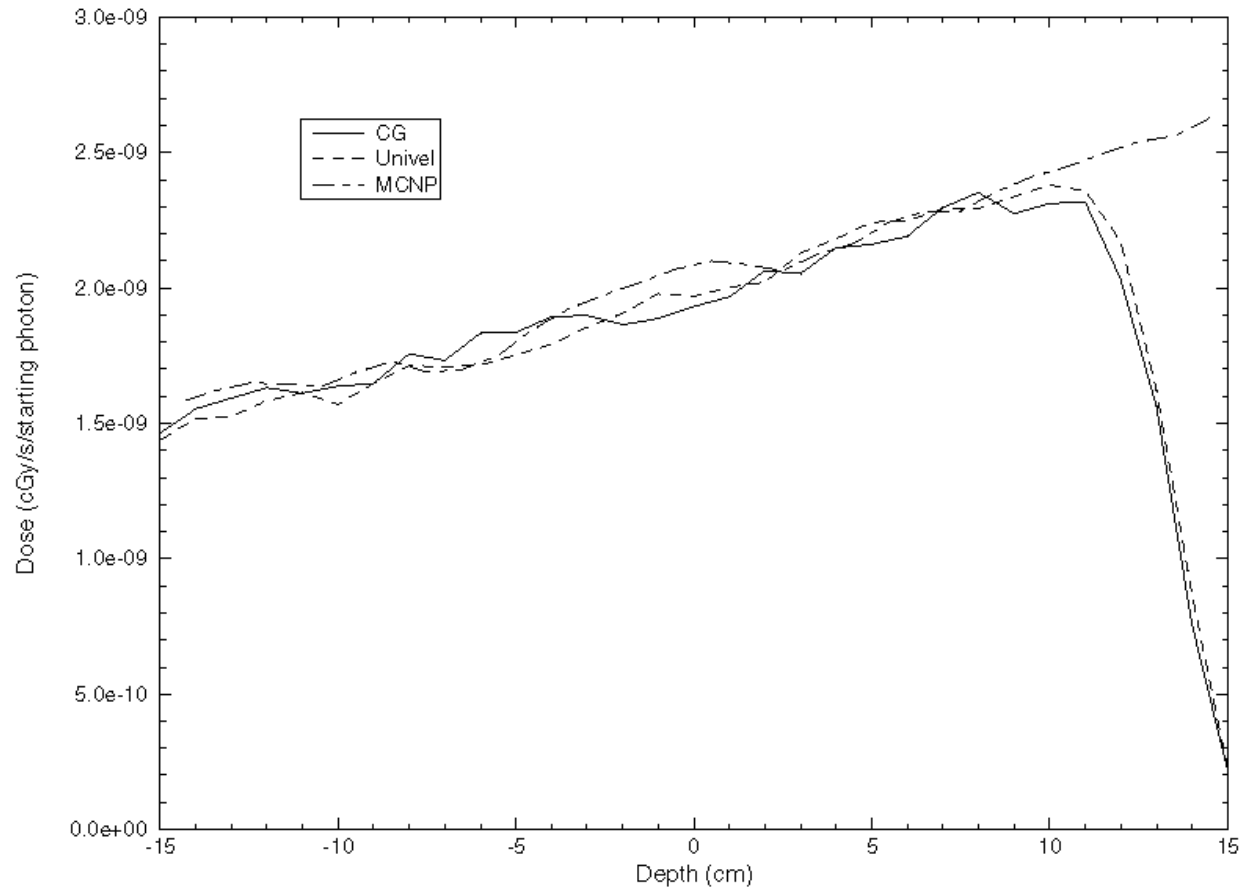

Figure 4. Dose-depth profile at phantom centerline for large cubic water phantom, $10 \mathrm{MeV}$ beam. 


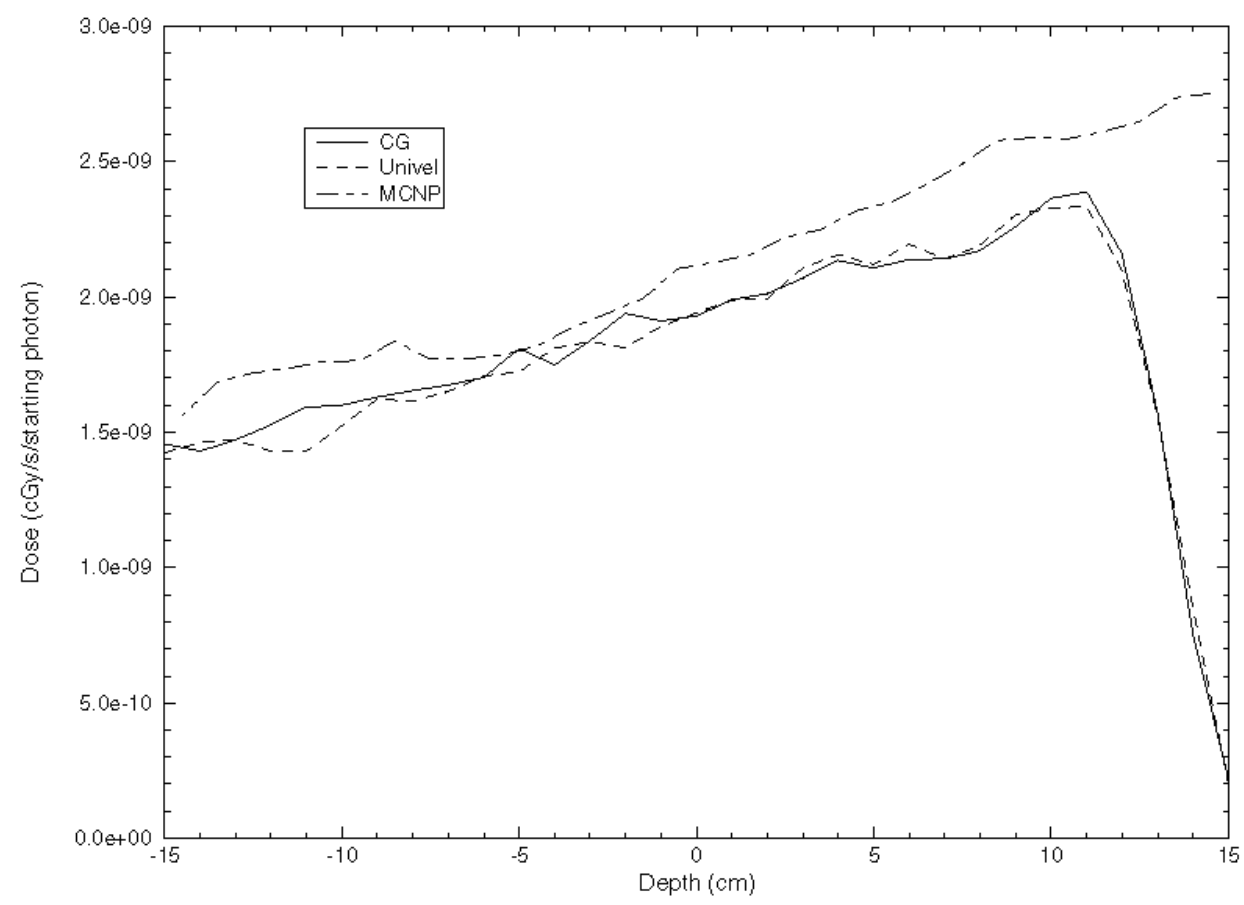

Figure 5. Dose-depth profile at $(3.5,0)$ for large cubic water phantom, $10 \mathrm{MeV}$ beam.

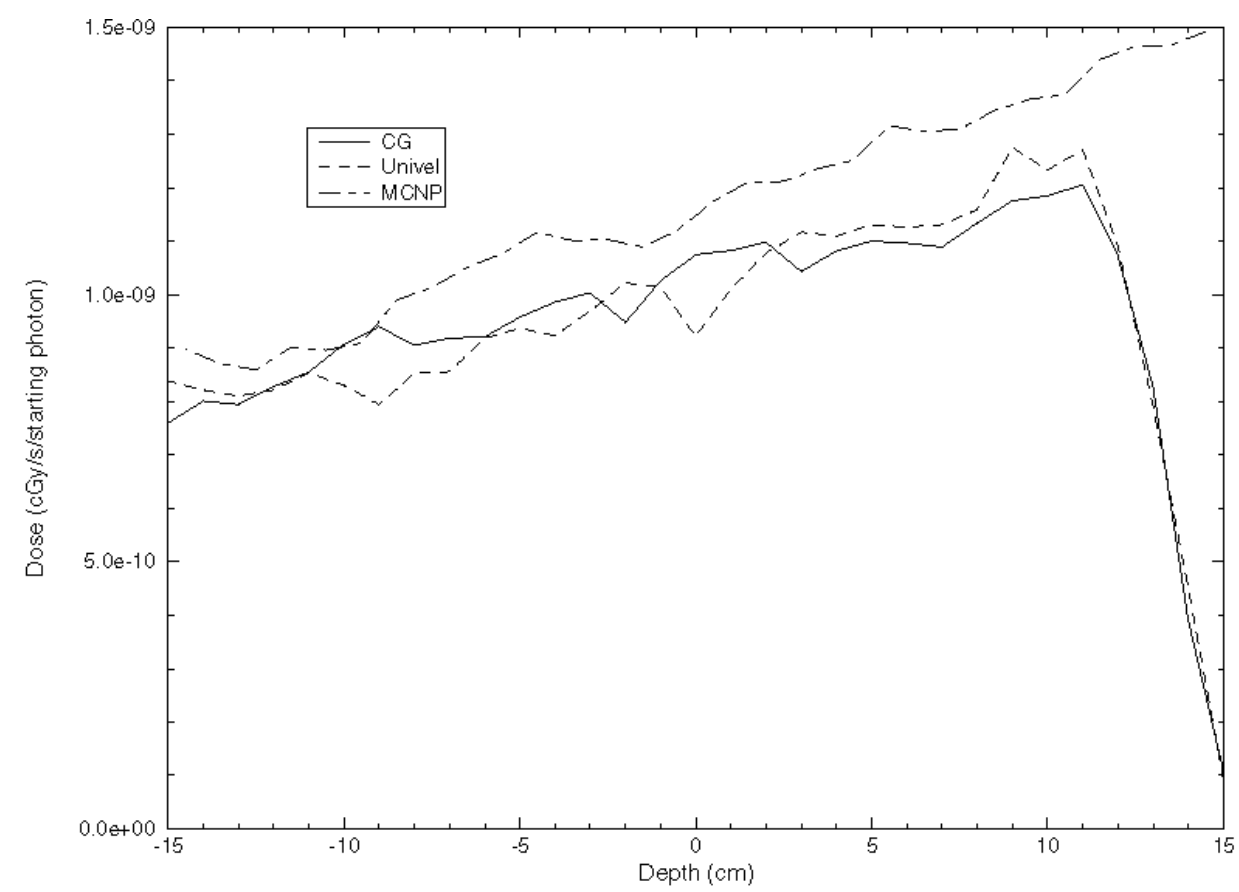

Figure 6. Dose-depth profile at $(3.5,3.5)$ for large cubic water phantom, $10 \mathrm{MeV}$ beam. 


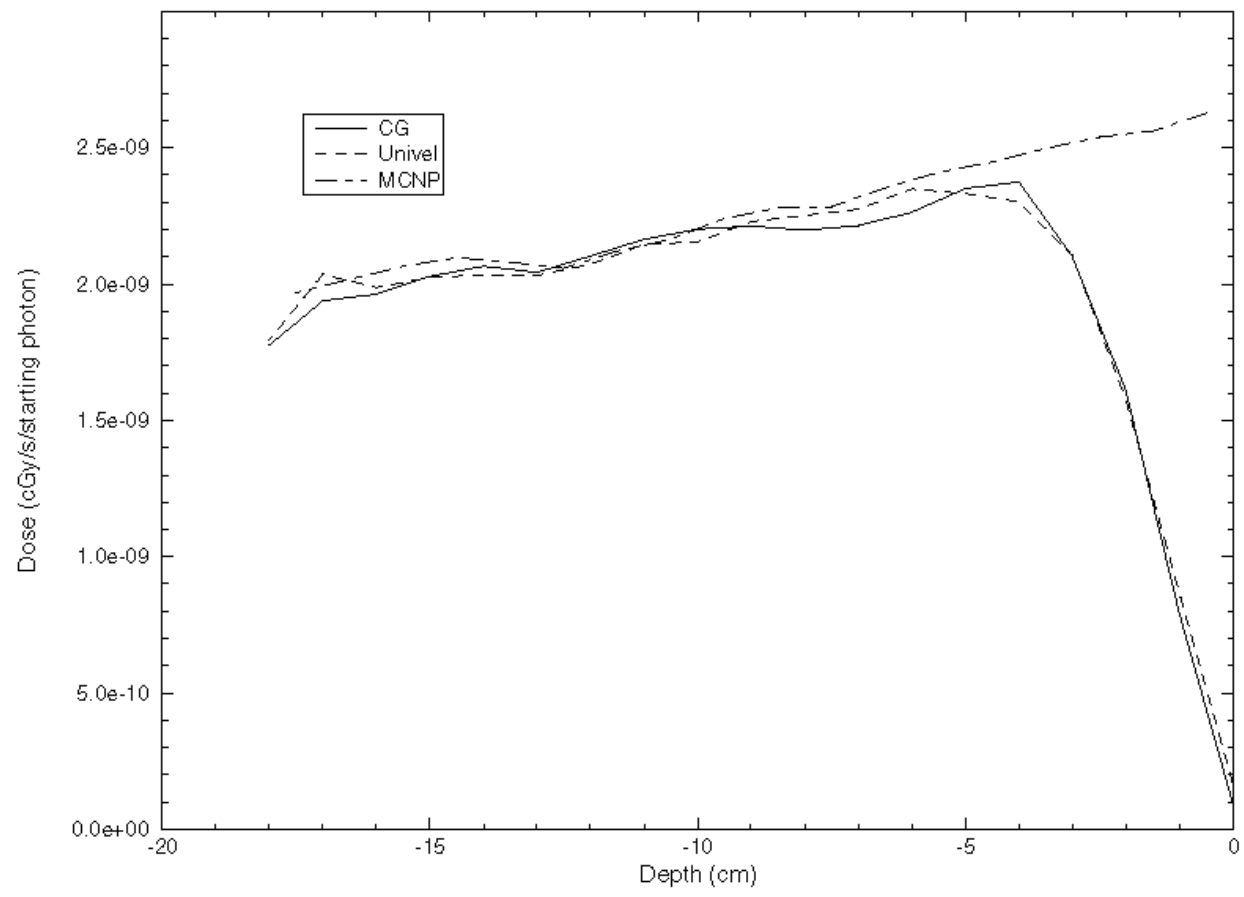

Figure 7. Dose-depth profile at phantom centerline for INEEL cylindrical phantom, $10 \mathrm{MeV}$ source. 


\title{
CONSTRUCTION PROGRESS OF AN EPITHERMAL NEUTRON BEAM FOR PRECLINICAL BNCT RESEARCH AT WASHINGTON STATE UNIVERSITY
}

\author{
J.R. Venhuizen ${ }^{1}$, D.W. Nigg ${ }^{1}$, C.A. Wemple ${ }^{1}$, G.E. Tripard ${ }^{2}$, S. Sharp ${ }^{2}$, P.R. Gavin ${ }^{2}$ \\ 1. Idaho National Engineering and Environmental Laboratory, Idaho Falls, ID. \\ 2. Washington State University, Pullman, WA.
}

\section{INTRODUCTION}

Veterinary radiation oncology researchers at the Washington State University (WSU) School of Veterinary Medicine have made major contributions to the understanding of the in-vivo radiobiology of Boron Neutron Capture Therapy (BNCT) over the years. For example, the large-animal model studies of normal brain tissue tolerance in BNCT conducted by this group ${ }^{1}$ provided a key component of the radiobiological basis for the resumption in 1994 of human BNCT trials in the US Those studies used the epithermalneutron beams available at Brookhaven National Laboratory and at the Petten facility, in The Netherlands, with technical support from the INEEL in several areas of physics, biophysics, and analytical chemistry. Recent attention has been focused upon the development of a more convenient and cost-effective local epithermal-neutron beam facility at WSU for collaborative INEEL/WSU BNCT preclinical research and boronated pharmaceutical screening in cell and animal models. The design of the new facility, which is being installed in the thermal column region of the TRIGA ${ }^{\mathrm{TM}}$ research reactor at WSU, was performed in a collaborative effort ${ }^{2,3}$ of WSU and the INEEL. Construction, again in a collaborative WSU/INEEL effort, is nearing completion. This article summarizes the major progress that has been made on this project during 2000 .

\section{FACILITY DESCRIPTION}

The $1 \mathrm{MW}$ reactor core is suspended from a movable bridge above the pool as shown in Figure 1. It can be positioned directly adjacent to a truncated aluminum cone that extends horizontally into the reactor pool from the tank wall on the upstream side of the filtering and moderating assembly. This cone and the adjacent thermal column area was originally filled with graphite. A water-filled shield was located downstream of the graphite thermal column. There was a large open floor area outside of this final shield, as shown in Figure 2. 


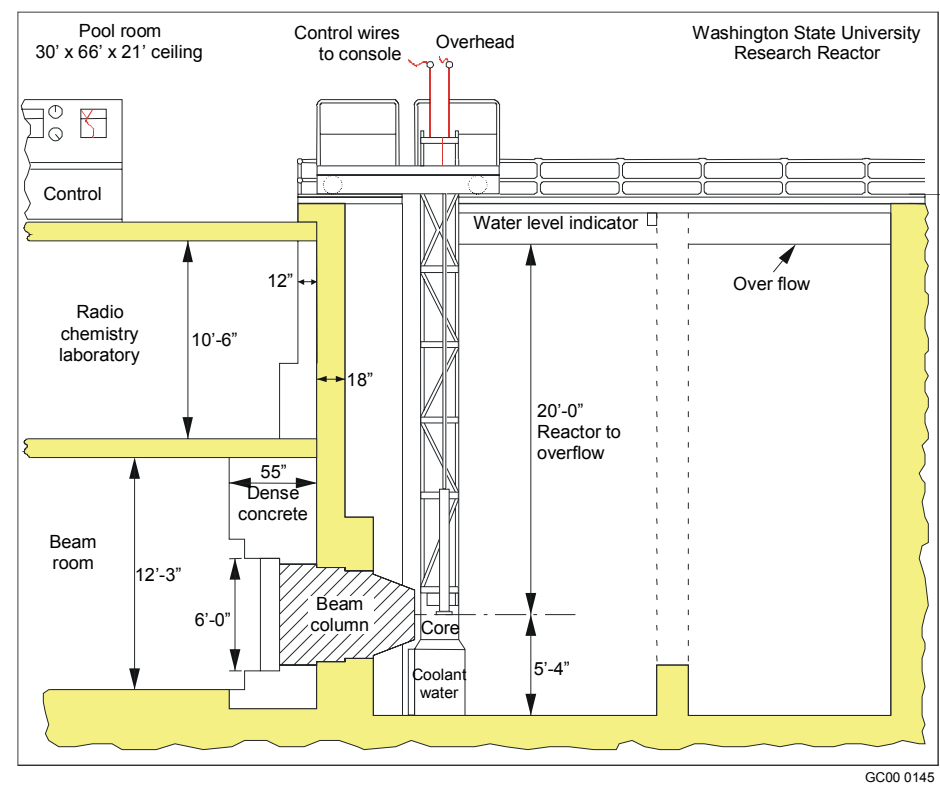

Figure 1. Elevation plan of the WSU TRIGA reactor facility.

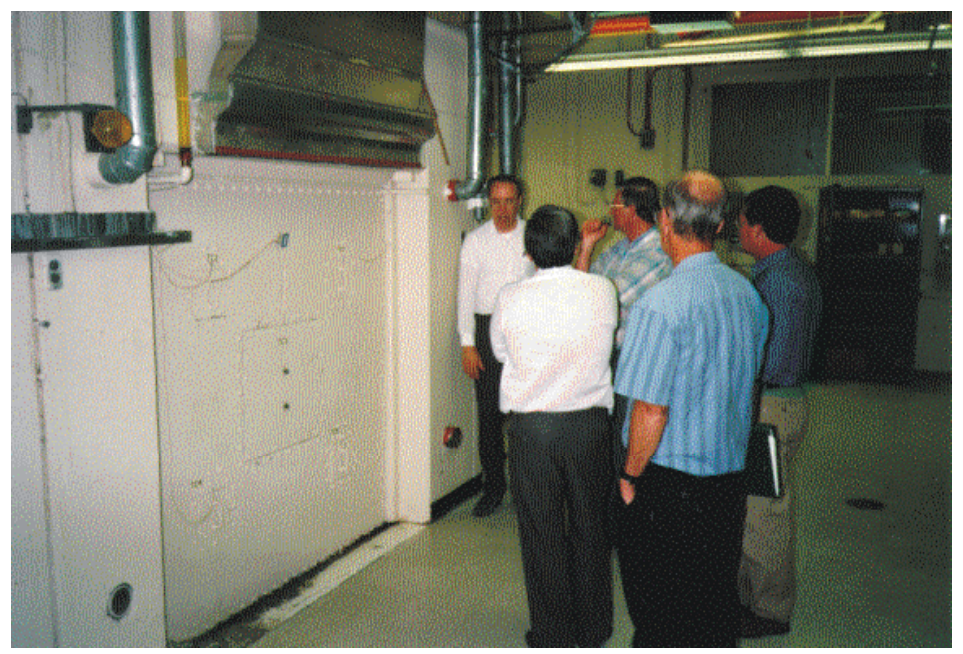

Figure 2. Final thermal column shield and adjacent floor area at the WSU TRIGA facility prior to modifications.

Figure 3 shows a schematic diagram of the WSU epithermal-neutron beam facility. The new epithermal-neutron beam extraction components are located in the thermal-column region of the reactor-shielding monolith. In this design, the original graphite has been removed from this region and replaced with a new epithermal-neutron filtering, moderating, and collimating assembly, as shown. Neutrons emanating from the core travel into the filtering and moderating region. The spectrum is tailored in this region 
such that most neutrons emerge with energies in the epithermal energy range $(0.5 \mathrm{eV}-10$ $\mathrm{keV})$. Downstream of the filtering and moderating region is a bismuth and lead gamma shield, followed by a conical neutron collimator composed of bismuth surrounded by borated polyethylene. Provision is made for several different exit port aperture sizes, as shown in Figure 3. A heavily shielded concrete beam stop and treatment room has been constructed just outside of the thermal column opening in the reactor shield wall, as shown in Figure 4.

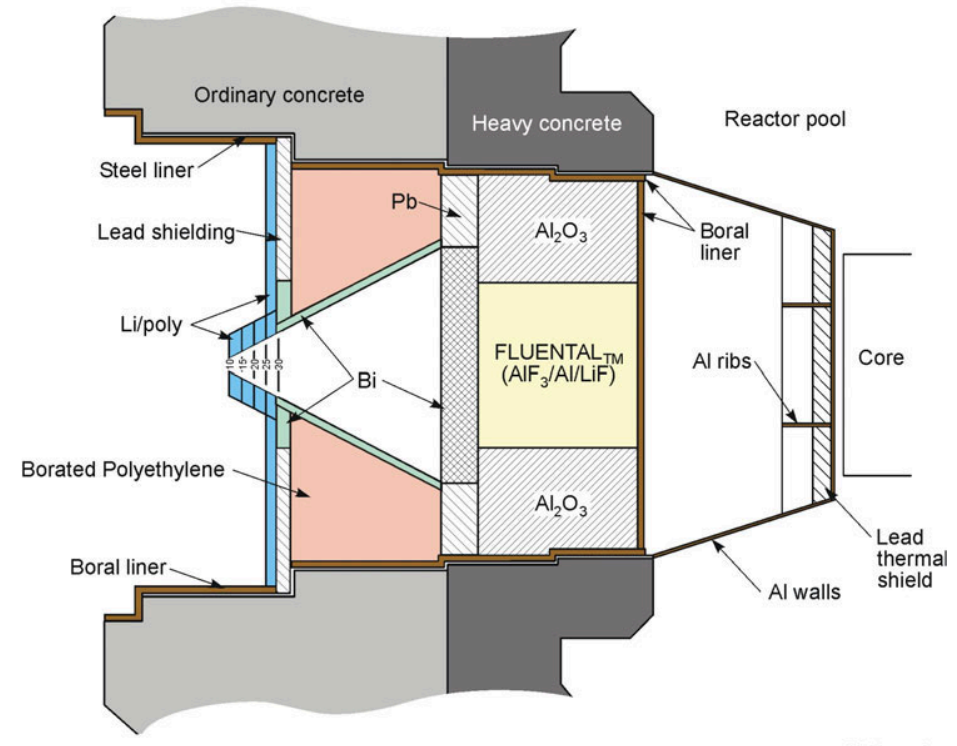

Not to scale

Figure 3. WSU column assembly, with epithermal neutron filter in place.

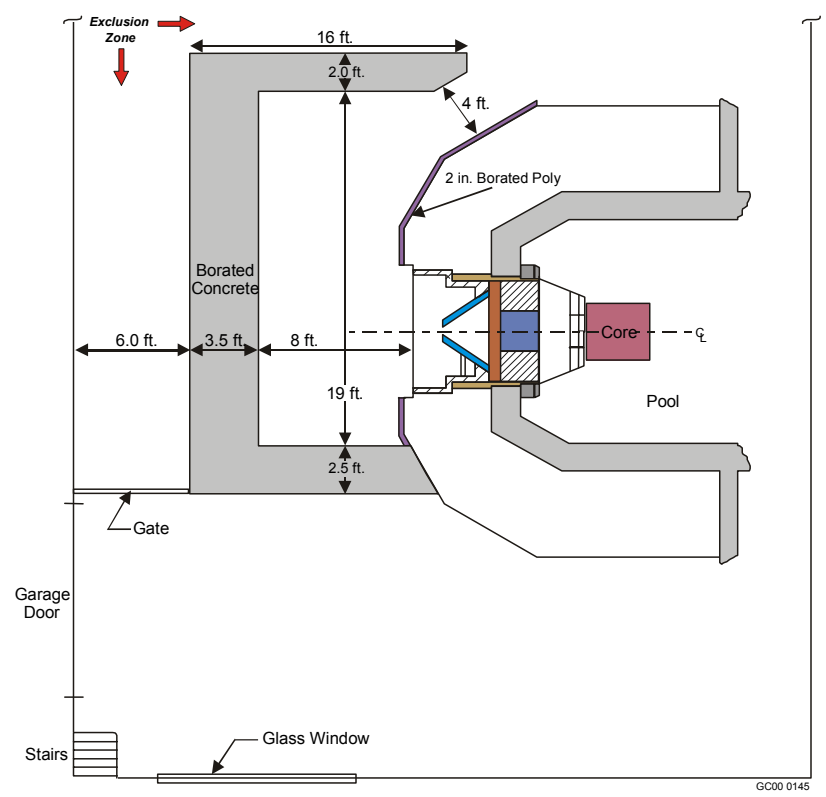

Figure 4. Approximate WSU beam stop and treatment room arrangement. 
A key distinguishing feature of the WSU facility is the incorporation of a new, highefficiency, neutron moderating and filtering material, (FLUENTAL ${ }^{\mathrm{TM}}{ }^{\mathrm{a}}$, developed by the Technical Research Centre of Finland ${ }^{4}$, into the design. FLUENTAL is manufactured by hot isostatic pressing of a mixture of $69 \%$ (by weight) aluminum fluoride, $30 \%$ aluminum, and 1\% lithium fluoride. A block of this material, having a thickness in the beam propagation direction of $0.64 \mathrm{~m}$ and transverse dimensions of approximately $0.6 \mathrm{~m}$, is surrounded by aluminum oxide to produce the neutron filtering and moderating region, as shown in Figure 3. $\mathrm{MCNP}^{5}$ and $\mathrm{DORT}^{6}$ radiation transport design calculations for the coupled core and filter-collimator assembly indicate that an epithermal neutron flux of approximately $10^{9} \mathrm{n} / \mathrm{cm}^{2}$-s at a reactor power of $1 \mathrm{MW}$ will be produced at the exit port of the collimator (with the reactor core optimally loaded). The background neutron KERMA (a measure of the fast-neutron contamination) for the beam is calculated to be in the range of approximately $2.0 \times 10^{-11}$ to $4.0 \times 10^{-11} \mathrm{cGy} / \mathrm{n}-\mathrm{cm}^{2}$. The computational methods used for this design were previously validated against INEEL measurements performed for a similar neutron beam facility that is already in operation at the FiR 1 TRIGA $^{\mathrm{TM}}$ research reactor in Finland ${ }^{7}$.

An additional key feature of the WSU beam facility design is the provision for adjustable filter-moderator thickness to systematically explore the radiobiological consequences of increasing the fast-neutron contamination above the nominal value associated with the baseline system described above. This is an important clinical issue for BNCT. Thinner filter/moderator arrangements will produce epithermal beams having correspondingly harder spectra and greater levels of fast-neutron contamination. The components shown in Figure 3 are designed for relative ease of disassembly and re-assembly, compared to other reactor-based epithermal-neutron facilities that are currently in operation. Thus, it will be possible to have a number of different filter/moderator arrangements over the life of the facility.

\section{STATUS OF CONSTRUCTION}

Construction of the new WSU beam facility was started in 1998, with an initial focus on removing the existing graphite from the thermal column. During 1999, the reactor tank was drained and completely refurbished, and the main heat exchanger was replaced. In the meantime, the FLUENTAL filter/moderator components were machined by VTT Finland to INEEL specifications and delivered to WSU. These components were first assembled on the reactor floor to verify the dimensions. In addition, the necessary aluminum oxide components were fabricated by Coors Ceramics and delivered to WSU. In late 1999 and early 2000, the focus shifted to assembly of the filter-moderator components in the empty thermal column region, shown in Figure 5.

\footnotetext{
${ }^{\text {a }}$ FLUENTAL is a trademark of The Technical Research Centre of Finland.
} 


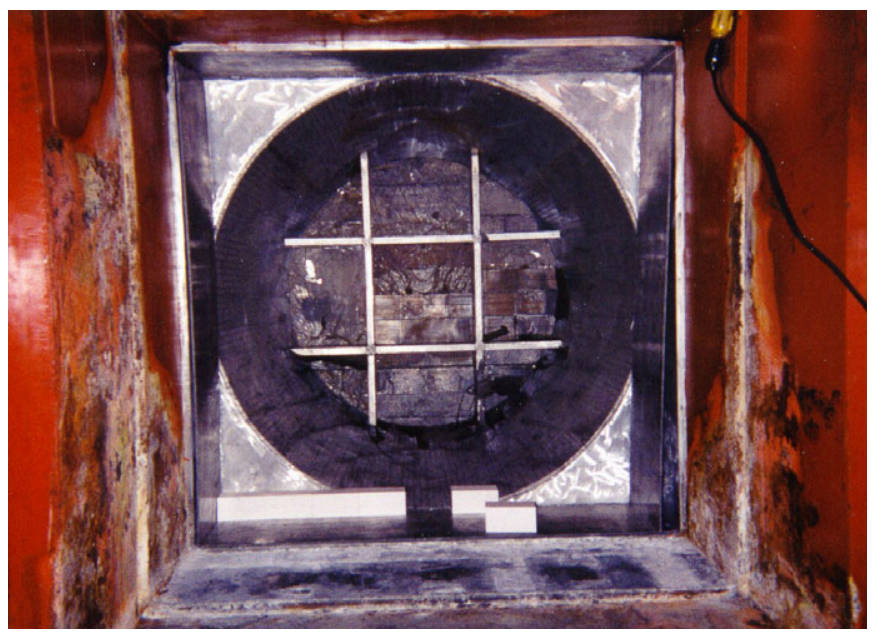

Figure 5. WSU thermal column with the original graphite and water shielding wall removed. The cone shaped area extends into the reactor coolant vessel.

Prior to installation of the filter-moderator components it was decided to place thermocouples at selected locations on the primary gamma shielding at the far end of the thermal column cone housing as shown in Figure 6. This shielding is composed of lead, and subject to heavy gamma heating from the adjacent reactor core. Hence, the temperature must be monitored to verify a suitable temperature margin. The primary filter moderator-filter assembly was then built up from blocks of aluminum oxide and FLUENTAL, as shown in Figure 7 for the partially completed assembly, and in Figure 8 for the fully completed assembly. A sheet of boral prevents the blocks from falling into the cone area. A nitrogen gas purge line was included for the cone area.

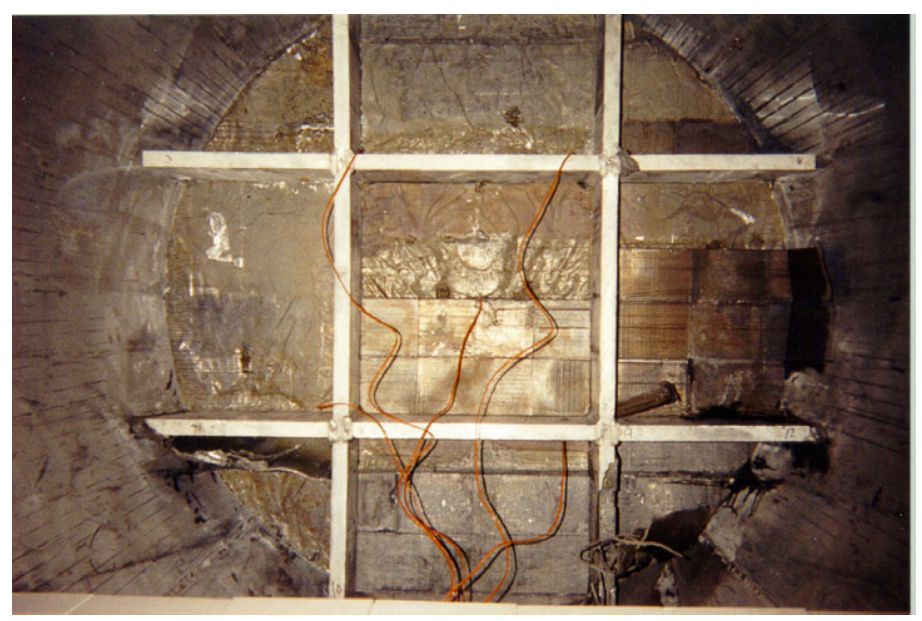

Figure 6. Thermocouple installation in the upstream gamma shielding region of the WSU thermal column cone. 


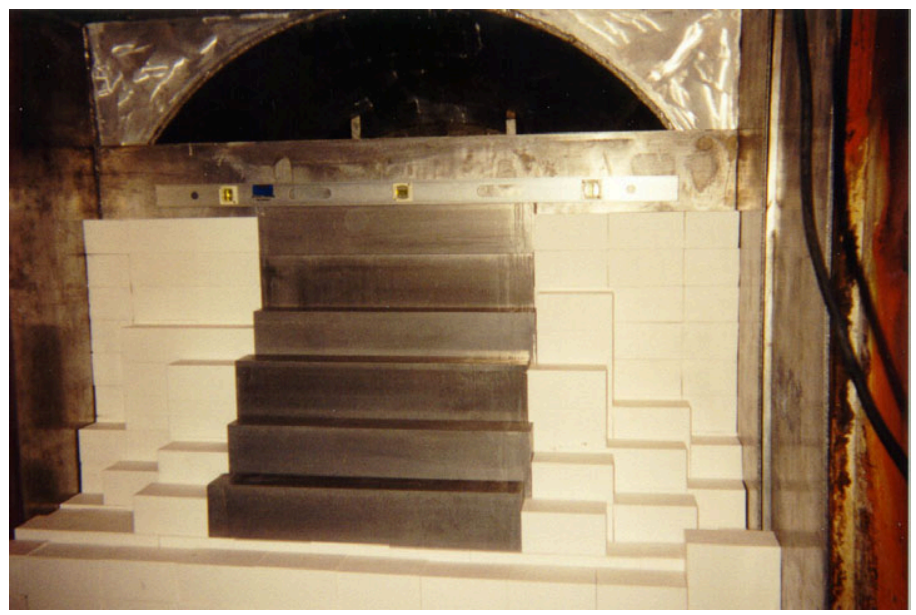

Figure 7. Partially completed WSU filter-moderator assembly, showing the $\mathrm{AlF}_{3}, \mathrm{Al}_{2} \mathrm{O}_{3}$ blocks and boral backing sheet.

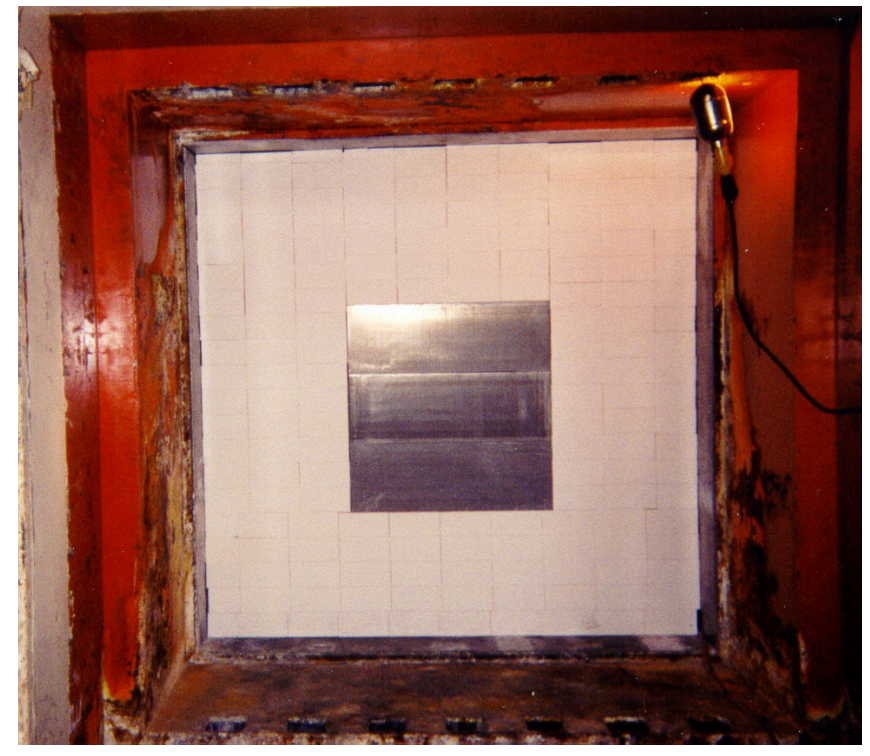

Figure 8. Completed WSU filter-moderator assembly.

Following completion of the filter-moderator assembly, the concrete walls and ceiling of the treatment room were constructed by an outside contractor. The partially completed treatment room is shown in Figure 9. During the two-month period of time required for this part of the project, the bismuth blocks for the final gamma shield were fabricated. 


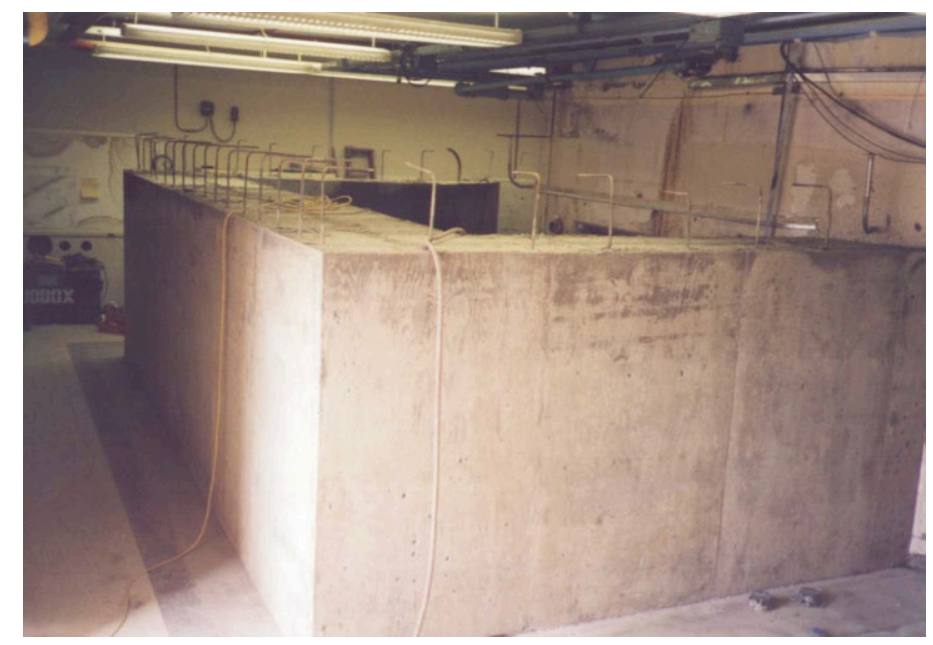

Figure 9. WSU treatment room walls during construction.

Four interlocking bismuth shield blocks were cast at the INEEL, and when the treatment room was completed and access to the thermal column was again possible, these were installed as shown in Figure 10. The bismuth bocks, which span the central part of the filter moderator are surrounded by standard lead shielding blocks. Prior to installing the shield blocks the entire filter-moderator assembly was covered by 1-mm (40-mil) of cadmium using $30.5 \mathrm{~cm}$ (12 inch) vertical strips as shown. The completed gamma shield is shown in Figure 11.

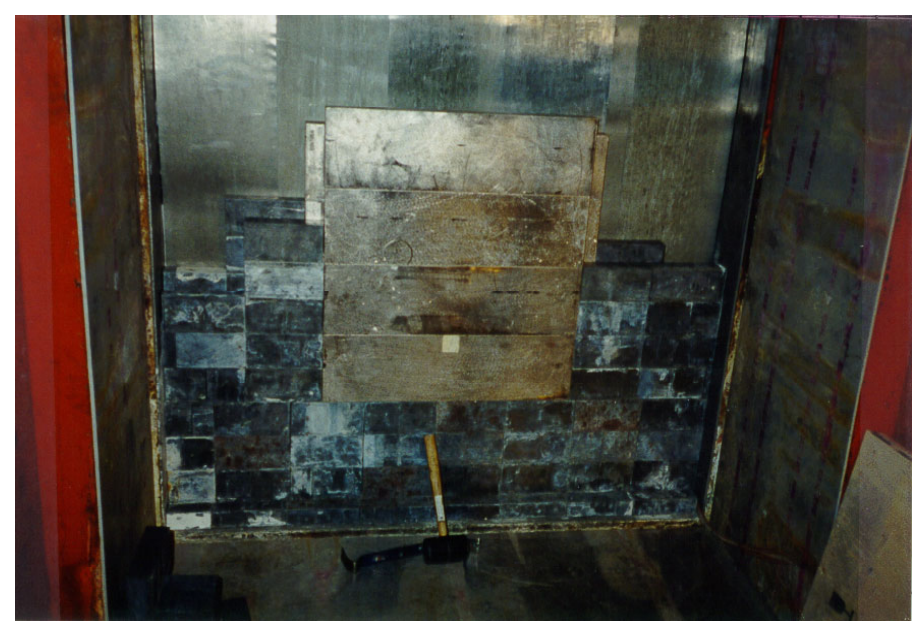

Figure 10. Cadmium thermal neutron shield and bismuth-lead gamma shield during installation at WSU. 


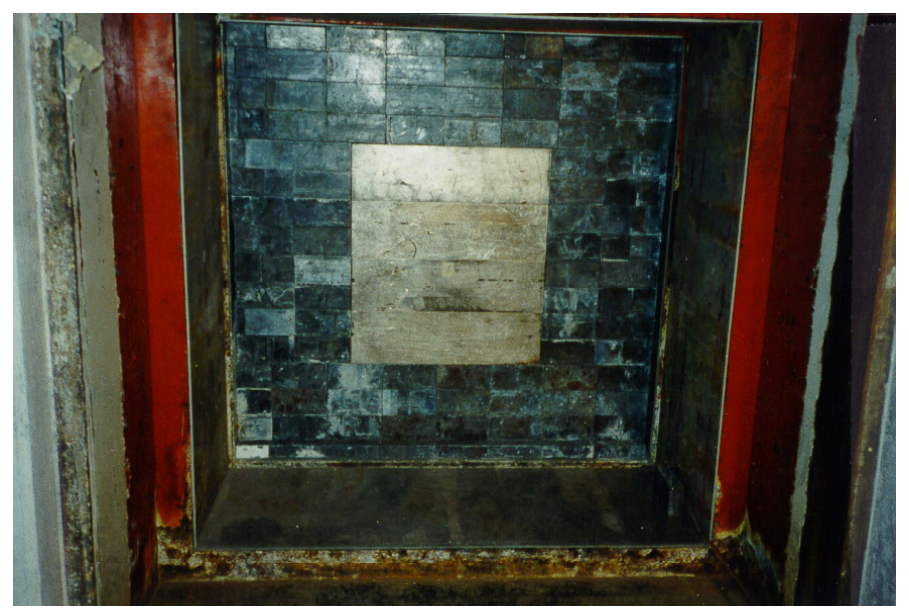

Figure 11. Completed gamma shield assembly at WSU.

During 2001, the conical collimator assembly depicted in Figure 3 will be fabricated and installed. Two basic shapes for the collimator were considered: a pyramid and a cone. Since the collimator material is bismuth, the pyramid shape was abandoned due to construction (weight) considerations, and the right circular cone shape was selected. The design of the cone shaped collimator was based on a tradeoff of cone height to maximize the collimation versus the loss of intensity of the neutrons. The final design selected was a truncated right circular cone with a base opening diameter of $91.4 \mathrm{~cm}$ (36 inches), a height of $38.1 \mathrm{~cm}$ (15 inches), and a wall thickness of $3 \mathrm{~cm}$ (1.2 inches). The angle of the cone is 45 degrees, giving an opening of $15.24 \mathrm{~cm}$ (6 inches). The final $5 \mathrm{~cm}$ of the cone is fitted with a collar, designed so that various shaped apertures can be fabricated from lithiated polyethylene and inserted in a flanged opening. The actual construction of the collimator bismuth section presented a challenge due to the final weight $(>270 \mathrm{~kg}(600$ pounds)) of the finished cone. It was decided to make the collimator out of sections much like barrel staves, as shown in Figure 12. Each of the 16 pieces weighs about 40 pounds.

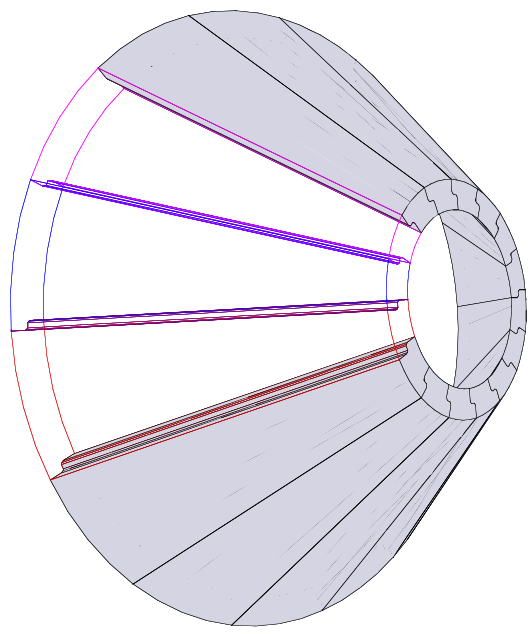

Figure 12. Bismuth collimator. 
A mold was constructed of aluminum, and the sections were formed from molten bismuth. The inside surface of the individual section was the free surface of the mold, which was machined off (bismuth expands when cooled from a liquid) to provide a smooth surface. Figure 13 is a drawing of a finished section.

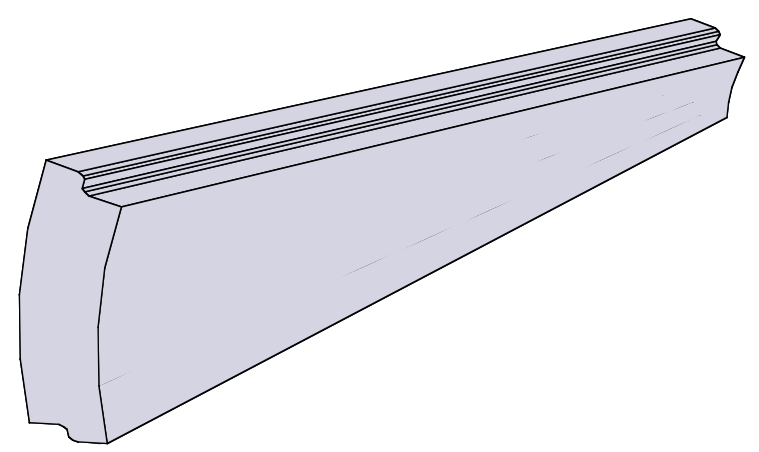

Figure 13. Bismuth collimator section.

The bismuth cone is supported by borated polyethylene (Reactor Experiments, 5\% Borated Polyethylene, Catalog Number 201) for the first 11 inches, and two rows (4 inches) of lead bricks. The last four inches of the bismuth staves will be fitted with a bismuth collar, as shown in Figure 14, designed to provide a transition from the cone shape to the lead while shielding the capture gammas generated from the boron in the polyethylene. The collar will be formed in a mold also, in two pieces due to the final weight ( $\sim 45 \mathrm{~kg}, 100 \mathrm{lbs}$ each). This final bismuth collar will be able to accommodate lithiated polyethylene inserts with various shaped apertures. Figures 15 and 16 are a mockup of the polyethylene-bismuth-lead sections.

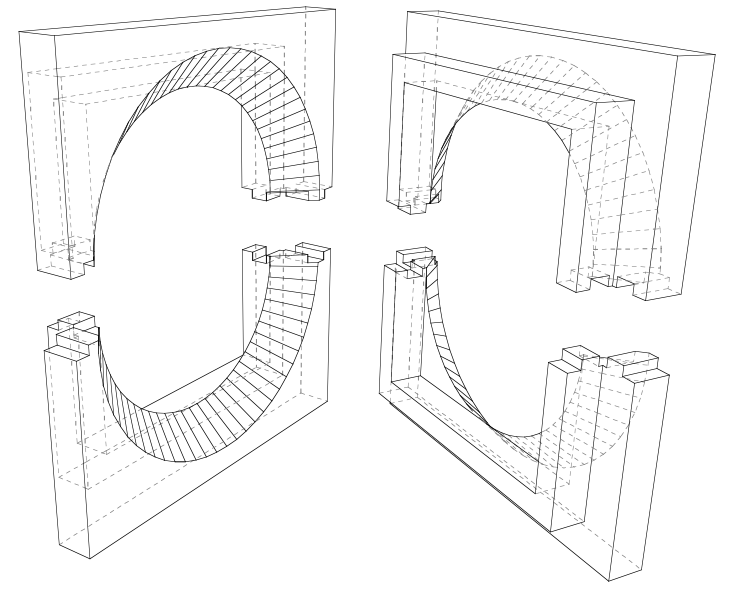

Figure 14. Collimator collar, a rear and front view. 


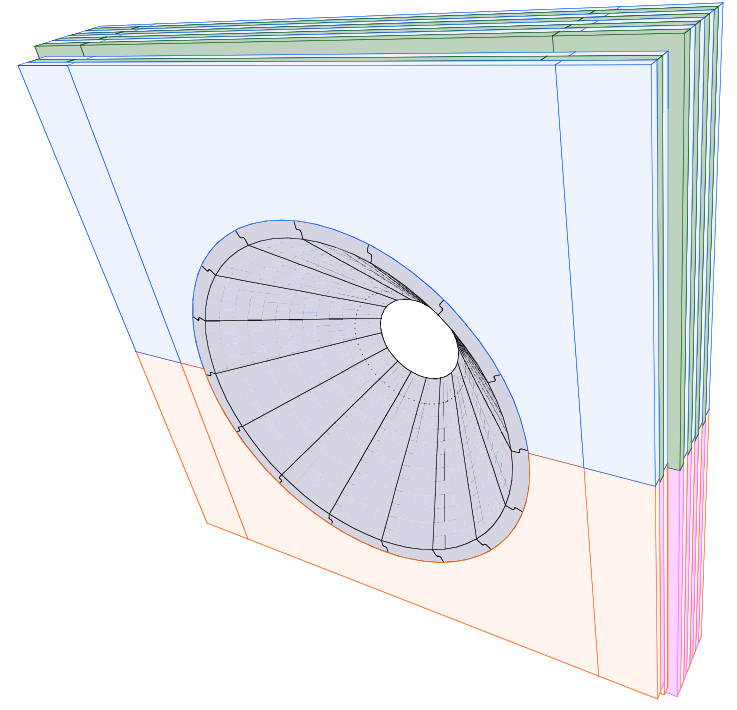

Figure 15. Mockup of the polyethylene-bismuth-lead from inside-out.

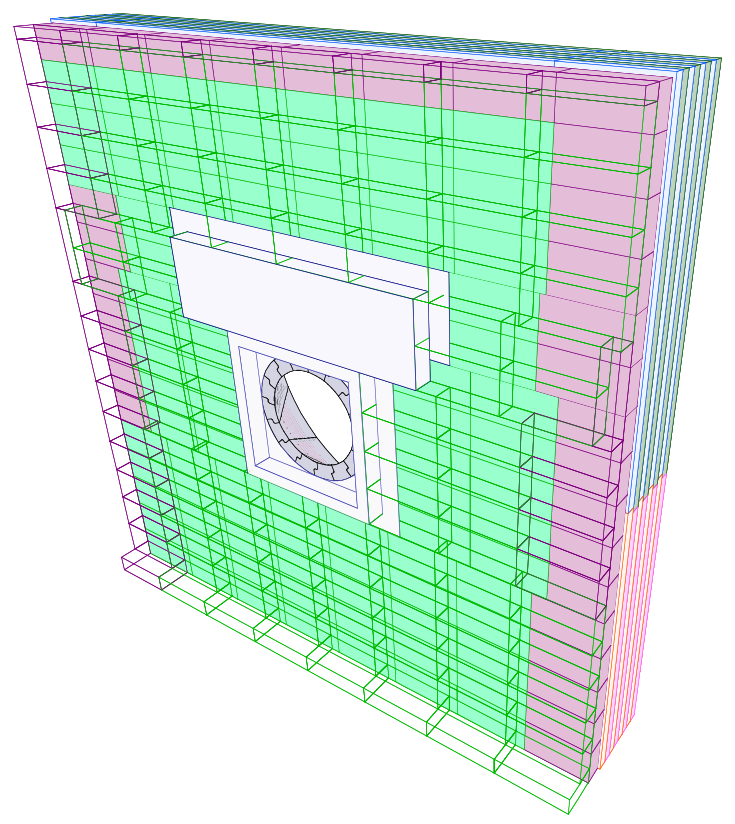

Figure 16. Mockup of the polyethylene-bismuth-lead looking in from the aperture opening. 
In addition, a Teflon ${ }^{\mathrm{TM}}$ bladder will be designed to fit inside the cone, so that it can be filled with heavy water to thermalize the neutrons, yielding a thermal neutron beam for cell or small animal studies. Figure 17 is a cut-away cross section of the collimator section, bismuth shield, and first row of the filter $\left(\mathrm{Al}_{2} \mathrm{O}_{3}\right.$ and $\left.\mathrm{AlF}_{3}\right)$.

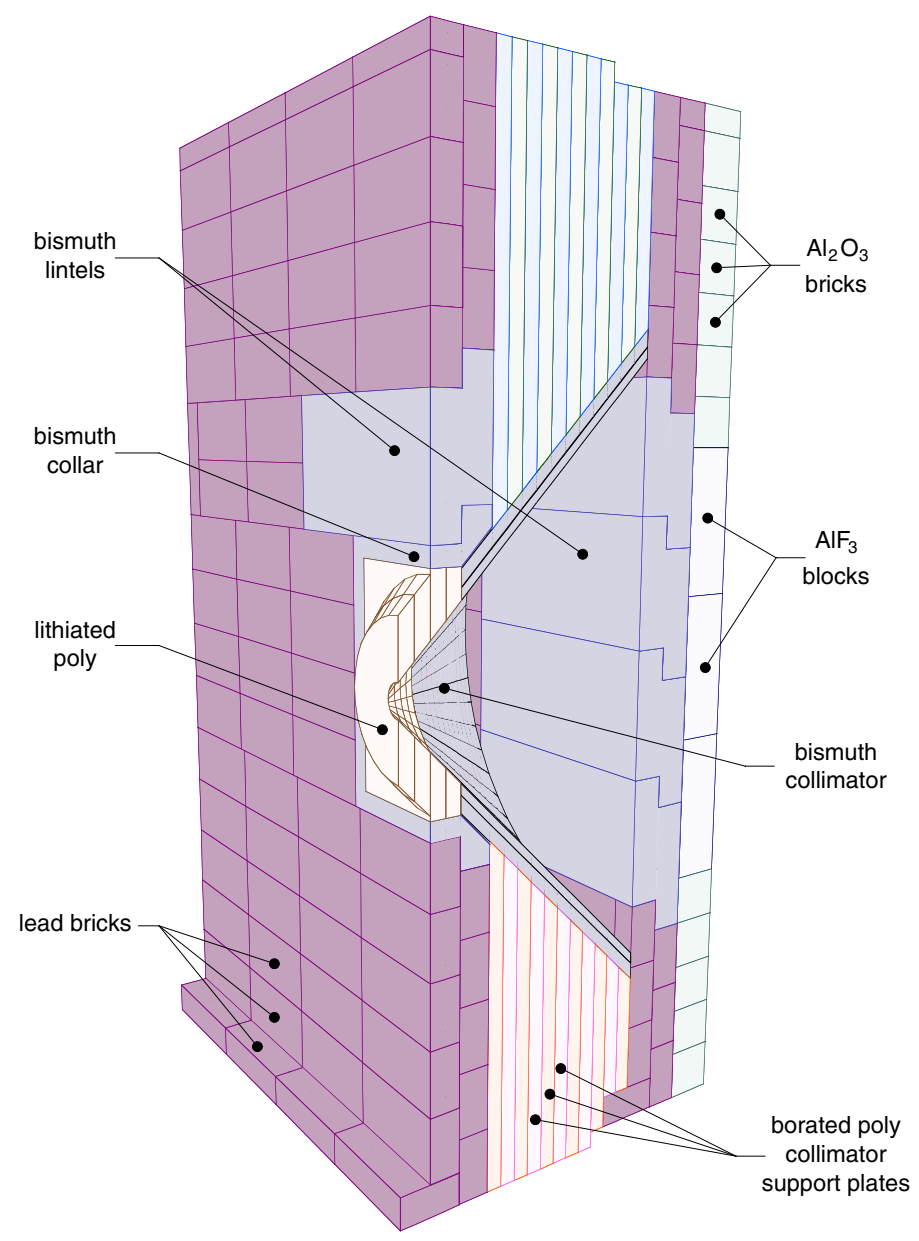

Figure 17. Cut-away cross section of the collimator section, bismuth shield, and first row of the filter.

\section{INITIAL NEUTRON SPECTRUM MEASUREMENTS}

Prior to construction of the collimator assembly, some initial measurements were made to characterize the neutron spectrum on the downstream face of the final bismuth gamma shield. These measurements were performed following a simplified version of the same protocol as was used for earlier INEEL measurements at the FiR 1 epithermal-neutron facility operated by the Technical Research Centre of Finland ${ }^{7}$. That protocol, in turn, was based on neutron activation analysis techniques ${ }^{8}$ that have been adapted for BNCT applications by the INEEL through extensive experience with several other epithermalneutron facilities in the US and in Europe. 
Neutronically thick circular activation foils of various types were used for the measurements. The foil specifications and corresponding neutron activation interactions of interest are listed in Table 1. A very limited set of foils was used for these initial measurements as compared to the FiR 1 protocol.

Table 1. Activation interactions and foils used for the INEEL/WSU preliminary epithermal-neutron beam measurements.

\begin{tabular}{|l|l|l|}
\hline $\begin{array}{l}\text { Neutron } \\
\text { Interaction }\end{array}$ & $\begin{array}{l}\text { Energy Range of } \\
\text { Primary Response }\end{array}$ & $\begin{array}{l}\text { Activation Gamma } \\
\text { Energy of Interest }(\mathrm{keV})\end{array}$ \\
\hline${ }^{115} \mathrm{In}(\mathrm{n}, \gamma)$ & $1 \mathrm{eV}$ Resonance & 1293,1097, and 416 \\
\hline${ }^{197} \mathrm{Au}(\mathrm{n}, \gamma)$ & $5 \mathrm{eV}$ Resonance & 411 \\
\hline${ }^{63} \mathrm{Cu}(\mathrm{n}, \gamma)$ & $1 \mathrm{keV}$ Resonance & 511 (Positron) \\
\hline${ }^{115} \mathrm{In}\left(\mathrm{n}, \mathrm{n}^{\prime}\right)$ & $430 \mathrm{keV}$ Threshold & 336 \\
\hline
\end{tabular}

\section{Positioning of Foils in the Beam}

There were two basic experimental foil packages that were placed on the bismuth face for these measurements. The first arrangement featured a device machined from aluminum by the INEEL to facilitate this type of measurement. This device, referred to as a "foil wheel", is shown in Figure 18. Reproducible positioning of the foil wheel near the center of the face was accomplished using a simple cardboard sheet, as shown in Figure 19.

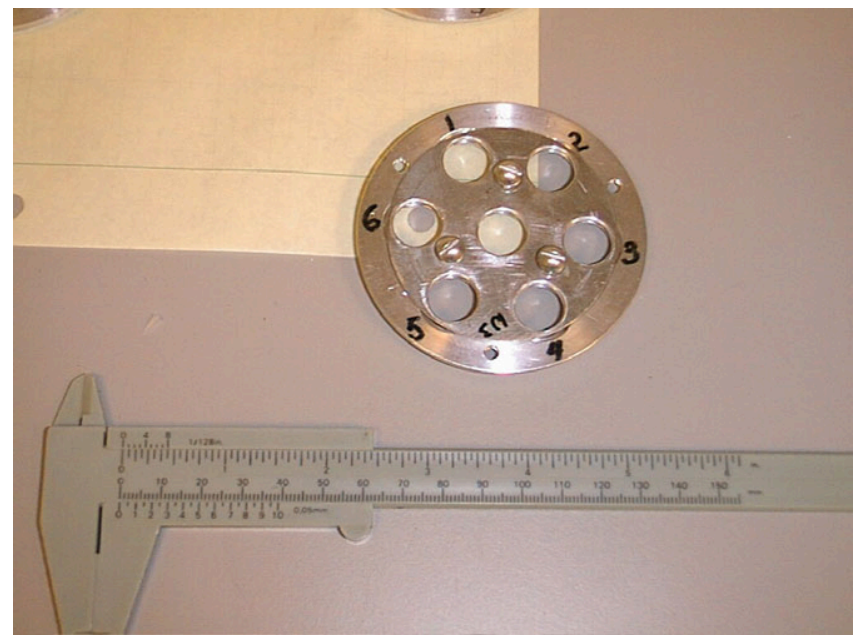

Figure 18. Activation foil wheel. 


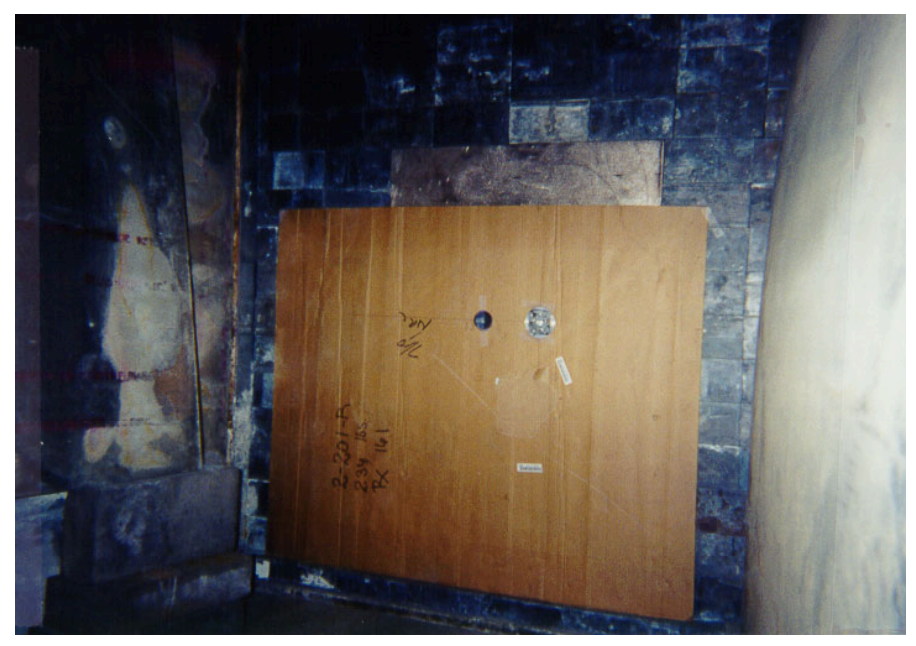

Figure 19. Activation foil packages positioned on the bismuth shield face at WSU.

Standard 12.7-mm (0.5") diameter gold $(\mathrm{Au})$, copper $(\mathrm{Cu})$, and indium $(\mathrm{In})$ foils were used with the foil wheel. A cadmium cover was placed around one foil of each type to suppress the thermal-neutron response. Thus, each foil responds largely to neutrons having energies at or near the energy of the respective primary resonance of the foil material, as shown in the first three lines of Table 1. The three covered foils were placed in three of the outer foil wheel positions. An uncovered gold foil was placed in a fourth outer position of the foil wheel to measure the thermal flux. The foils had nominal thicknesses in the range of $0.0254 \mathrm{~mm}(0.001 \mathrm{inch})$ to $0.127 \mathrm{~mm}(0.005 \mathrm{inch})$, depending on the material type.

A second foil package was used to provide additional spectral information in the highenergy range. A heavy ( $\sim \mathrm{g})$ 25.4-mm (1 inch) diameter indium foil was placed in a small hollow boron sphere, shown (disassembled) in Figure 20. The composition of the sphere is approximately $93 \%{ }^{10} \mathrm{~B}$ and $7 \%{ }^{11} \mathrm{~B}$ by weight, with a total boron density of $2.6 \mathrm{~g} / \mathrm{cm}^{3}$. This arrangement provides essentially total suppression of thermal and epithermal flux within the inner cavity of the boron sphere. Thus, an artificial threshold above the resonance energy range is imposed on the neutron capture reactions in the foil within the sphere. Since the activation gamma emissions that arise from neutron capture in indium are thereby suppressed, the relatively weak $336 \mathrm{keV}$ gamma line from inelastic scatter in indium, which is of crucial interest in these measurements, is much more prominent in the spectrum of the activated indium foil. The activated indium foil is also much easier to handle when the boron sphere is used in this manner, since the induced activity is significantly lower than it would be without the sphere. The inside diameter of the boron sphere is approximately $2.8 \mathrm{~cm}$ (1.1 inch). The outside diameter is approximately $4.75 \mathrm{~cm}$ (1.9 inch). The boron sphere assembly was irradiated in a symmetric position relative to the foil wheel on the bismuth face, as shown in Figure 19. 


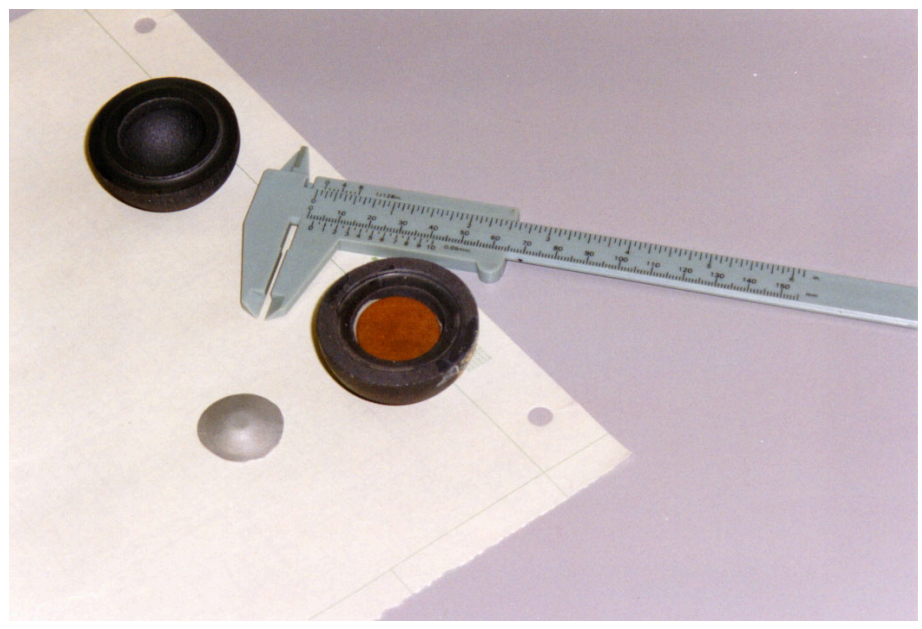

Figure 20. Boron sphere used to suppress low-energy neutron flux.

Use of the foils as described provided 5 basic neutron response functions having a useful degree of linear independence. These response functions were:

1. Resonance capture in the copper, gold, and indium foils in the foil wheel, all with thermal neutron capture suppressed by cadmium (3 responses);

2. Total neutron capture in the single uncovered gold foil in the foil wheel (1 response);

3. Inelastic scatter in the indium foil in the boron sphere (1 response).

The measurements reported here are based on the results of a one-hour irradiation at a reactor power of $100 \mathrm{~kW}$, one irradiation for the foil wheel and one for the boron sphere.

\section{Foil Data Acquisition and Analysis}

The irradiated foils were assayed at WSU using a standard high-purity germanium (HPGe) gamma spectrometry system (Canberra/Genie). The induced activities in the free-beam foils were computed from the photopeak areas and system efficiencies based on calibration of the spectrometer using a National Institute of Standards and Technology (NIST)-tracable mixed europium-antimony calibration source. The measured activity of the heavy indium foil in the boron sphere was corrected for gamma self-shielding using an escape fraction at $336 \mathrm{keV}$, calculated using a combination of MCNP computations and handbook data for the specific source-detector geometry that was used for the assay. This factor was $0.90 \pm 0.01$. The activity of the indium foil in the cadmium cover was taken as the average of the results, derived separately, from the measured activities of the three primary gamma lines. 


\section{Computation of the Free-Beam Neutron Spectrum}

The activation rates of the various foils were used to estimate the neutron spectrum by way of a simple direct matrix unfolding procedure, derived as shown below.

The volume-average activation rate per atom for a foil dosimeter placed in a neutron flux field may be calculated as:

$$
R=\int_{0}^{\infty} \sigma_{f}(E) \Psi_{f}(E) d E
$$

where $\sigma_{\mathrm{f}}(\mathrm{E})$ is the microscopic activation cross section of interest for the foil material, as a function of neutron energy, and $\Psi_{\mathrm{f}}(\mathrm{E})$ is the volume-average scalar neutron flux within the foil, again as a function of energy. Equation (1) can also be expressed as:

$$
R=\int_{0}^{\infty} \sigma_{f}(E)\left(\frac{\Psi_{f}(E)}{\Psi(E)}\right) \Psi(E) d E=\int_{0}^{\infty} \sigma_{f}(E) P_{f}(E) \Psi(E) d E,
$$

where $\Psi(E)$ is the unperturbed neutron flux that would exist at the measurement location in the absence of the foil and any surrounding spectral modification devices ( $\mathrm{Cd}$ covers, boron sphere, etc.).

It may be noted here that, as a practical matter, the function $\mathrm{P}_{\mathrm{f}}(\mathrm{E})$ in Equation 2 can be determined independently from $\Psi(\mathrm{E})$ if desired since it is simply a flux ratio. In this case, $\Psi(\mathrm{E})$ on the far right hand side of Equation 2 can be any appropriate a-priori freebeam unperturbed flux estimate that is then modified by the self-shielding function $P_{f}(E)$.

Equation 2 may be written as a summation, rather than as an integral, by partitioning the range of the energy variable into a number of discrete contiguous energy groups:

$$
R=\sum_{j=1}^{N G} a_{j} \phi_{j}
$$

where NG is the total number of groups, and

$$
a_{j}=\frac{\int_{E L_{j}}^{E H_{j}} \sigma_{f}(E) P_{f}(E) \Psi(E) d E}{\int_{E L_{j}}^{E H_{j}} \Psi(E) d E}
$$

and

$$
\phi_{j}=\int_{E L_{j}}^{E H_{j}} \Psi(E) d E
$$


where $\mathrm{EL}_{\mathrm{j}}$ and $\mathrm{EH}_{\mathrm{j}}$ are the lower and upper limits of energy group $\mathrm{j}$.

If additional foils are placed in the beam, or if a particular foil exhibits more than one activation response, then Equation (3) may be written as a system of equations:

$$
R_{i}=\sum_{j=1}^{N G} a_{i j} \phi_{j},
$$

where $R_{i}$ is the total activation rate for interaction $i$, and $a_{i j}$ is the activation constant from Equation (4) for reaction $i$ due to neutrons in energy group $j$. There will be a total of NF equations, where NF is the total number of activation responses available.

Effective shielded cross sections $\sigma_{\mathrm{f}}(\mathrm{E})$ and the corresponding shielded and unshielded neutron fluxes suitable for computing the function $\mathrm{P}_{\mathrm{f}}(\mathrm{E})$ in Equation 4 for this work were generated by the INEEL using MCNP models of the dosimeter packages. The a-priori neutron flux exiting the beam port, computed using MCNP, was used to represent $\Psi(\mathrm{E})$ in Equation 2.

It should also be noted here that in practical applications the functions $\sigma_{\mathrm{f}}(\mathrm{E}), \mathrm{P}_{\mathrm{f}}(\mathrm{E})$, and $\Psi(\mathrm{E})$ are ordinarily not continuous functions. For the work reported here, they are 47group representations of the actual functions, computed using MCNP and tallied according to the BUGLE-80 neutron energy structure ${ }^{9}$. The integrals in Equations 4 and 5 are, therefore, actually summations over the fine-group structure within each broad group used for spectral unfolding.

The system of activation equations, Equation (6), may be written out in matrix form as:

$$
\left[\begin{array}{lllll}
a_{11} & a_{12} & a_{13} & \cdots & a_{1 N G} \\
a_{21} & a_{22} & a_{23} & \cdots & a_{2 N G} \\
a_{31} & a_{32} & a_{33} & \cdots & a_{3 N G} \\
\vdots & \vdots & \vdots & & \vdots \\
\vdots & \vdots & \vdots & & \vdots \\
a_{N F 1} & a_{N F 2} & a_{N F 3} & & a_{N F N G}
\end{array}\right] \quad\left[\begin{array}{l}
\phi_{1} \\
\phi_{2} \\
\phi_{3} \\
\vdots \\
\vdots \\
\phi_{N G}
\end{array}\right]=\left[\begin{array}{l}
R_{1} \\
R_{2} \\
R_{3} \\
\vdots \\
\vdots \\
R_{N F}
\end{array}\right]
$$

or, more compactly:

$$
[A][\Phi]=[R] .
$$

Equation (7) is exact, provided that the reaction rates, $R_{\mathrm{i}}$, the activation constants, $\mathrm{a}_{\mathrm{ij}}$, and the group fluxes, $\phi_{\mathrm{j}}$, are all self-consistent. If measured reaction rates for each interaction, $R_{i}$, are substituted into Equation (7), a solution of the resulting new system of 
equations for "measured" fluxes corresponding to the measured reaction rates may also be obtained under certain conditions.

If $\mathrm{NF}=\mathrm{NG}$ (as is the case for the measurements presented here), then the matrix [A] is square, its inverse will ordinarily exist, and the unknown "measured" flux vector may be obtained by any standard solution method that converges, provided that the rows of [A] are linearly-independent. In physical terms this implies that the response functions (cross sections) for the activation interactions used in the measurement must be selected such that they have different shapes as functions of energy. It may be noted that positive fluxes are not guaranteed to result from this procedure, but if the elements of [A] are computed in a sufficiently valid, physically-realistic manner for the specific measurement configuration, and if the measured reaction rates are accurately determined, a positive solution can generally be obtained.

Propagation of the measurement uncertainties in the unfolding process can be analyzed as follows. An estimate for the variance of the unfolded flux in group $\mathrm{j}$ may be expressed as:

$$
s_{j}^{2}=\sum_{i=1}^{N F}\left(\frac{\partial \phi_{j}}{\partial R_{i}}\right)^{2}\left[u_{i}^{2}\right],
$$

where $u_{i}$ is the experimental uncertainty associated with reaction rate $i$. Thus, it is necessary to compute a matrix of derivatives of the group fluxes with respect to each reaction rate in order to evaluate the uncertainties in the unfolded fluxes from Equation (9).

If the matrix [A] is square, i.e., if $\mathrm{NF}=\mathrm{NG}$, as in the measurements presented here, the evaluation of the derivatives begins with a rearrangement of Equation (8):

$$
[\Phi]=[C][R]
$$

where [C] is defined to be the inverse of [A]. Expansion of Equation (10) yields:

$$
\left[\begin{array}{l}
\phi_{1} \\
\phi_{2} \\
\vdots \\
\phi_{N G}
\end{array}\right]=\left[\begin{array}{l}
c_{11} R_{1}+c_{12} R_{2} \cdots c_{1 N G} R_{N F} \\
c_{21} R_{1}+c_{22} R_{2} \cdots c_{2 N G} R_{N F} \\
\vdots \\
c_{N G 1} R_{1}+c_{N G 2} R_{2} \cdots c_{N G N G} R_{N F}
\end{array}\right],
$$


where $\mathrm{NF}=\mathrm{NG} . \quad$ Differentiating with respect to $\mathrm{R}_{1}$ now yields

$$
\begin{aligned}
& \frac{\partial \phi_{1}}{\partial R_{1}}=c_{11}, \\
& \frac{\partial \phi_{2}}{\partial R_{1}}=c_{21}, \\
& \frac{\partial \phi_{1}}{\partial R_{2}}=c_{12}, \\
& \frac{\partial \phi_{2}}{\partial R_{2}}=c_{22}, \text { etc. }
\end{aligned}
$$

Thus:

$$
\frac{\partial[\Phi]}{\partial R_{1}}=[C]\left[\begin{array}{c}
1 \\
0 \\
0 \\
\vdots \\
0
\end{array}\right]=[C][\text { column } 1 \text { of an } N G \times N G \text { identity matrix }]
$$

and, in general,

$$
[A] \frac{\partial[\Phi]}{\partial R_{i}}=[\text { column i of an } N G \times N G \text { identity matrix }],
$$

since

$$
[C]=[A]^{-1} .
$$

Equation (14) describes NF systems of NG simultaneous equations in NG variables that can be solved for the necessary derivatives. These are used to evaluate Equation (9).

The method outlined here, as well as the more general extension to the overdetermined case, where NF $>\mathrm{NG}$, has been implemented in a FORTRAN program SPECTRE, Version 5.2. This program inputs self-shielded activation cross section functions, $\sigma_{\mathrm{f}}(\mathrm{E})$, and the a-priori volume-average unperturbed and perturbed fluxes, $\Psi(\mathrm{E})$ and $\Psi_{\mathrm{f}}(\mathrm{E})$, in a user-specified fine-group structure for each activation foil interaction of interest. These, along with a user-input a-priori spectrum (which in the most rigorous case is the same as $\Psi(\mathrm{E})$, as noted previously), are used to compute the elements of the matrix [A] for NG broad groups, each of which spans one or more specified fine groups. Solution of the various systems of equations to produce the unfolded fluxes and associated uncertainties corresponding to a user-input set of NF measured activation rates (and associated 
experimental uncertainties) is accomplished using standard Gauss-Seidel iterations, with linear extrapolation to accelerate convergence.

\section{RESULTS}

Figure 21 shows the unfolded 5-group free-field unperturbed neutron spectrum at the downstream face of the bismuth shield. The computed 47-group a-priori neutron spectrum, normalized to $100 \mathrm{~kW}$, is also shown in Figure 21 for comparison. The broad group structure used for the unfolded spectrum presented in Figure 21 was selected to provide a well-conditioned unfolding matrix, and because it permits the most accurate integration of the measured spectrum in the epithermal energy range to determine the total epithermal neutron flux.

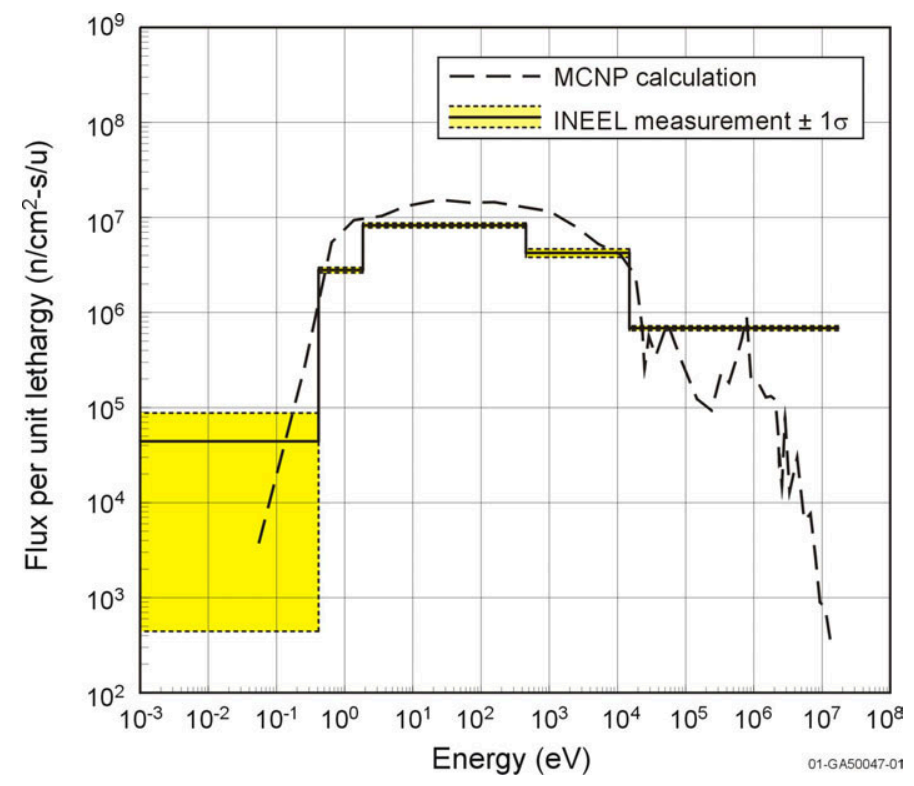

Figure 21. Unfolded free beam neutron spectrum at the downstream bismuth shield face obtained by direct fitting for the WSU epithermal neutron beam facility. The reactor power is $100 \mathrm{~kW}$.

It will be observed that the propagated uncertainty associated with the thermal flux $(\mathrm{E}<0.414 \mathrm{eV})$ in Figure 21 is quite large. This is a result of the fact that the thermal flux is very small compared to the remainder of the spectrum. The measured activities of the gold foils, with and without $\mathrm{Cd}$ covers, differ by only about $1 \%$--- less than the uncertainties of the activities themselves. This leads to a magnification of the uncertainty when the thermal flux is estimated from these foil activities in the spectral unfolding process.

Integrating the measured curve shown in Figure 21 between the standard epithermal energy limits of $0.414 \mathrm{eV}$ and $10 \mathrm{keV}$ produces a measured epithermal neutron flux of $6.35 \times 10^{7} \mathrm{n} / \mathrm{cm}^{2}-\mathrm{sec}$ at $100 \mathrm{~kW}$, with a propagated uncertainty of approximately $5 \%$ $(1 \sigma)$. This is somewhat smaller than the value of $1.11 \times 10^{8} \mathrm{n} / \mathrm{cm}^{2}-\mathrm{sec}$ that is obtained by 
integrating the a-priori curve in Figure 21 between the same energy limits. However, the computational model used for design of the filter/moderator components is somewhat approximate at this stage of construction. The current configuration of the reactor core (not the optimal configuration) is not consistent with what was assumed for the design calculations, and a few "as-built" dimensions are not yet entered into the model. At this point, the measurements provide satisfactory confirmation of the anticipated performance of the design, and will support final design and installation of the collimator assembly during the first half of 2001.

\section{DISCUSSION}

The WSU facility, in addition to the facilities at Brookhaven National Laboratory and the Massachusetts Institute of Technology, will be the third clinical-scale reactor-based epithermal-neutron source for BNCT research that has been constructed in the US. With the recent announcement that the Brookhaven Medical Research Reactor will be decommissioned, the new WSU neutron source will be one of only two operating facilities of its type. Initial plans for collaborative INEEL/WSU preclinical research using the new facility include measurement of the background neutron beam Relative Biological Effectiveness as a function of spectral purity, as well as various preclinical studies for promising alternative boron agents.

\section{REFERENCES}

1. P.R. Gavin, S.L. Kraft, C.E. DeHann, C.D. Swartz, M.L. Griebenow, "Large Animal Normal Tissue Tolerance with Boron Neutron Capture", Int. J. Radiat. Oncol. Bio. Phys., 28:1099-1106 (1994).

2. F.J. Wheeler, D.W. Nigg, "Feasibility Study for an Epithermal-Neutron Beam Facility at the Washington State University Radiation Center, EGG-NRE-11296, Idaho National Engineering Laboratory, USA, 1994.

3. T.D. Burns Jr., "A Monte Carlo Model System for Core Analysis and Design at the Washington State University Radiation Center", INEL-95/0458, Idaho National Engineering Laboratory, 1996.

4. I. Auterinen, P. Hiismäki, "Epithermal BNCT Neutron Beam Design for a Triga II Reactor", Advances in Neutron Capture Therapy, Plenum Press, New York, 1993, Pages 81-84.

5. Breismeister, J.F. (1993) MCNP - A General Monte Carlo N-Particle Transport Code, Version 4A, LA-12625-M, Los Alamos National Laboratory, USA.

6. W.A. Rhoades, et. al., "TORT-DORT: Two and Three-Dimensional DiscreteOrdinates Transport", Radiation Shielding Information Center, Oak Ridge National Laboratory, CCC-543, 1993. 
7. D.W. Nigg, Y.D. Harker, J.K. Hartwell, C.A. Wemple, T. Seren, I. Auterinen, P. Kotiluoto, P. Hiismaki, T. Sepala, M. Kortesniemi, S Savolainen, R. Risler, "Collaborative Neutronic Performance Characterization of the FiR-1 Clinical Epithermal Neutron Beam Facility for BNCT", In: J.R. Venhuizen (ed.), "INEEL BNCT Research Program Annual Report - 1998”, INEEL-EXT-99-00293, April, 1999.

8. Y.D. Harker, et al., "Spectral Characterization of the Epithermal Neutron Beam at the Brookhaven Medical Research Reactor", Nuclear Science and Engineering, 110:355$368,1992$.

9. R.W. Roussin, "BUGLE-80 Coupled 47-Neutron, 20 Gamma-Ray P3 Cross Section Library", DLC-75, Radiation Shielding Information Center, 1980. 


\title{
Improved Evaluation Of The Free-Beam Spectrum Of The FiR 1 Clinical Epithermal-Neutron Beam Facility For BNCT
}

\author{
Part 2
}

D. W. Nigg

C. A. Wemple

T. Serén

T. Seppälä

I. Auterinen

March 2001

Idaho National Engineering and Environmental Laboratory

Idaho Falls, Idaho 83415

\author{
Prepared for the \\ U.S. Department of Energy \\ Office of Science \\ Under DOE Idaho Operations Office \\ Contract DE-AC07-99ID13727
}




\title{
IMPROVED EVALUATION OF THE FREE-BEAM SPECTRUM OF THE FiR 1 CLINICAL EPITHERMAL-NEUTRON BEAM FACILITY FOR BNCT
}

\author{
D.W. Nigg ${ }^{1}$, C.A. Wemple ${ }^{1}$, T. Serén ${ }^{2}$, T. Seppälä ${ }^{3}$, I. Auterinen ${ }^{2}$ \\ 1. Idaho National Engineering and Environmental Laboratory, Idaho Falls, ID. \\ 2. VTT Chemical Technology, Technical Research Centre of Finland, Helsinki, Finland. \\ 3. Department of Physics, University Of Helsinki, Helsinki, Finland.
}

\section{INTRODUCTION}

An advanced epithermal neutron beam facility ${ }^{1}$ for Boron Neutron Capture Therapy (BNCT) research and clinical application was brought into full operation in 1998 by the Technical Research Centre of Finland (VTT). This facility is located at the $250 \mathrm{~kW} \mathrm{FiR} 1$ research reactor installation in Otaniemi, near Helsinki. FiR 1 is a standard TRIGA ${ }^{\mathrm{TM}}$ research reactor of the Mark-II design, produced by the General Atomics Company, La Jolla, California, US. The reactor core, surrounded by a graphite reflector, is at the bottom of a heavily-shielded, lightwater-filled concrete tank. There is a large horizontal access port through one side of the shield monolith providing direct access to the source of neutrons leaking from the adjacent side of the reactor core. This access port was originally filled with graphite to produce a thermal neutron beam.

The configuration of the FiR 1 facility is illustrated in Figure 1.

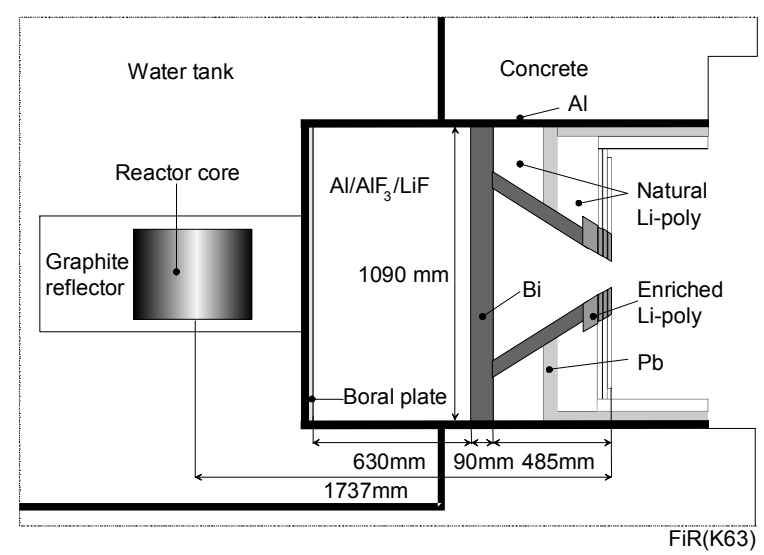

Figure 1. FiR 1 core and filter/moderator/collimator arrangement (FiR(K63)) as installed since autumn 1997. 
To obtain a high quality epithermal-neutron beam from such a low-power neutron source, a patented high-efficiency filter/moderator material with a composition of $69 \% \mathrm{AlF}_{3}, 30 \% \mathrm{Al}$, and $1 \% \mathrm{LiF}$ was developed by $\mathrm{VTT}^{2}$. This material is fabricated by hot isostatic pressing into highdensity $\left(3 \mathrm{~g} / \mathrm{cm}^{3}\right)$ blocks. In 1996, this material was used to construct a $75-\mathrm{cm}$ thick filter in the large horizontal access port to produce an epithermal neutron beam. In 1997, the moderator was shortened to a thickness of $63 \mathrm{~cm}$ to produce the current FiR 1 epithermal-neutron beam, designated FiR(K63). Measurements performed in 1997-98 by the Finnish group ${ }^{3,4}$ and by collaborators from the Idaho National Engineering and Environmental Laboratory (INEEL) validated the design calculations, ${ }^{5}$, which had predicted a beam having a particularly high intensity per MW of reactor power, with minimal fast-neutron and gamma components.

Several things have changed since the 1998 INEEL FiR 1 neutronic performance measurements were originally reported ${ }^{5}$. In particular, new information has become available that has allowed an improved evaluation of the free-beam spectrum. New, apparently improved, measured values of the gamma emission probabilities of ${ }^{187} \mathrm{~W}$, a key activation product in the tungsten foils used for the 1998 measurements, have been reported in the literature ${ }^{6}$. Re-evaluations of the 1998 FiR 1 free-beam spectrum measurements to estimate the effect of using the new tungsten data were recently completed by both INEEL and $\mathrm{VTT}^{7}$. In addition, a recent careful examination of the activation foil packages used by the INEEL for the 1998 measurements has revealed the fact that the thicknesses of the gold and manganese-copper foils were different enough from the nominal values assumed in 1998 that a recalculation of the shielded cross sections used for these foils in the spectral unfolding process was deemed appropriate. Finally, an improved computational model for calculation of shielded cross sections for foils placed within a small boron sphere that is used in the INEEL measurement protocol has been developed.

This article documents a revised evaluation of the FiR 1 free beam spectrum by the INEEL using the basic 1998 foil activation data in conjunction with the various updated unfolding parameters described above.

\section{METHODS AND MATERIALS}

Computations and corresponding measurements of the neutronic performance of the FiR 1 epithermal-neutron beam were performed using extensions of techniques that have been adapted for BNCT applications by the INEEL as a result of experience with other epithermal-neutron facilities in the US and elsewhere. The various computational and experimental methods are summarized in the following sections. Further details are available in Reference 5.

\section{Theoretical Computations}

The expected neutronic performance of the FiR 1 epithermal-neutron beam facility was computed by VTT using the two-dimensional discrete-ordinates method as implemented in the well-known DORT $^{8}$ code, with a cross section library prepared largely from basic data available on the 67-group coupled (47 neutron groups, 20 gamma groups) BUGLE-80 library ${ }^{9}$. Supplementary cross section data for bismuth were provided by INEEL for use in the calculation. 
The entire reactor-moderator system was modeled in cylindrical (R-Z) geometry using the DORT code. The Z-axis in the DORT calculation was aligned with the physical beam centerline, and a forward-biased quadrature set was employed. Experience has shown that these modeling assumptions can produce remarkably accurate results, both in comparison with measurement and with exact-geometry $\mathrm{MCNP}^{10}$ Monte Carlo calculations, as long as certain key dimensions and component volumes are preserved.

The basic DORT computational model for the reactor-moderator system was constructed by VTT in two parts, following previous practice at INEEL. A "core" model, which included the core itself, the surrounding graphite reflector, and immediately adjacent water, as well as the first 20 centimeters of the moderator region, was first used to compute the leakage spectrum of core neutrons into the moderator. This was an eigenvalue-type calculation. A "moderator" model then accepts the computed leakage source from the core model as a boundary condition, applies this to the upstream side of the moderator, and computes the resulting moderated, filtered, and collimated flux exiting at the beam port. The calculation performed with the moderator model is thus of the fixed-source type. It is very computationally-efficient and can be run repeatedly for a wide variety of downstream moderator configurations and measurement apparatus arrangements without having to rerun the time-consuming core calculation, as long as the part of the moderator immediately adjacent to the core and graphite reflector is not significantly changed.

\section{Activation Foil Measurements}

There were two basic experimental arrangements for positioning the foils in the beam. The first arrangement featured a device machined from aluminum by the INEEL to facilitate this type of measurement. This device, referred to as a "foil wheel", is shown in Figure 2 positioned in the epithermal neutron beam port. The foil materials and neutron interactions that were used in conjunction with the foil wheel are listed in the first six lines of Table 1. The foils in the foil wheel were $1.27 \mathrm{~cm}(0.5 \mathrm{inch})$ in diameter and had nominal thicknesses in the range of 0.0254 $\mathrm{mm}(0.001 \mathrm{inch})$ to $0.127 \mathrm{~mm}(0.005 \mathrm{inch})$. Actual thickness varied in some cases by up to $10 \%$ from these nominal thicknesses. Six sets of foils, one set for each foil type, were arranged in stacks of five, with a cadmium cover surrounding each package of five foils to suppress the responses of the foils to thermal neutrons. Single cadmium-covered and bare gold foils were also used to measure the thermal flux. 


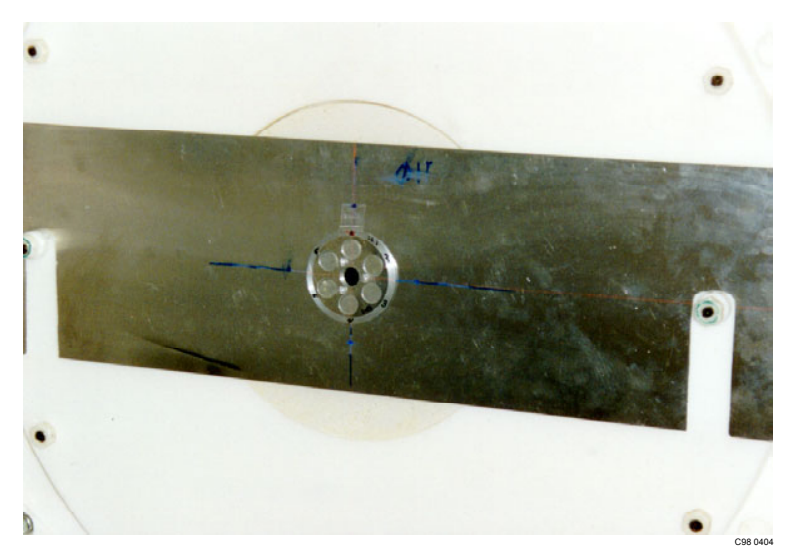

Figure 2. Foil wheel in position in the 14-cm aperture plane of the FiR 1 epithermal neutron beam.

A second arrangement was used to provide additional spectral information in the high-energy range. Heavy $(\sim 1-2 \mathrm{~g})$ sets of indium and copper foils were placed in a small, hollow, boron sphere, and irradiated separately from the foil sets in the foil wheel, in the same position in the beam port, and at the same reactor power. The composition of the sphere is approximately $93 \%$ ${ }^{10} \mathrm{~B}$ and $7 \%{ }^{11} \mathrm{~B}$ by weight, with a total boron density of $2.6 \mathrm{~g} / \mathrm{cm}^{3}$. This arrangement provides essentially total suppression of thermal and epithermal flux within the inner cavity of the boron sphere. Thus, an artificial threshold is imposed on the neutron capture reactions in the foils within the sphere. Since the activation gamma emissions resulting from neutron capture in indium are heavily suppressed, the relatively weak $336 \mathrm{keV}$ gamma line from inelastic scatter in indium (line 7 in Table 1), which is of crucial interest in these measurements, is much more prominent in the spectrum of the activated indium foil. The activated indium foil is also much easier to handle when the boron sphere is used in this manner, since the induced activity is significantly lower than it would be without the sphere. The inside diameter of the boron sphere is approximately $2.8 \mathrm{~cm}(1.1 \mathrm{inch})$. The outside diameter is approximately $4.75 \mathrm{~cm}(1.9 \mathrm{inch})$.

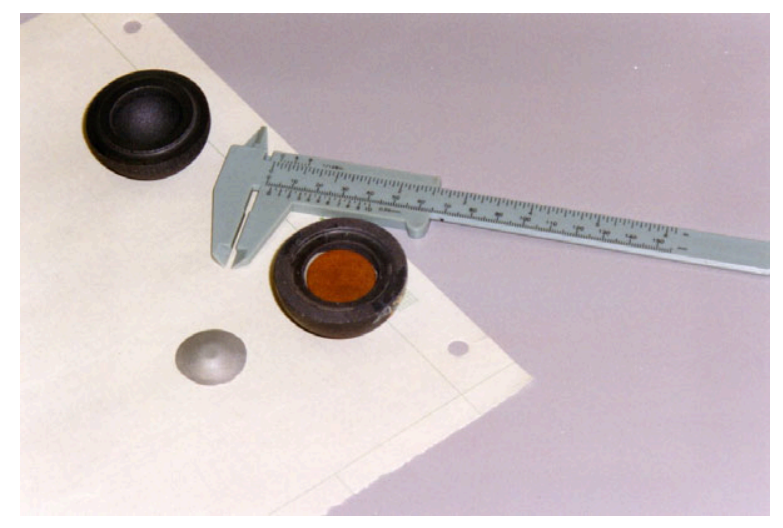

Figure 3. Boron sphere used to suppress low-energy neutron flux. 
Use of the foils as described provided 16 basic neutron response functions having a useful degree of linear independence for use in a direct spectral unfolding process described in the following section. These response functions were: resonance capture in the first and third copper, manganese, cobalt, tungsten, gold, and indium foils in each stack in the spectrum wheel, all with thermal capture suppressed by cadmium (12 responses); total neutron capture in the single uncovered gold foil in the foil wheel (1 response); inelastic scatter in the indium foils in the boron sphere (1 response); and, finally, capture of neutrons above the resonance energy range in the indium and copper foils in the boron sphere (2 responses). A somewhat redundant, but confirmatory, response was also provided by irradiation of the single cadmium-covered gold foil in the foil wheel. The foils irradiated in the boron sphere were in stacks of four, but the responses of all four foils were combined to provide better counting statistics for the activity induced in these foils.

Table 1. Activation interactions used in the INEEL/VTT FiR 1 epithermal-neutron beam measurements.

\begin{tabular}{lll} 
Interaction & $\begin{array}{c}\text { Energy Range of } \\
\text { Primary Response }\end{array}$ & $\begin{array}{l}\text { Activation Gamma } \\
\text { Energy of Interest }(\mathrm{keV}\end{array}$ \\
\hline${ }^{115} \mathrm{In}(\mathrm{n}, \gamma)$ & $1 \mathrm{eV}$ Resonance & 1293,1097 , and 416 \\
${ }^{197} \mathrm{Au}(\mathrm{n}, \gamma)$ & $5 \mathrm{eV}$ Resonance & 411 \\
${ }^{186} \mathrm{~W}(\mathrm{n}, \gamma)$ & $18 \mathrm{eV}$ Resonance & 686 \\
${ }^{59} \mathrm{Co}(\mathrm{n}, \gamma)$ & $32 \mathrm{eV}$ Resonance & 1173 \\
${ }^{55} \mathrm{Mn}(\mathrm{n}, \gamma)$ & $340 \mathrm{eV}$ Resonance & 847 \\
${ }^{63} \mathrm{Cu}(\mathrm{n}, \gamma)$ & $1 \mathrm{keV}$ Resonance & 511 (Positron) \\
${ }^{115} \mathrm{In}\left(\mathrm{n}, \mathrm{n}^{\prime}\right)$ & $430 \mathrm{keV}$ Threshold & 336
\end{tabular}

The measurements reported here are based on the results of six full-power $(250 \mathrm{~kW}) \mathrm{FiR} 1$ irradiations: two for the single gold foils with and without cadmium; two for the stacked foil packages; and two for the sets of foils in the boron sphere. Thus, there were two independent measurements of each response. The induced activities of all foils and wires were measured by VTT using standard calibrated gamma spectroscopy instrumentation (germanium detector with appropriate electronics, PC-based spectral analysis hardware and software, etc.) that was available at the VTT facility. The gamma spectra were analyzed with the SAMPO 90 program $^{11}$, and the foil activation results were reported by VTT to the INEEL team as effective saturation activities. Subsequent spectral unfolding analysis was carried out by the INEEL team using PCbased software developed especially for the purpose. 


\section{Free-Beam Spectral Unfolding Algorithm}

The activation rates of the various foils were used to estimate the neutron spectrum of the FiR 1 epithermal neutron beam by way of a direct least-squares fitting procedure adapted for the purpose, as follows.

The volume-average activation rate per atom for a foil dosimeter placed in a neutron flux field may be calculated as:

$$
R=\int_{0}^{\infty} \sigma_{f}(E) \Psi_{f}(E) d E
$$

where $\sigma_{f}(E)$ is the microscopic activation cross section of interest for the foil material, as a function of neutron energy and $\Psi_{\mathrm{f}}(\mathrm{E})$ is the volume-average scalar neutron flux within the foil, again as a function of energy. Equation 1 can also be expressed as:

$$
R=\int_{0}^{\infty} \sigma_{f}(E)\left(\frac{\Psi_{f}(E)}{\Psi(E)}\right) \Psi(E) d E=\int_{0}^{\infty} \sigma_{f}(E) P_{f}(E) \Psi(E) d E
$$

where $\Psi(\mathrm{E})$ is the unperturbed neutron flux that would exist at the measurement location in the absence of the foil and any surrounding spectral modification devices ( $\mathrm{Cd}$ covers, boron sphere, etc.).

It may be noted here that, as a practical matter, the function $\mathrm{P}_{\mathrm{f}}(\mathrm{E})$ in Equation 2 can be determined independently from $\Psi(\mathrm{E})$, if desired, since it is simply a flux ratio. In this case, $\Psi(\mathrm{E})$ on the far right hand side of Equation 2 can be any appropriate a-priori free-beam unperturbed flux estimate, which is then modified by the self-shielding function $\mathrm{P}_{\mathrm{f}}(\mathrm{E})$.

Equation 2 may be written as a summation, rather than as an integral, by partitioning the range of the energy variable into a number of discrete contiguous energy groups:

$$
R=\sum_{j=1}^{N G} a_{j} \phi_{j}
$$

where NG is the total number of energy groups, and

$$
a_{j}=\frac{\int_{E L_{j}}^{E H_{j}} \sigma_{f}(E) P_{f}(E) \Psi(E) d E}{\int_{E L_{j}}^{E H_{j}} \Psi(E) d E}
$$

and 


$$
\phi_{j}=\int_{E L_{j}}^{E H_{j}} \Psi(E) d E
$$

where $\mathrm{EL}_{\mathrm{j}}$ and $\mathrm{EH}_{\mathrm{j}}$ are the lower and upper energy limits of energy group $\mathrm{j}$.

If additional foils are placed in the beam, or if a particular foil exhibits more than one activation response, then Equation 3 may be written as a system of equations:

$$
R_{i}=\sum_{j=1}^{N G} a_{i j} \phi_{j},
$$

where $R_{i}$ is the total activation rate for interaction $i$, and $a_{i j}$ is the activation constant from Equation 4 for reaction $\mathrm{i}$ due to neutrons in energy group $\mathrm{j}$. There will be a total of NF equations, where NF is the total number of activation responses available.

Effective shielded cross sections, $\sigma_{\mathrm{f}}(\mathrm{E})$, and the corresponding shielded and unshielded neutron fluxes suitable for computing the function $\mathrm{P}_{\mathrm{f}}(\mathrm{E})$ in Equation 4 for this work, were generated by the INEEL using MCNP models of the dosimeter packages. The a-priori neutron flux exiting the beam port, computed by VTT, was used to construct the neutron source for the MCNP foil package computations. The same computed a-priori flux was also used to represent $\Psi(E)$ in Equation 2. Foil reaction rates for each interaction of interest were computed using the MCNP volume-averaged flux tally.

It should also be noted here that, in practical applications, the functions $\sigma_{\mathrm{f}}(\mathrm{E}), \mathrm{P}_{\mathrm{f}}(\mathrm{E})$, and $\Psi(\mathrm{E})$ are ordinarily not continuous functions. For the work reported here, they are 47-group representations of the actual functions, computed by MCNP and tallied according to the BUGLE80 neutron energy structure. The integrals in Equations 4 and 5 are, therefore, actually summations over the fine-group structure within each broad group used for spectral unfolding.

The system of activation equations, Eq. 6, may be written out in matrix form as:

$$
\left[\begin{array}{lllll}
a_{11} & a_{12} & a_{13} & \cdots & a_{1 N G} \\
a_{21} & a_{22} & a_{23} & \cdots & a_{2 N G} \\
a_{31} & a_{32} & a_{33} & \cdots & a_{3 N G} \\
\vdots & \vdots & \vdots & & \vdots \\
\vdots & \vdots & \vdots & & \vdots \\
a_{N F 1} & a_{N F 2} & a_{N F 3} & & a_{N F N G}
\end{array}\right] \quad\left[\begin{array}{l}
\phi_{1} \\
\phi_{2} \\
\phi_{3} \\
\vdots \\
\vdots \\
\phi_{N G}
\end{array}\right]=\left[\begin{array}{l}
R_{1} \\
R_{2} \\
R_{3} \\
\vdots \\
\vdots \\
R_{N F}
\end{array}\right]
$$


or, more compactly,

$$
[A][\Phi]=[R] .
$$

Equation 7 is exact, provided that the reaction rates, $R_{i}$, the activation constants, $a_{i j}$, and the group fluxes, $\phi_{\mathrm{j}}$, are all self-consistent. If measured reaction rates for each interaction, $\mathrm{R}_{\mathrm{i}}$, are substituted into Equation 7, a solution of the resulting new system of equations for "measured" fluxes corresponding to the measured reaction rates may also be obtained under certain conditions.

If $\mathrm{NF}=\mathrm{NG}$ in Equation 7, then the matrix [A] is square, its inverse will ordinarily exist, and the unknown "measured" flux vector may be obtained by any standard solution method that converges, provided that the rows of [A] are linearly-independent. In physical terms, this implies that the response functions (cross sections) for the activation interactions used in the measurement must be selected such that they have different shapes as functions of energy. It may be noted that positive fluxes are not guaranteed to result from this procedure, but if the elements of $[\mathrm{A}]$ are computed in a sufficiently valid, physically-realistic manner for the specific measurement configuration, and if the measured reaction rates are accurately determined, a positive solution can generally be obtained.

There are two possibilities for the situation where NF, the number of available activation response functions, is not equal to $\mathrm{NG}$, the number of energy groups for which it is desired to obtain unfolded fluxes. If $\mathrm{NF}<\mathrm{NG}$, the problem is underdetermined, and additional information must be introduced in some manner to permit a realistic solution, as is done in the various types of "adjustment" techniques for spectrum estimation from activation data. If NF > NG (as is the case for the work presented here), the problem is overdetermined, and the "extra" information that is thereby available can be incorporated into the solution for the group fluxes by a linear least-squares fitting procedure as follows.

When NF $>$ NG, an approximation for the flux vector is sought such that the sum of the squares of the weighted differences between the measured reaction rates and the calculated reaction rates, obtained by substituting the desired approximate solution vector into each row of Equation 7, is minimized. That is, we wish to minimize the quantity $\Delta$,

$$
\Delta=\sum_{i=1}^{N F} \frac{\delta_{i}^{2}}{u_{i}^{2}},
$$

where $u_{i}$ is the experimental uncertainty associated with reaction rate $i$, and 


$$
\delta_{i}=\left(R_{i}-\left(a_{i 1} \phi+a_{i 2} \phi_{2} \cdots+a_{i N G} \phi_{N G}\right)\right) \text {. }
$$

To accomplish this, Equation 9 is differentiated successively with respect to each group flux, and the result in each case is set to zero. This produces a new set of NG equations, one for each differentiation operation. Upon some additional manipulation the new set of equations has the following compact form:

$$
[A]^{T}[V][A][\Phi]=[A]^{T}[V][R]
$$

where [V] is an NF $\mathrm{x}$ NF diagonal matrix whose elements are the inverse squares of the measurement uncertainties for the NF reaction rates. This can be expressed compactly as:

$$
[B][\Phi]=[S]
$$

where the new matrix $[\mathrm{B}]=[\mathrm{A}]^{\mathrm{T}}[\mathrm{V}][\mathrm{A}]$ will be of dimensions NG $\mathrm{x}$ NG and the new vector $[\mathrm{S}]$ will be of length NG. Equation 12 is then solved in the work presented here by standard GaussSeidel iteration, with linear extrapolation to accelerate convergence, to yield the desired flux vector.

Propagation of uncertainties in the unfolding process can be analyzed as follows. In general, the measured reaction rates in Equation 11 will each have an associated experimental uncertainty. In addition, there will be a component of variance in the unfolded fluxes associated with the nature of the least-squares process itself. It should also be noted that, ordinarily, insertion of the unfolded fluxes back into the basic balance equation (Equation 7) will not produce calculated reaction rates that are the same as the measured reaction rates, unless, of course, $\mathrm{NF}=\mathrm{NG}$, in which case the fluxes are forced by definition to produce the measured reaction rates exactly.

An estimate for the variance of the unfolded flux in group $\mathrm{j}$ may be expressed as:

$$
s_{j}^{2}=\sum_{i=1}^{N F}\left(\frac{\partial \phi_{j}}{\partial R_{i}}\right)^{2}\left[\delta_{i}^{2}+u_{i}^{2}\right]
$$

where $\delta_{\mathrm{i}}$ is computed from Equation 10, and $\mathrm{u}_{\mathrm{i}}$ is the experimental uncertainty associated with reaction rate $i$. It is therefore necessary to compute a matrix of derivatives of the group fluxes with respect to each reaction rate in order to evaluate the uncertainties in the unfolded fluxes from Equation 13. 
To obtain the required matrix of derivatives, the rows of Equation 11 are differentiated successively with respect to each reaction rate and the results are rearranged and combined to yield:

$$
[B] \frac{\partial[\Phi]}{\partial R_{i}}=\left[\text { column i of }[A]^{T}[V]\right] .
$$

Equation 14 describes NF systems of NG simultaneous equations that can be solved to obtain all of the derivatives necessary to evaluate Equation 13 for the uncertainties associated with the group fluxes.

It is also of interest to note here that the inverse of the matrix [B] is a covariance matrix for the unfolded fluxes, based on propagation of the measurement uncertainties $u_{i}$. Accordingly, the diagonal elements of $[\mathrm{B}]^{-1}$ correspond to the components of the flux variance in each group that are attributable to propagation of the measurement uncertainties.

\section{RESULTS}

Table 2 shows the measured effective saturation activities (i.e., the activation rates) per atom for all of the foils. Including the redundant single cadmium-covered gold foil measurement, there were 17 responses, which were each measured twice, for a total of 34 activation measurements. Of these, only 33 were usable, due to a technical problem with the second measurement of neutron capture in the indium foils inside the boron sphere. The values for tungsten have been adjusted downward, relative to the Reference 5 values, to account for the effect of the new Marnada emission data. This causes a reduction in the rate relative to Reference 5, since the Marnada gamma yields are higher than the previously accepted values. 
Table 2. Foil activation rates for the FiR 1 free-beam spectrum measurements.

\begin{tabular}{|c|c|c|}
\hline \multirow[b]{2}{*}{ Interaction Type } & \multicolumn{2}{|c|}{ Activation Rates (acts/s-atom) } \\
\hline & First Run & Second Run \\
\hline${ }^{197} \mathrm{Au}(\mathrm{n}, \gamma)$ single bare foil & $(7.78 \pm 0.30) \mathrm{E}-14$ & $(7.75 \pm 0.30) \mathrm{E}-14$ \\
\hline${ }^{197} \mathrm{Au}(\mathrm{n}, \gamma)$ single foil $-\mathrm{Cd}$ & $(7.00 \pm 0.27) \mathrm{E}-14$ & $(6.93 \pm 0.27) \mathrm{E}-14$ \\
\hline${ }^{115} \operatorname{In}(\mathrm{n}, \gamma)$ foil $1 / 5-\mathrm{Cd}$ & $(8.17 \pm 0.20) \mathrm{E}-14$ & $(9.18 \pm 0.28) \mathrm{E}-14$ \\
\hline${ }^{115} \operatorname{In}(\mathrm{n}, \gamma)$ foil $3 / 5-\mathrm{Cd}$ & $(2.93 \pm 0.08) \mathrm{E}-14$ & $(3.49 \pm 0.11) \mathrm{E}-14$ \\
\hline${ }^{197} \mathrm{Au}(\mathrm{n}, \gamma)$ foil $1 / 5-\mathrm{Cd}$ & $(7.13 \pm 0.28) \mathrm{E}-14$ & $(7.00 \pm 0.27) \mathrm{E}-14$ \\
\hline${ }^{197} \mathrm{Au}(\mathrm{n}, \gamma)$ foil $3 / 5-\mathrm{Cd}$ & $(2.80 \pm 0.11) \mathrm{E}-14$ & $(2.77 \pm 0.11) \mathrm{E}-14$ \\
\hline${ }^{186} \mathrm{~W}(\mathrm{n}, \gamma)$ foil $1 / 5-\mathrm{Cd}$ & $(4.56 \pm 0.15) \mathrm{E}-14$ & $(4.58 \pm 0.12) \mathrm{E}-14$ \\
\hline${ }^{186} \mathrm{~W}(\mathrm{n}, \gamma)$ foil $3 / 5-\mathrm{Cd}$ & $(1.87 \pm 0.07) \mathrm{E}-14$ & $(1.86 \pm 0.06) \mathrm{E}-14$ \\
\hline${ }^{59} \mathrm{Co}(\mathrm{n}, \gamma)$ foil $1 / 5-\mathrm{Cd}$ & $(7.75 \pm 0.47) \mathrm{E}-15$ & $(6.87 \pm 0.54) \mathrm{E}-15$ \\
\hline${ }^{59} \mathrm{Co}(\mathrm{n}, \gamma)$ foil $3 / 5-\mathrm{Cd}$ & $(4.21 \pm 0.25) \mathrm{E}-15$ & $(4.04 \pm 0.18) \mathrm{E}-15$ \\
\hline${ }^{55} \mathrm{Mn}(\mathrm{n}, \gamma)$ foil $1 / 5-\mathrm{Cd}$ & $(1.49 \pm 0.07) \mathrm{E}-15$ & $(1.47 \pm 0.07) \mathrm{E}-15$ \\
\hline${ }^{55} \mathrm{Mn}(\mathrm{n}, \gamma)$ foil $3 / 5-\mathrm{Cd}$ & $(9.77 \pm 0.49) \mathrm{E}-16$ & $(9.85 \pm 0.49) \mathrm{E}-16$ \\
\hline${ }^{63} \mathrm{Cu}(\mathrm{n}, \gamma)$ foil $1 / 5-\mathrm{Cd}$ & $(3.75 \pm 0.17) \mathrm{E}-16$ & $(3.96 \pm 0.18) \mathrm{E}-16$ \\
\hline${ }^{63} \mathrm{Cu}(\mathrm{n}, \gamma)$ foil $3 / 5-\mathrm{Cd}$ & $(2.71 \pm 0.12) \mathrm{E}-16$ & $(3.06 \pm 0.13) \mathrm{E}-16$ \\
\hline${ }^{115} \operatorname{In}(\mathrm{n}, \gamma)$ boron sphere & $(7.07 \pm 0.17) \mathrm{E}-17$ & - \\
\hline${ }^{63} \mathrm{Cu}(\mathrm{n}, \gamma)$ boron sphere & $(1.49 \pm 0.04) \mathrm{E}-17$ & $(1.60 \pm 0.05) \mathrm{E}-17$ \\
\hline${ }^{115} \operatorname{In}\left(\mathrm{n}, \mathrm{n}^{\prime}\right)$ boron sphere & $(6.06 \pm 0.20) \mathrm{E}-19$ & $(6.04 \pm 0.20) \mathrm{E}-19$ \\
\hline
\end{tabular}


Figure 4 shows an unfolded 8-group free-field unperturbed neutron spectrum obtained from the previously-described least square fitting process. This unfolded spectrum was actually computed using only 30 of the available 33 activation measurements (i.e., NF was 30 and NG was 8 in Equation 7). The neutron capture responses of the copper and indium foils in the boron sphere were not required for this evaluation. Experience has shown that these responses sometimes do not add any significant information with typical unfolding group structures used to accurately represent epithermal neutron spectra. However, they can tend to significantly degrade conditioning of the unfolding matrix, as well as the quality of the least-squares fit, as measured by the reduced chi-squared parameter (Equation 9 divided by the difference between NF and NG). It may be noted, in this regard, that the reduced chi-squared parameter for the spectrum shown in Figure 3 is approximately 1.7, indicating a good fit relative to the uncertainties of the reaction rate data.

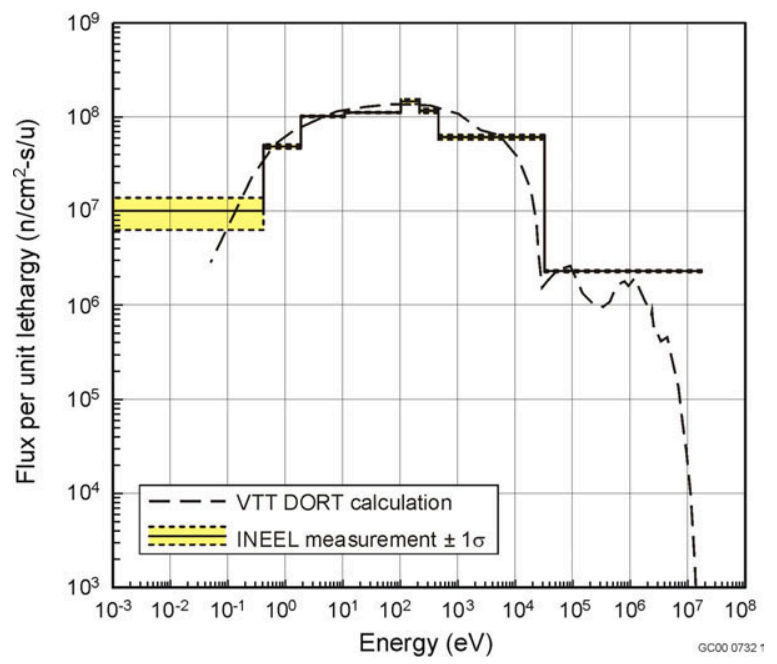

Figure 4. Unfolded free-beam neutron spectrum obtained by direct least-square fitting for the FiR 1 epithermal neutron beam facility (14 cm aperture). The reactor power was $250 \mathrm{~kW}$.

Integrating the measured curve shown in Figure 4 over the thermal $(<0.414 \mathrm{eV})$, epithermal $(0.414 \mathrm{eV}-10 \mathrm{keV})$, and fast $(>10 \mathrm{keV})$ neutron energy ranges yields the flux parameters shown in the first column of Table 3. The uncertainties are based on the propagated measurement uncertainties, plus estimates of systematic uncertainty due to foil positioning uncertainty, mass uncertainty, and uncertainties in the a-priori spectrum used to compute average unfolding constants for each broad group. Independent measurements performed by $\mathrm{VTT}^{3,4}$, using a somewhat different foil set and the $\mathrm{LSL}^{12}$ adjustment program, yielded thermal, epithermal, and fast flux values (and associated uncertainties) as shown in the third column of Table 3. The DORT calculations performed by VTT yielded values shown in the last column of Table 3 . Of particular note is the fact that the epithermal neutron flux is noticeably higher in the revised INEEL evaluation, relative to what was reported in Reference 5, bringing it into closer agreement with the VTT evaluation. Note also that the VTT measurements, as well as the calculation, are for a location at the center of the beam exit aperture. According to the calculation, the flux 
values at the outer foil positions of the INEEL foil wheel are $3 \%$ smaller for the thermal and fast fluxes and $2 \%$ smaller for the epithermal flux. This further reduces the discrepancy of the two determinations.

Table 3. Integral neutronic parameters for the FiR 1 free beam (14 cm aperture) at $250 \mathrm{~kW}$. Uncertainties at the $1 \sigma$ level are shown in parentheses.

\begin{tabular}{|c|c|c|c|c|}
\hline & $\begin{array}{l}\text { INEEL Direct } \\
\text { Unfolding }\end{array}$ & $\begin{array}{l}\text { INEEL SAND-II } \\
\text { Type Adjustment }\end{array}$ & $\begin{array}{l}\text { VTT LSL-M2 } \\
\text { Adjustment }\end{array}$ & $\begin{array}{l}\text { VTT DORT } \\
\text { Calculation }\end{array}$ \\
\hline Fast Flux (n/cm $\left.{ }^{2}-\mathrm{s}\right)$ & $3.83 \times 10^{7}(4 \%)$ & $3.15 \times 10^{7}$ & $3.45 \times 10^{7}(25 \%)$ & $3.20 \times 10^{7}$ \\
\hline $\begin{array}{l}\text { Epithermal Flux } \\
\left(\mathrm{n} / \mathrm{cm}^{2}-\mathrm{s}\right)\end{array}$ & $9.32 \times 10^{8}(1.9 \%)$ & $9.52 \times 10^{8}$ & $1.08 \times 10^{9}(5 \%)$ & $1.03 \times 10^{9}$ \\
\hline $\begin{array}{l}\text { Thermal Flux } \\
\left(\mathrm{n} / \mathrm{cm}^{2}-\mathrm{s}\right)\end{array}$ & $1.06 \times 10^{8}(38 \%)$ & $5.71 \times 10^{7}$ & $6.36 \times 10^{7}(21 \%)$ & $5.91 \times 10^{7}$ \\
\hline $\begin{array}{l}\text { Neutron Dose Rate } \\
\text { (cGy/min) }\end{array}$ & 1.43 & 1.44 & 1.40 & 1.35 \\
\hline 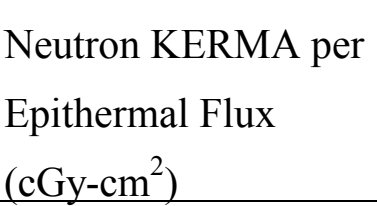 & $2.56 \times 10^{-11}$ & $2.52 \times 10^{-11}$ & $2.15 \times 10^{-11}$ & $2.18 \times 10^{-11}$ \\
\hline
\end{tabular}

Figure 5 shows the results of an alternate spectrum estimation procedure based on adjusting the unnormalized 47-group a-priori neutron spectrum using an INEEL implementation of the iterative method described by Draper ${ }^{13}$, which itself is a variation of the method used in the wellknown SAND-II code ${ }^{14}$. It attempts to find a spectrum that reproduces the measured foil responses as closely as possible by iteratively adjusting the a-priori fine group flux until a satisfactory result is obtained, as indicated by the reduced chi-squared parameter for the fit and by the absence of further significant change in the adjusted spectrum from one iteration to the next. During each iteration through the energy groups, the adjustment factor for the flux in a given group is taken as the weighted sum of the ratios, as determined by dividing the measured reaction rate by the computed reaction rate for each foil response, where the calculated reaction rate for each response is computed using the flux spectrum from the previous iteration. The weight function is simply the macroscopic activation cross section for each foil in each group. Typically, only a few iterations through the energy groups are required to produce a reasonable result using this method. The a-priori and the adjusted fluxes are shown in Figure 5. The integral flux parameters computed from the adjusted spectrum are shown in the second column of Table 3. 


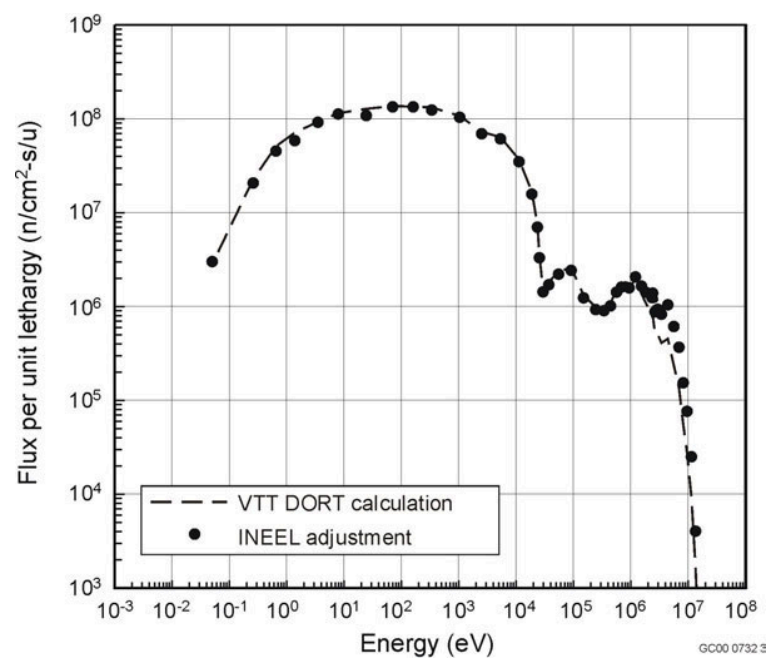

Figure 5. Measured free-beam neutron spectrum obtained by iterative adjustment for the FiR 1 epithermal neutron beam facility (14 cm aperture). The reactor power is $250 \mathrm{~kW}$.

A simple, but widely used, metric for the quality of reactor-based epithermal-neutron beams is based on dividing the free-field neutron KERMA rate of the beam (integrated over all energies above thermal) by the useful epithermal-neutron flux, again measured in the free field. This is a measure of the non-selective background dose that will be produced in tissue by the beam itself, in the absence of any neutron capture agent that may be administered to the patient. This parameter can be estimated using the measured flux spectrum in conjunction with broad group KERMA factors based on the assumed tissue composition and microscopic KERMA factor data available on File 27 of the BUGLE library. The assumed tissue composition is given in Table 4. Fine-group neutron KERMA factors from File 27 are averaged over the broad unfolding groups, using the a-priori spectrum as a weighting function, to produce the necessary information in the case of the broad-group, least-squares unfolding method. The factors are used directly in the case of the empirical adjustment method, where the 47-group energy structure is retained. The measured and calculated values of this parameter are also shown in Table 3. Approximately $91 \%$ of this neutron dose results from proton recoil. The remainder is from other components. The results are reasonably consistent, and are all well within the range considered acceptable in clinical BNCT practice.

Finally, it may be noted that the stacked foil technique described here offers a simple method for measurement of the neutron flux at specific energy points of interest across the epithermal range. Pointwise (actually, averages across a single fine energy group) flux values at the energies of the primary resonance for the materials in the foil wheel were obtained using the measured responses of the first and third foils in each foil stack. A system of two equations in two unknowns, similar to Equation 7, was constructed for each foil type. The first unknown was the energy-integrated flux within a narrow energy group centered on the primary resonance for a given foil material. 
Table 4. Assumed tissue composition used for FiR 1 beam dosimetry (attributed to Fairchild ${ }^{15}$ )

\begin{tabular}{|c|c|}
\hline Element & Density (atoms/barn-cm) \\
\hline $\mathrm{H}$ & 0.06011 \\
\hline $\mathrm{C}$ & 0.01153 \\
\hline $\mathrm{N}$ & 0.001118 \\
\hline $\mathrm{O}$ & 0.02296 \\
\hline $\mathrm{Cl}$ & 0.00003397 \\
\hline
\end{tabular}

The second unknown was the total neutron flux outside of the narrow resonance group, integrated over all energies above and below the resonance group. The reaction rates of the first and third foils in the stack were used on the right hand side of the $2 \times 2$ system. The response function of the third foil in a stack is linearly-independent from that of the first foil due to suppression of the resonance flux in the third foil by the first foil. Hence, the first foil is relatively more sensitive to the resonance flux, while the third foil is relatively more sensitive to the flux outside of the primary resonance. Solution of the $2 \times 2$ system of equations then yields the total flux in the resonance group as one element of the solution flux vector. These fluxes (per unit lethargy) are plotted in Figure 6, with the computed spectrum again shown for comparison. They were obtained using the response data from, in order of increasing neutron energy, the indium, gold, tungsten, cobalt, manganese, and copper foil stacks. Good agreement with the computed spectrum is apparent.

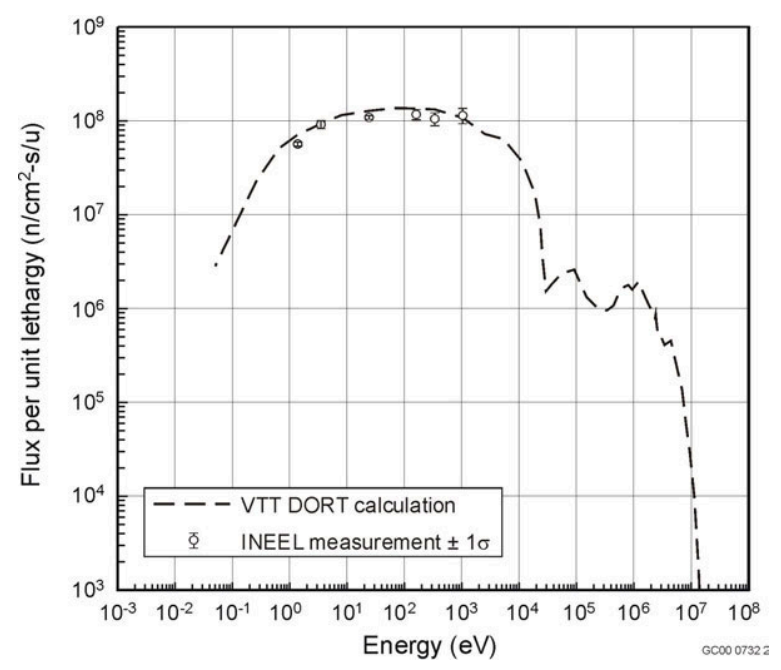

Figure 6. Measured pointwise free-beam neutron flux values (14 $\mathrm{cm}$ aperture) obtained at various energy points of interest across the epithermal spectrum by analysis of the stacked foil packages individually. The reactor power is $250 \mathrm{~kW}$. 


\section{DISCUSSION}

The INEEL has had a strong historical interest in the use of the VTT aluminum fluoride based epithermal neutron moderating material (FLUENTAL ${ }^{\mathrm{TM}}$ ) for applications involving new reactorbased and accelerator-based epithermal-neutron sources for BNCT. These applications include the epithermal-neutron beam currently under construction at the Washington State University (WSU) TRIGA $^{\mathrm{TM}}$ research reactor facility ${ }^{16}$ as well as certain advanced accelerator-based epithermal-neutron source concepts ${ }^{17}$. The opportunity to perform these measurements, and to cross-compare the results with the independent VTT measurements, has been of great value, both as a validation of the beam design as well as a basis for improvement of the spectral measurement techniques.

\section{REFERENCES}

1. I. Auterinen, P. Hiismäki, et al., "The new boron neutron capture therapy facility at the Finnish nuclear research reactor (FiR 1)", Med. \& Biol. Eng. \& Comp., 37, suppl. 1 (1999) 398-399.

2. I. Auterinen, P Hiismäki, T Serén, T. Seppälä, "Creating an Epithermal-Neutron Field for BNCT Using a TRIGA Reactor and an Aluminum Fluoride Composite as Neutron Moderator", In: Proceedings of the 1998 ANS Radiation Protection and Shielding Division Topical Conference, Technologies for the New Century, April 19-23, 1998, Nashville, Tennessee, USA, ANS 1998, Vol 2, pp 77-83

3. Tom Serén, et al., "Spectral Characterization of the Neutron Field at the Improved Finnish Epithermal BNCT Facility", In: Proceedings of the Eighth International Symposium on Neutron Capture Therapy, Plenum Press, New York (In Publication).

4. Tom Serén, et al., "A Tale of Two Beams - Comparison of the Radiation Fields at the BMRR and FiR Epithermal BNCT Facilities", Proceedings of the $11^{\text {th }}$ Nordic-Baltic Conference on Biomedical Engineering, Tallinn, Estonia, June, 1999 (In Publication).

5. D.W. Nigg, et al., "Collaborative Neutronic Performance Characterization of the FiR 1 Clinical Epithermal-Neutron Beam Facility for BNCT”, In: J.R. Venhuizen (ed.), INEEL BNCT Research Program Annual Report 1998, INEEL/EXT-99-00293, April 1999, pp 1338.

6. Marnada et al., Journal of Nuclear Science and Engineering 36 (1999) 1119-1124.

7. T.Seren, and D.W. Nigg, "The Impact of New Decay Data for ${ }^{187} \mathrm{~W}$ on Epithermal Beam Characterization, Proceedings of the Ninth International Symposium on Neutron Capture Therapy for Cancer, October, 2000, Osaka, Japan. 
8. W.A. Rhoades and R.L. Childs, "An Updated Version of the DOT-4 One- and Two Dimensional Neutron/Photon Transport Code", ORNL-5851, Oak Ridge National Laboratory, April 1982.

9. R.W. Roussin, "BUGLE-80 Coupled 47-Neutron, 20 Gamma-Ray P3 Cross Section Library", DLC-75, Radiation Shielding Information Center, 1980.

10. Breismeister, J.F., MCNP - A General Monte Carlo N-Particle Transport Code, Version 4A, LA-12625-M, Los Alamos National Laboratory, USA, 1993.

11. P. A. Aarnio et al., SAMPO 90 High Resolution Interactive Gamma Spectrum Analysis Including Automation with Macros, Report TKK-F-A682, Helsinki University of Technology, Espoo 1991.

12. F. W. Stallmann, LSL-M2: A Computer Program for Least-Squares Logarithmic Adjustment of Neutron Spectra, NUREG/CR-4349, ORNL/TM-9933, Oak Ridge 1986.

13. E.L. Draper Jr. "Integral Reaction Rate Determinations - Part I: Tailored Reactor Spectrum Preparation and Measurement", Nuclear Science and Engineering 48:22-30 (1971).

14. W.N. McElroy et al. "SAND-II Neutron Flux Spectra Determination by Multiple Foil Activation Iterative Method", AWRL-TR-67-41, Vol 1-4 (1967).

15. R.G. Fairchild, "Development and Dosimetry of an Epithermal Neutron Beam for Possible Use in Neutron Capture Therapy", Phys. Med. Biol., 10(4):491 (1965).

16. J.R. Venhuizen, et al., "Progress on Construction of an Epithermal Neutron Beam for Preclinical BNCT Research at Washington State University", In: J.R. Venhuizen (ed.), INEEL BNCT Research program Annual Report 1999, April, 2000, INEEL-EXT-200000392.

17. D.W. Nigg, H.E. Mitchell, Y.D. Harker, J. Frank Harmon, "Experimental Investigation of Filtered Epithermal Neutron Beams for BNCT", In: B. Larsson et al. (Editors), Advances in Neutron Capture Therapy, Volume I- Medicine and Physics, Elsevier Science BV, Amsterdam, 1997. 


\title{
COLLABORATIVE NEUTRONIC PERFORMANCE CHARACTERIZATION OF THE CNEA EPITHERMAL-NEUTRON BEAM FACILITY FOR BNCT
}

\author{
D.W. Nigg ${ }^{1}$, H. Blaumann ${ }^{2}$, O. Calzetta Larrieu ${ }^{2}$, J. Longhino ${ }^{2}$, C.A. Wemple ${ }^{1}$, S. Ribeiro ${ }^{2}$ \\ 1. Idaho National Engineering and Environmental Laboratory, Idaho Falls, ID, USA. \\ 2. Comision Nacional de Energia Atomica, Centro Atomico Bariloche, San Carlos de \\ Bariloche, Argentina.
}

\section{INTRODUCTION}

The National Atomic Energy Commission of Argentina (CNEA) has constructed an epithermalneutron beam facility for Boron Neutron Capture Therapy (BNCT) applications at their laboratory complex near San Carlos de Bariloche. The RA-6 research reactor at this installation is used, in conjunction with an epithermal-neutron filtering, moderating, and beam extraction structure located adjacent to the reactor core, to produce an epithermal neutron source suitable for preclinical research as well as selected clinical applications. Primary neutron filtering and moderating materials used in the beam line are aluminum and aluminum oxide. Figure 1 shows the epithermal beam port and treatment room interior.

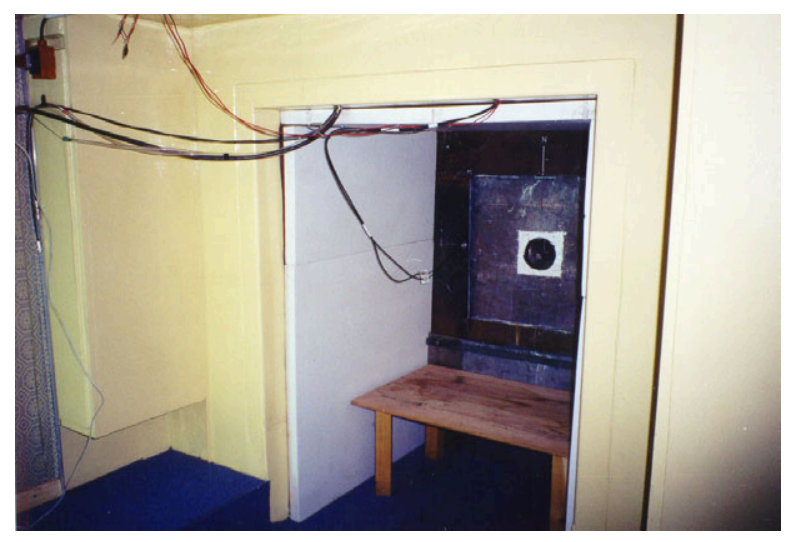

Figure 1. RA-6 epithermal neutron beam port.

The Idaho National Engineering and Environmental Laboratory (INEEL), in collaboration with CNEA under a bilateral US/Argentina agreement on peaceful uses of nuclear science, conducted some basic neutron spectrum measurements at the RA-6 facility during November, 2000 . The free-field spectrum of the RA- 6 epithermal beam was measured using activation foils, following a simplified version of the same protocol used for earlier INEEL measurements at the epithermalneutron facility (FiR 1) operated by the Technical Research Centre of Finland ${ }^{1}$. 


\section{METHODS AND MATERIALS}

The measurements were performed using simplified extensions of neutron activation analysis techniques $^{2}$ that have been adapted for BNCT applications by the INEEL through extensive experience with several other epithermal-neutron facilities in the US and in Europe. Auxiliary neutron transport computations of various types are also required as part of the experimental

protocol. CNEA performed some of these computations, while others were performed by the INEEL. The various computational and experimental methods used for the RA-6 beam characterization are described in the following sections.

\section{Theoretical Computations}

The expected neutronic performance of the RA-6 epithermal-neutron beam facility was computed by CNEA using the well-known MCNP Monte Carlo transport code ${ }^{3}$. MCNP was also used by INEEL to compute various other parameters required for analysis of the measured data.

\section{Activation Foil Measurements in the Free Beam}

Activation measurements to characterize the free beam were conducted using neutronically thick circular foils of various types. The foil specifications and corresponding neutron activation interactions of interest are listed in Table 1. Because of the limited time available, a very simple set of foils was used for these measurements compared to the FiR 1 protocol. Nonetheless, useful results were still obtained.

\section{Positioning of Foils in the Beam}

There were two basic experimental arrangements for positioning the foils in the beam. The first arrangement featured a device machined from Teflon ${ }^{\mathrm{TM}}$ material by the INEEL to facilitate this type of measurement. This device, referred to as a "foil wheel", is shown in Figure 2, positioned in the epithermal neutron beam port. Reproducible positioning of the foil wheel in the plane of the beam exit port was accomplished using a simple cardboard mounting plate, as shown in Figure 2. The gold $(\mathrm{Au})$, copper $(\mathrm{Cu})$, and indium $(\mathrm{In})$ foils used with the foil wheel were 12.7 $\mathrm{mm}$ (0.5 inch) in diameter. A cadmium cover was placed around one foil of each type to suppress the thermal-neutron response. Thus, each foil responds largely to neutrons having energies at or near the energy of the respective primary resonance of the foil material, as shown in the first three lines of Table 1. The three covered foils were placed in three of the outer foil wheel positions. An uncovered gold foil was placed in a fourth outer position of the foil wheel to measure the thermal flux. 
Table 1. Activation interactions and foils used in the INEEL/CNEA epithermal-neutron beam measurements.

\begin{tabular}{|l|l|l|l|l|}
\hline $\begin{array}{l}\text { Neutron } \\
\text { Interaction }\end{array}$ & $\begin{array}{l}\text { Foil } \\
\text { Mass }(\mathrm{g})\end{array}$ & $\begin{array}{l}\text { Actual Foil } \\
\text { Thickness }(\mathrm{cm})\end{array}$ & $\begin{array}{l}\text { Energy Range of } \\
\text { Primary Response }\end{array}$ & $\begin{array}{l}\text { Activation Gamma Energy } \\
\text { of Interest }(\mathrm{keV})\end{array}$ \\
\hline${ }^{115} \mathrm{In}(\mathrm{n}, \gamma)$ & 0.0263 & 0.00284 & $1 \mathrm{eV}$ Resonance & 1293,1097, and 416 \\
\hline${ }^{197} \mathrm{Au}(\mathrm{n}, \gamma)$ & 0.0624 & 0.00255 & $5 \mathrm{eV}$ Resonance & 411 \\
\hline${ }^{63} \mathrm{Cu}(\mathrm{n}, \gamma)$ & 0.1407 & 0.01240 & $1 \mathrm{keV}$ Resonance & 511 (Positron) \\
\hline${ }^{115} \mathrm{In}\left(\mathrm{n}, \mathrm{n}^{\prime}\right)$ & 4.9939 & 0.18820 & $430 \mathrm{keV}$ Threshold & 336 \\
\hline
\end{tabular}

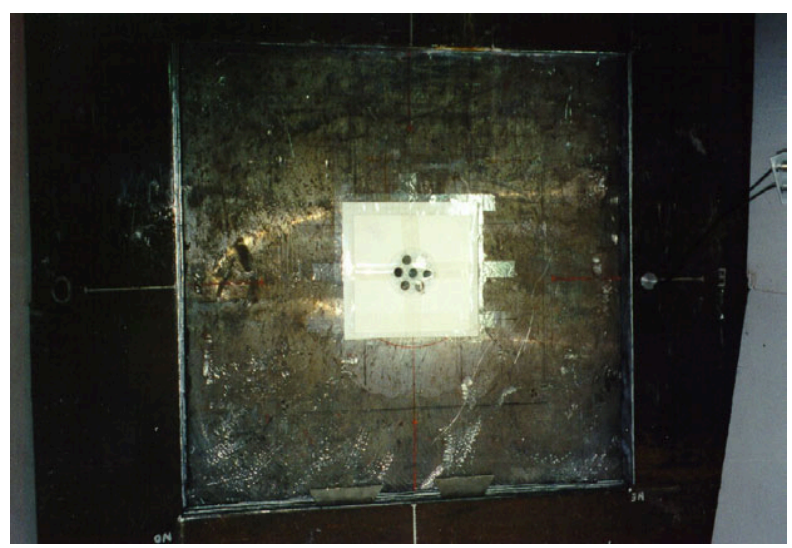

Figure 2. Positioning of foil wheel in the RA-6 beam port.

A second arrangement was used to provide additional spectral information in the high-energy range. A heavy $(\sim 5 \mathrm{~g})$ indium foil, approximately $25.4 \mathrm{~mm}$ (1 inch) in diameter, as shown in the last line of Table 1, was placed in a small hollow boron sphere, shown (disassembled) in Figure 3. The composition of the sphere is approximately $93 \%{ }^{10} \mathrm{~B}$ and $7 \%{ }^{11} \mathrm{~B}$ by weight, with a total boron density of $2.6 \mathrm{~g} / \mathrm{cm}^{3}$. This arrangement provides essentially total suppression of the thermal and epithermal neutron flux within the inner cavity of the boron sphere. Thus, an artificial threshold above the resonance energy range is imposed on the neutron capture reactions in the foil within the sphere. Since the activation gamma emissions that arise from neutron capture in indium are thereby suppressed, the relatively weak $336 \mathrm{keV}$ gamma line from inelastic scatter in indium, which is of crucial interest in these measurements, is much more prominent in the spectrum of the activated indium foil. The activated indium foil is also much easier to handle when the boron sphere is used in this manner, since the induced activity is significantly lower than it would be without the sphere. The inside diameter of the boron sphere is approximately $2.8 \mathrm{~cm}$ (1.1 inchs). The outside diameter is approximately $4.75 \mathrm{~cm}$ (1.9 inchs). The boron 
sphere assembly was irradiated separately from the foils in the foil wheel, but in the same position in the beam port, and at the same reactor power.

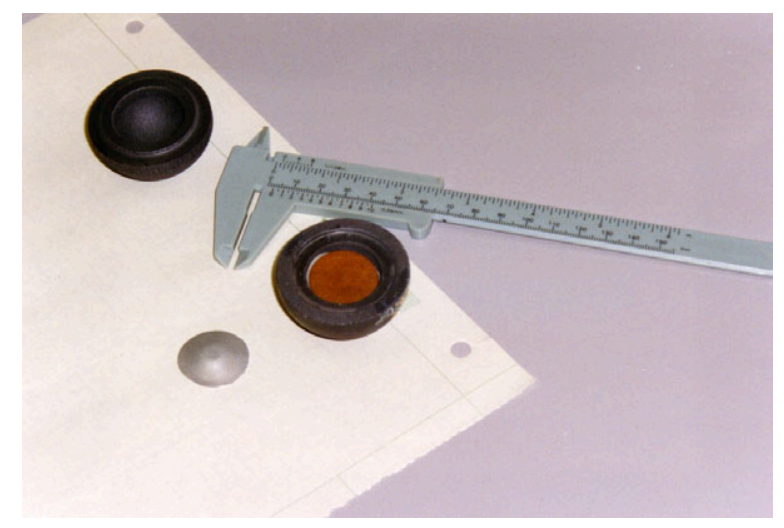

Figure 3. Boron sphere used to suppress low-energy neutron flux.

Use of the foils as described provided 5 basic neutron response functions having a useful degree of linear independence. These response functions were:

1. Resonance capture in the copper, gold, and indium foils in the foil wheel, all with thermal neutron capture suppressed by cadmium (3 responses);

2. Total neutron capture in the single uncovered gold foil in the foil wheel (1 response);

3. Inelastic scatter in the indium foil in the boron sphere (1 response).

The measurements reported here are based on the results of two one-hour irradiations at a reactor power of $360 \mathrm{~kW}$ : one irradiation for the foil wheel; and one for the boron sphere.

\section{Foil Data Acquisition and Analysis}

The irradiated foils were assayed by CNEA using a standard high purity germanium (HPGe) gamma spectrometry system. The induced activities in the free-beam foils were computed from the photopeak areas and system efficiencies reported by CNEA. The measured activity of the heavy indium foil in the boron sphere was corrected for gamma self-shielding using an escape fraction at $336 \mathrm{keV}$, calculated using a combination of MCNP computations and handbook data, for the specific source-detector geometry that was used for the assay. This factor was $0.90 \pm 0.01$. The activity of the indium foil in the cadmium cover was taken as the average of the results derived separately from the measured activities of the three primary gamma lines. The activity of each gold foil was measured twice, and the average of the two values was taken in each case. The final activity results for the free beam monitoring foils are presented in Table 2 . The expected foil activation rates based on the a-priori free beam flux, computed from Equation 2 described in the following section, are also shown for comparison. 
Table 2. Saturation activities for the foils used in the RA-6 free beam spectrum measurements. Uncertainties are given in parentheses at the $1 \sigma$ level.

\begin{tabular}{|c|c|c|}
\hline Interaction Type & $\begin{array}{c}\text { Measured Activation } \\
\text { Rate per Atom }\end{array}$ & $\begin{array}{c}\text { Calculated } \\
\text { Activation Rate } \\
\text { per Atom }\end{array}$ \\
\hline $\mathrm{Au}-197(\mathrm{n}, \gamma)-$ No Cd Cover & $6.48 \times 10^{-14}(3.3 \%)$ & $7.55 \times 10^{-14}$ \\
\hline In-115 (n, $\gamma)-$ Cd Cover & $1.12 \times 10^{-13}(4.3 \%)$ & $1.11 \times 10^{-13}$ \\
\hline $\mathrm{Au}-197(\mathrm{n}, \gamma)-\mathrm{Cd}$ Cover & $6.54 \times 10^{-14}(3.3 \%)$ & $7.49 \times 10^{-14}$ \\
\hline $\mathrm{Cu}-63(\mathrm{n}, \gamma)-\mathrm{Cd}$ Cover & $2.89 \times 10^{-16}(6.6 \%)$ & $2.76 \times 10^{-16}$ \\
\hline Indium (n,n') Foil in B-Sphere & $1.52 \times 10^{-18}(5.4 \%)$ & $1.23 \times 10^{-18}$ \\
\hline
\end{tabular}

\section{Computation of the Free-Beam Neutron Spectrum}

The activation rates of the various foils were used to estimate the neutron spectrum of the RA-6 beam by way of a direct matrix unfolding procedure adapted by the INEEL for this type of measurement. The method is derived as follows. The volume-average activation rate per atom for a foil dosimeter placed in a neutron flux field may be calculated as:

$$
R=\int_{0}^{\infty} \sigma_{f}(E) \Psi_{f}(E) d E
$$

where $\sigma_{f}(E)$ is the microscopic activation cross section of interest for the foil material, as a function of neutron energy, and $\Psi_{\mathrm{f}}(\mathrm{E})$ is the volume-average scalar neutron flux within the foil, again as a function of energy. Equation (1) can also be expressed as:

$$
R=\int_{0}^{\infty} \sigma_{f}(E)\left(\frac{\Psi_{f}(E)}{\Psi(E)}\right) \Psi(E) d E=\int_{0}^{\infty} \sigma_{f}(E) P_{f}(E) \Psi(E) d E
$$

where $\Psi(\mathrm{E})$ is the unperturbed neutron flux that would exist at the measurement location in the absence of the foil and any surrounding spectral modification devices ( $\mathrm{Cd}$ covers, boron sphere, etc.).

It may be noted here that, as a practical matter, the function $\mathrm{P}_{\mathrm{f}}(\mathrm{E})$ in Equation 2 can be determined independently from $\Psi(\mathrm{E})$, if desired, since it is simply a flux ratio. In this case, $\Psi(\mathrm{E})$ on the far right hand side of Equation 2 can be any appropriate a-priori free-beam unperturbed flux estimate, which is then modified by the self-shielding function, $\mathrm{P}_{\mathrm{f}}(\mathrm{E})$. 
Equation 2 may be written as a summation, rather than as an integral, by partitioning the range of the energy variable into a number of discrete contiguous energy groups:

$$
R=\sum_{j=1}^{N G} a_{j} \phi_{j},
$$

where NG is the total number of groups, and

$$
a_{j}=\frac{\int_{E L_{j}}^{E H_{j}} \sigma_{f}(E) P_{f}(E) \Psi(E) d E}{\int_{E L_{j}}^{E H_{j}} \Psi(E) d E},
$$

and

$$
\phi_{j}=\int_{E L_{j}}^{E H_{j}} \Psi(E) d E
$$

where $\mathrm{EL}_{\mathrm{j}}$ and $\mathrm{EH}_{\mathrm{j}}$ are the lower and upper limits of energy group $\mathrm{j}$.

If additional foils are placed in the beam, or if a particular foil exhibits more than one activation response, then Equation (3) may be written as a system of equations:

$$
R_{i}=\sum_{j=1}^{N G} a_{i j} \phi_{j},
$$

where $R_{i}$ is the total activation rate for interaction $i$, and $a_{i j}$ is the activation constant from Equation (4) for reaction $\mathrm{i}$ due to neutrons in energy group $\mathrm{j}$. There will be a total of NF equations, where NF is the total number of activation responses available.

Effective shielded cross sections, $\sigma_{\mathrm{f}}(\mathrm{E})$, and the corresponding shielded and unshielded neutron fluxes suitable for computing the function $\mathrm{P}_{\mathrm{f}}(\mathrm{E})$ in Equation 4 for this work were generated by the INEEL using MCNP models of the dosimeter packages. The a-priori neutron flux exiting the beam port, computed by CNEA, was used to construct the neutron source for the MCNP foil package computations. The same computed a-priori flux was also used to represent $\Psi(\mathrm{E})$ in Equation 2.

It should also be noted here that, in practical applications, the functions $\sigma_{f}(E), P_{f}(E)$, and $\Psi(E)$ ordinarily are not continuous functions. For the work reported here, they are 47-group representations of the actual functions, computed using MCNP and tallied according to the BUGLE-80 neutron energy structure ${ }^{4}$. The integrals in Equations 4 and 5 are, therefore, actually summations over the fine-group structure within each broad group used for spectral unfolding. 
The system of activation equations, Equation (6), may be written out in matrix form as:

$$
\left[\begin{array}{lllll}
a_{11} & a_{12} & a_{13} & \cdots & a_{1 N G} \\
a_{21} & a_{22} & a_{23} & \cdots & a_{2 N G} \\
a_{31} & a_{32} & a_{33} & \cdots & a_{3 N G} \\
\vdots & \vdots & \vdots & & \vdots \\
\vdots & \vdots & \vdots & & \vdots \\
a_{N F 1} & a_{N F 2} & a_{N F 3} & & a_{N F N G}
\end{array}\right] \quad\left[\begin{array}{l}
\phi_{1} \\
\phi_{2} \\
\phi_{3} \\
\vdots \\
\vdots \\
\phi_{N G}
\end{array}\right]=\left[\begin{array}{l}
R_{1} \\
R_{2} \\
R_{3} \\
\vdots \\
\vdots \\
R_{N F}
\end{array}\right]
$$

or, more compactly:

$$
[A][\Phi]=[R]
$$

Equation (7) is exact, provided that the reaction rates, $\mathrm{R}_{\mathrm{i}}$, the activation constants, $\mathrm{a}_{\mathrm{ij}}$, and the group fluxes, $\phi_{\mathrm{j}}$, are all self-consistent. If measured reaction rates for each interaction, $\mathrm{Ri}$, are substituted into Equation (7), a solution of the resulting new system of equations for "measured" fluxes corresponding to the measured reaction rates may also be obtained under certain conditions.

If $\mathrm{NF}=\mathrm{NG}$ (as is the case for the measurements presented here), then the matrix [A] is square, its inverse will ordinarily exist, and the unknown "measured" flux vector may be obtained by any standard solution method that converges, provided that the rows of [A] are linearly-independent. In physical terms, this implies that the response functions (cross sections) for the activation interactions used in the measurement must be selected such that they have different shapes as functions of energy. It may be noted that positive fluxes are not guaranteed to result from this procedure, but if the elements of [A] are computed in a sufficiently valid, physically-realistic manner for the specific measurement configuration, and if the measured reaction rates are accurately determined, a positive solution can generally be obtained.

Propagation of the measurement uncertainties in the unfolding process can be analyzed as follows. An estimate for the variance of the unfolded flux in group $\mathrm{j}$ may be expressed as:

$$
s_{j}^{2}=\sum_{i=1}^{N F}\left(\frac{\partial \phi_{j}}{\partial R_{i}}\right)^{2}\left[u_{i}^{2}\right],
$$

where $u_{i}$ is the experimental uncertainty associated with reaction rate $i$. Thus, it is necessary to compute a matrix of derivatives of the group fluxes with respect to each reaction rate in order to evaluate the uncertainties in the unfolded fluxes from Equation (9). 
If the matrix [A] is square, i.e., if $\mathrm{NF}=\mathrm{NG}$, as in the measurements presented here, the evaluation of the derivatives begins with a rearrangement of Equation (8):

$$
[\Phi]=[C][R]
$$

where $[\mathrm{C}]$ is defined to be the inverse of $[\mathrm{A}]$. Expansion of Equation (10) yields:

$$
\left[\begin{array}{l}
\phi_{1} \\
\phi_{2} \\
\vdots \\
\phi_{N G}
\end{array}\right]=\left[\begin{array}{l}
c_{11} R_{1}+c_{12} R_{2} \cdots c_{1 N G} R_{N F} \\
c_{21} R_{1}+c_{22} R_{2} \cdots c_{2 N G} R_{N F} \\
\vdots \\
c_{N G 1} R_{1}+c_{N G 2} R_{2} \cdots c_{N G N G} R_{N F}
\end{array}\right],
$$

where $\mathrm{NF}=\mathrm{NG}$. Differentiating with respect to $\mathrm{R}_{1}$ now yields

$$
\begin{aligned}
& \frac{\partial \phi_{1}}{\partial R_{1}}=c_{11}, \\
& \frac{\partial \phi_{2}}{\partial R_{1}}=c_{21}, \\
& \frac{\partial \phi_{1}}{\partial R_{2}}=c_{12}, \\
& \frac{\partial \phi_{2}}{\partial R_{2}}=c_{22}, \text { etc. }
\end{aligned}
$$

Thus:

$$
\frac{\partial[\Phi]}{\partial R_{1}}=[C]\left[\begin{array}{c}
1 \\
0 \\
0 \\
\vdots \\
0
\end{array}\right]=[C][\text { column } 1 \text { of an } N G \times N G \text { identity matrix }]
$$

and, in general, 


$$
[A] \frac{\partial[\Phi]}{\partial R_{i}}=[\text { column i of an } N G \times N G \text { identity matrix }],
$$

since

$$
[C]=[A]^{-1} \text {. }
$$

Equation (14) describes NF systems of NG simultaneous equations in NG variables that can be solved for the necessary derivatives. These are used to evaluate Equation (9).

The method outlined here, as well as the more general extension to the overdetermined case, where NF $>$ NG as described in Reference 1, has been implemented in a FORTRAN program, SPECTRE, Version 5.2. This program inputs self-shielded activation cross section functions, $\sigma_{f}(E)$, and the a-priori volume-average unperturbed and perturbed fluxes, $\Psi(\mathrm{E})$ and $\Psi_{f}(\mathrm{E})$, in a user-specified fine-group structure for each activation foil interaction of interest. These, along with a user-input a-priori spectrum (which, in the most rigorous case is the same as $\Psi(\mathrm{E})$, as noted previously), are used to compute the elements of the matrix [A] for NG broad groups, each of which spans one or more specified fine groups. Solution of the various systems of equations to produce the unfolded fluxes and associated uncertainties, corresponding to a user-input set of NF measured activation rates (and associated experimental uncertainties), is accomplished using standard Gauss-Seidel iterations, with linear extrapolation to accelerate convergence.

\section{RESULTS}

Figure 4 shows an unfolded 4-group free-field unperturbed neutron spectrum for the RA-6 beam. The computed 47-group a-priori neutron spectrum from CNEA, normalized to $360 \mathrm{~kW}$, is also shown in Figure 4 for comparison. The unfolded spectrum presented in Figure 4 was actually computed only for the above-thermal energy range, using only 4 of the 5 available responses listed in Table 2 (i.e., NF and NG were both 4 in Equation 7, and the lower energy cutoff for the unfolding calculation was set at $0.414 \mathrm{eV}$ ). The response of the uncovered gold foil was not used because it was not statistically different from that of the covered gold foil, and, in fact, the measured value was slightly smaller (the calculated value was slightly larger, as normally would be expected). This indicates that the thermal flux was not readily measurable with this particular experimental setup due to its very small magnitude, as compared to that of the above-thermal flux.

The broad group structure used for the unfolded spectrum presented in Figure 4 was selected to provide a well-conditioned unfolding matrix and, because it permits the most accurate integration of the measured spectrum in the epithermal energy range, to determine the total epithermal neutron flux. 


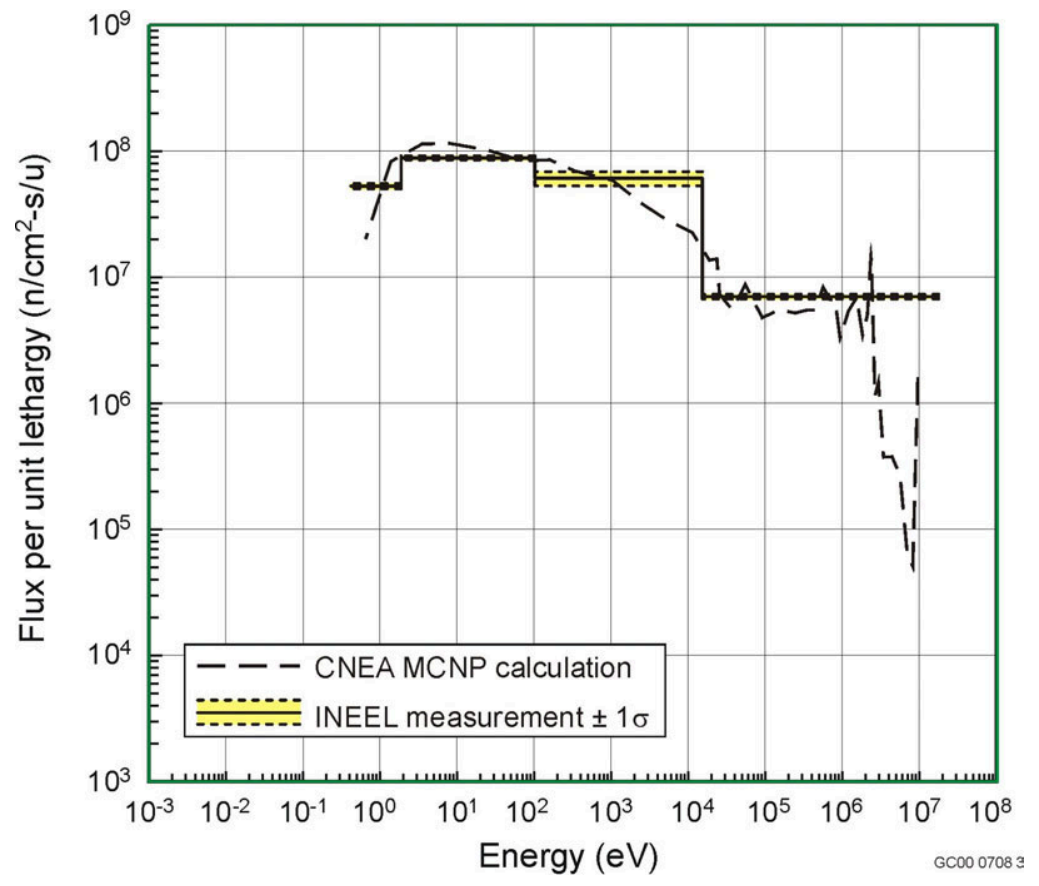

Figure 4. Unfolded free beam neutron spectrum obtained by direct fitting for the CNEA RA-6 epithermal neutron beam facility. The reactor power is $360 \mathrm{~kW}$.

Integrating the measured curve shown in Figure 4 between the standard epithermal energy limits of $0.414 \mathrm{eV}$ and $10 \mathrm{keV}$ produces a measured epithermal neutron flux of $7.22 \times 10^{8} \mathrm{n} / \mathrm{cm}^{2}-\mathrm{sec}$ at $360 \mathrm{~kW}$ with a propagated uncertainty of $5.5 \%(1 \sigma)$. This is in excellent agreement with the value of $7.32 \times 10^{8} \mathrm{n} / \mathrm{cm}^{2}-\mathrm{sec}$ that is obtained by integrating the a-priori curve in Figure 4 between the same energy limits.

A simple, but widely used, metric for the quality of reactor-based epithermal-neutron beams is based on dividing the free-field neutron KERMA rate of the beam (integrated over all energies above thermal) by the useful epithermal-neutron flux, again measured in the free field. This parameter is an indicator of the non-selective background dose that will be produced in tissue by the beam itself, in the absence of any neutron capture agent that may be administered to the patient. It can be computed using the measured flux spectrum in conjunction with broad group KERMA factors based on data for the components of standard tissue available on File 27 of the BUGLE library. Fine-group neutron KERMA factors from File 27 are averaged over the broad unfolding group structure, using the a-priori spectrum as a weighting function to produce the necessary information. This procedure yields a measured free-beam neutron KERMA of $7.94 \mathrm{x}$ $10^{-11} \mathrm{cGy}$ total neutron dose from all components per unit useful epithermal-neutron flux, with an estimated uncertainty of about $7 \%$. Approximately $91 \%$ of the background neutron dose results from proton recoil. The remainder is from other components. It may be noted that the result obtained using this particular measurement technique is somewhat higher $(21 \%)$ than the computed value based on the four-group a-priori spectrum $\left(6.52 \times 10^{-11}\right)$. 
Previous in-phantom neutron dose measurements performed by $\mathrm{CNEA}^{5}$ also yielded a measured background neutron dose rate that was higher than expected by roughly the same ratio $(\sim 20 \%)$. However, the nature of the spectrum unfolding technique used here is such that this apparent agreement could be fortuitous. The accuracy of the broad-group unfolded fluxes can be affected by the accuracy of the fine-group a-priori spectrum within each broad group. The unfolded flux in the highest broad group used here spans a very large energy range compared to the others, and there are some very steep flux gradients with respect to energy in the range. So it is possible that small inaccuracies in the a-priori spectrum could produce a computed shielded cross section (and corresponding element of the matrix [A] in Equation 7), for the first group in particular, that could lead to an overestimate or an underestimate of the unfolded flux in this group. Thus, it is always advisable to verify the unfolded spectrum using more than one analysis technique.

Figure 5 shows the results of an alternate spectrum estimation procedure, based on adjusting the unnormalized 47-group a-priori neutron spectrum, using an INEEL implementation of the iterative method described by Draper ${ }^{6}$. This adjustment method is a variation of the method used in the well-known SAND-II code ${ }^{7}$. It attempts to find a spectrum that reproduces the measured foil responses as closely as possible by iteratively adjusting the a-priori fine group flux until a satisfactory result is obtained, as indicated by the reduced chi-squared parameter for the fit and by the absence of further significant change in adjusted spectrum from one iteration to the next. During each iteration through the energy groups, the adjustment factor for the flux in a given group is taken as the weighted sum of the ratios determined by dividing the measured reaction rate by the computed reaction rate for each foil response, where the calculated reaction rate for each response is computed using the flux spectrum from the previous iteration. The weight function is simply the macroscopic activation cross section for each foil in each group. Typically, only a few iterations through the energy groups are required to produce a reasonable result using this method. The a-priori and the adjusted fluxes for the CNEA beam are shown in Figure 5.

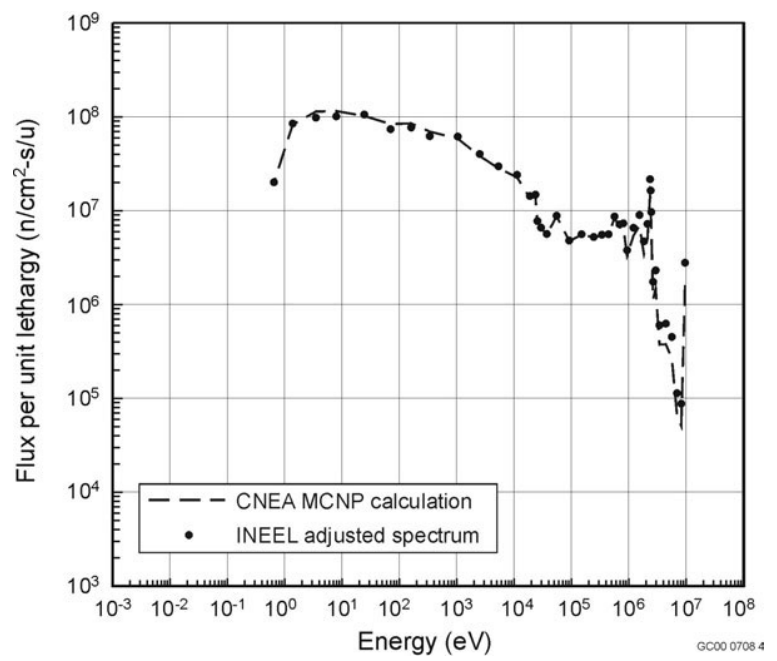

Figure 5. Unfolded free beam neutron spectrum obtained by iterative adjustment for the CNEA RA-6 epithermal neutron beam facility. The reactor power is $360 \mathrm{~kW}$. 
The integrated epithermal flux corresponding to the adjusted curve in Figure 5 is $6.98 \times 10^{8}$ $\mathrm{n} / \mathrm{cm}^{2}-\mathrm{s}$, approximately $3.5 \%$ lower than the epithermal flux obtained by direct unfolding, and within the statistical uncertainty of that result. However, the integrated fast neutron flux $(\mathrm{E}>10$ $\mathrm{keV}$ ) is $4.87 \times 10^{7} \mathrm{n} / \mathrm{cm}^{2}$-s, approximately $13 \%$ lower than is obtained using the direct unfolding method. The corresponding free-beam background neutron KERMA parameter based on the iterative adjustment technique is $7.61 \times 10^{-11}$ cGy per unit epithermal flux. This is about $17 \%$ higher than the computed value from the a-priori spectrum, roughly consistent with the direct unfolding result, as well as with what would be expected based on the previous CNEA phantom measurements. The various integral parameters discussed here are summarized below in Table 3 .

Table 3. Calculated and measured integral flux parameters for the CNEA RA-6 epithermal neutron beam facility. Uncertainties are given in parentheses at the $1 \sigma$ level. The reactor power was $360 \mathrm{~kW}$.

\begin{tabular}{|l|l|l|l|}
\hline & A-Priori Calculation & Direct Unfolding & Iterative Adjustment \\
\hline $\begin{array}{l}\text { Fast Neutron Flux } \\
\left(\mathrm{n} / \mathrm{cm}^{2} \text {-sec) }\right.\end{array}$ & $4.58 \times 10^{7}$ & $5.62 \times 10^{7}(5.1 \%)$ & $4.87 \times 10^{7}$ \\
\hline $\begin{array}{l}\text { Epithermal Neutron } \\
\text { Flux } \\
\left(\mathrm{n} / \mathrm{cm}^{2} \text {-sec) }\right.\end{array}$ & $7.32 \times 10^{8}$ & $7.22 \times 10^{8}(5.5 \%)$ & $6.98 \times 10^{8}$ \\
\hline $\begin{array}{l}\text { Neutron Dose Rate } \\
(\mathrm{cGy} / \mathrm{min})\end{array}$ & 2.86 & 3.44 & 3.19 \\
\hline $\begin{array}{l}\text { Neutron KERMA } \\
(\mathrm{cGy} / \text { Epithermal Flux })\end{array}$ & $6.52 \times 10^{-11}$ & $7.94 \times 10^{-11}$ & $7.61 \times 10^{-11}$ \\
\hline
\end{tabular}

\section{DISCUSSION}

The RA-6 facility is the first clinical scale epithermal-neutron source for neutron capture therapy research in Latin America, and one of only about 10 such facilities currently operational in the world. The results presented here independently confirm the neutronic performance of the RA-6 neutron beam using a very simple experimental approach. Planned future collaborative work of this type may include a measurement of the free beam spectrum using an activation foil protocol that provides more spectral detail, as well as application of the technique to characterize the neutron spectrum at various depths in a water-filled anthropomorphic phantom constructed by CNEA, illustrated in Figure 6. 


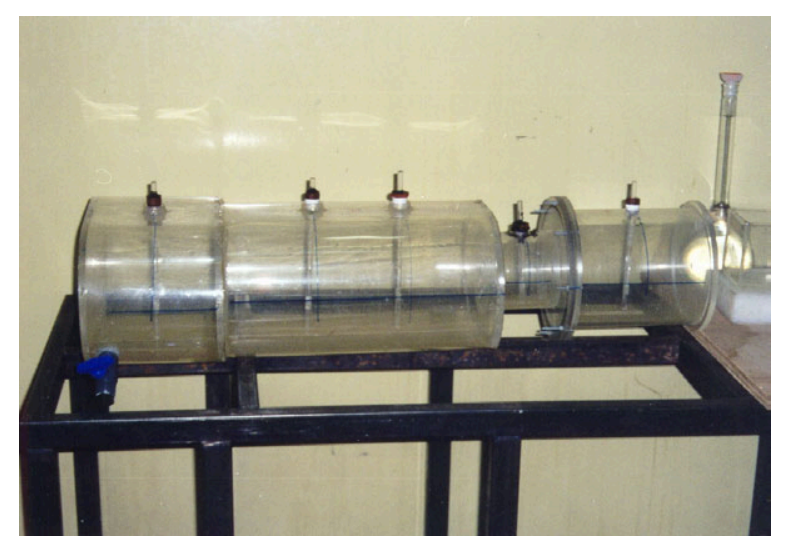

Figure 6. Anthropomorphic phantom constructed by CNEA for neutron capture therapy research.

\section{ACKNOWLEDGEMENTS}

INEEL participation in this work was sponsored by the US Department of Energy, Office of Nuclear Nonproliferation (NN-44), through the Sister Laboratory Program at Argonne National Laboratory. The INEEL and CNEA participants would like to acknowledge the assistance and support of Dr. Basil Picologlou (ANL) and Dr. Sara Liberman (CNEA) in particular.

\section{REFERENCES}

1. D.W. Nigg, et al., "Collaborative Neutronic Performance Characterization of the FiR 1 Clinical Epithermal-Neutron Beam Facility for BNCT", In: J.R. Venhuizen (ed.), INEEL BNCT Research Program Annual Report 1998, INEL/EXT-99-00293, April 1999, pp 13-38.

2. Y.D. Harker, et al., "Spectral Characterization of the Epithermal Neutron Beam at the Brookhaven Medical Research Reactor", Nuclear Science and Engineering, 110:355-368, 1992.

3. Breismeister, J.F., MCNP - A General Monte Carlo N-Particle Transport Code, Version 4A, LA-12625-M, Los Alamos National Laboratory, USA, 1993.

4. R.W. Roussin, "BUGLE-80 Coupled 47-Neutron, 20 Gamma-Ray P3 Cross Section Library", DLC-75, Radiation Shielding Information Center, 1980.

5. J. Longhino, H. Blaumann, O. Calzetta Larrieu, “ In-Phantom Dosimetry Improvement at the RA-6 Beam", Proceedings of the Ninth International ISNCT Symposium on Neutron Capture Therapy for Cancer, Osaka, Japan, October, 2000, pp 267-268. 
6. E.L. Draper Jr. "Integral Reaction Rate Determinations - Part I: Tailored Reactor Spectrum Preparation and Measurement", Nuclear Science and Engineering 48:22-30 (1971).

7. W.N. McElroy et al. "SAND-II Neutron Flux Spectra Determination by Multiple Foil Activation Iterative Method", AWRL-TR-67-41, Vol 1-4 (1967). 


\title{
ADVANCED PROOF-OF-PRINCIPAL EXPERIMENTS FOR FILTERED EPITHERMAL PHOTONEUTRON BEAMS
}

\author{
D.W. Nigg', W. Scates ${ }^{2}$, Y.D. Harker ${ }^{1}$, C.A. Wemple ${ }^{1}$, F. Harmon ${ }^{2}$ \\ 1. Idaho National Engineering and Environmental Laboratory, Idaho Falls, ID. \\ 2. Idaho State University, Pocatello, ID.
}

\section{INTRODUCTION}

The Idaho National Engineering Laboratory (INEEL) has been investigating the feasibility of a concept for an accelerator-based source of epithermal neutrons for Boron Neutron Capture Therapy (BNCT) and other applications, which is based on the use of a two-stage photoneutron production process driven by an electron accelerator. In this concept, shown in Figure 1, electron beams impinge upon heavily-shielded tungsten targets located at the outer radius of a small cylindrical tank of circulating heavy water $\left(\mathrm{D}_{2} \mathrm{O}\right)$. A fraction of the energy of the electrons is converted in the tungsten targets into radially-inward-directed bremsstrahlung radiation.

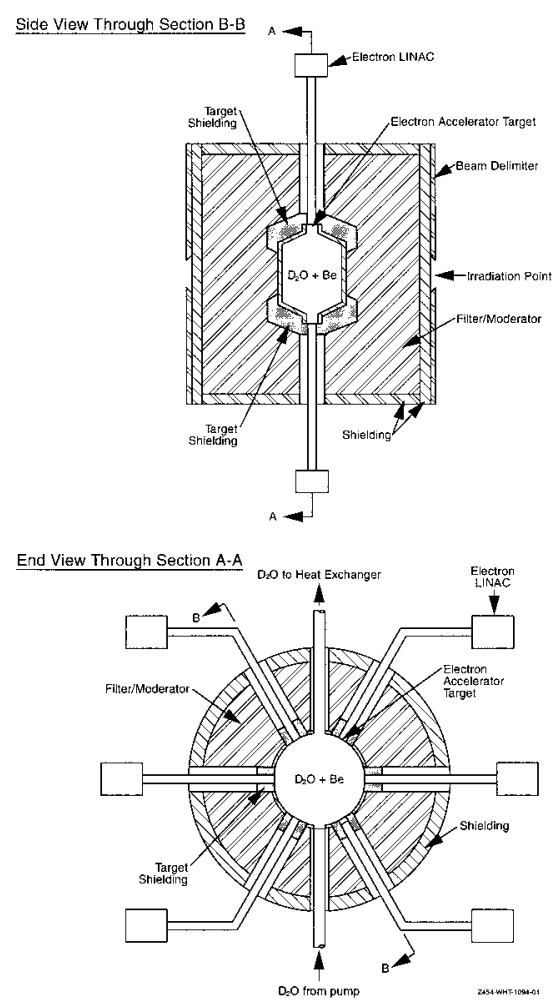

Figure 1. Epithermal photoneutron source concept for BNCT. 
Neutrons subsequently generated by photodisintegration of deuterons in the $\mathrm{D}_{2} \mathrm{O}$ within the tank are directed to the patient through a suitable beam tailoring system. The entire assembly can be constructed in a standard shielded hospital radiotherapy facility. The activities described in this article represent the continuation of a multi-year effort, in collaboration with the Idaho Accelerator Center (IAC) at Idaho State University (ISU), to experimentally demonstrate the feasibility of the concept, using a realistic prototype. With some simple design changes, the device could also be adapted to the production of thermal neutrons for various purposes, including treatment of certain shallow lesions.

\section{BACKGROUND}

Initial proof-of-principal tests, using a low-current benchtop prototype of the filtered photoneutron source concept, were conducted in 1994 and 1995. Testing included extensive measurements of the unfiltered photoneutron source ${ }^{1}$, as well as initial measurements of filtered epithermal-neutron spectra produced using two different advanced neutron filtering assemblies ${ }^{2}$. The results of these tests were used to support a US patent application for the general concept, and a patent was awarded in $1999^{3}$.

In the early experiments, a tunable electron linear accelerator, manufactured by the Varian Corporation, was used to drive the experimental apparatus shown in Figure 2. The electron beam energy was established at a nominal average value of $6 \mathrm{MeV}$, with an approximately Gaussian distribution in energy and an estimated spread of plus or minus roughly $2 \mathrm{MeV}$ (2 sigma) about this value. The forward-peaked bremstrahlung radiation from the tungsten accelerator target was collimated by a cylindrical tungsten shield, and was subsequently directed into a sealed cylindrical lucite container of $\mathrm{D}_{2} \mathrm{O}$, where a well-characterized source of photoneutrons was produced. Neutron filtering and moderating structures were placed downstream of the heavy

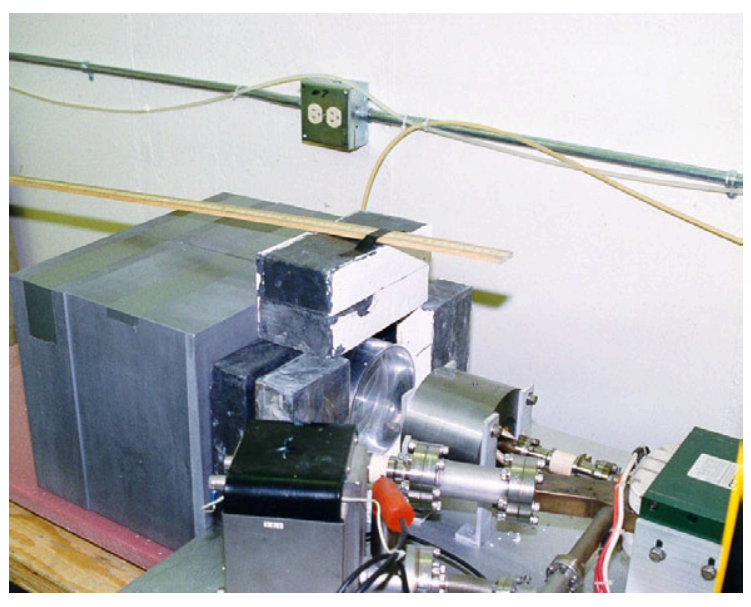

Figure 2. Early apparatus for filtered photoneutron source experiments. 
water photoneutron source region. This arrangement would not be typical of an actual clinical device, where the axis of the neutron beam would be at right angles to that of the electron beam to reduce photon contamination at the patient irradiation point. For these early experiments, however, it was desired to have a simple geometry that could be easily modeled in theoretical calculations.

The neutron filtering and moderating assembly of primary interest was constructed of a composite material $\left(69 \% \mathrm{AlF}_{3}, 30 \% \mathrm{Al} \text {, and } 1 \% \text { natural } \mathrm{LiF} \text {, trade name } \text { FLUENTAL }^{\mathrm{TM}}\right)^{\mathrm{a}}$, developed by the Technical Research Center of Finland (VTT-Finland), and provided for this work to the INEL by VTT under a research agreement. The dimensions of the filter region were $30 \times 30 \times 40 \mathrm{~cm}$. The filter thickness along the beam axis was $30 \mathrm{~cm}$. The measured density of the VTT filtering material was $3.01 \mathrm{~g} / \mathrm{cm}^{3}$. The entire filter was surrounded by $2.54 \mathrm{~cm}$ of borated polyethylene to provide a degree of isolation from room return of neutrons.

Neutron intensity and spectral measurements using standard resonance and threshold activation foil techniques were performed in the early experiments. The results were generally as expected, and thus it was concluded that, on the basis of neutronic performance, the proposed photoneutron device could offer a promising alternate approach to the production of epithermal neutrons for BNCT. However, the measurements were performed at rather low electron currents, leading to somewhat large uncertainties in the results, and, more importantly, the geometry was, by intention, not prototypical. Thus, the next stage of the development effort for this concept, which began in late FY 1999, was focused on construction of a new experimental prototype using a much higher-power L-band electron linear accelerator (LINAC), shown in Figure 3, that was concurrently being brought into operation at the Idaho Accelerator Center.

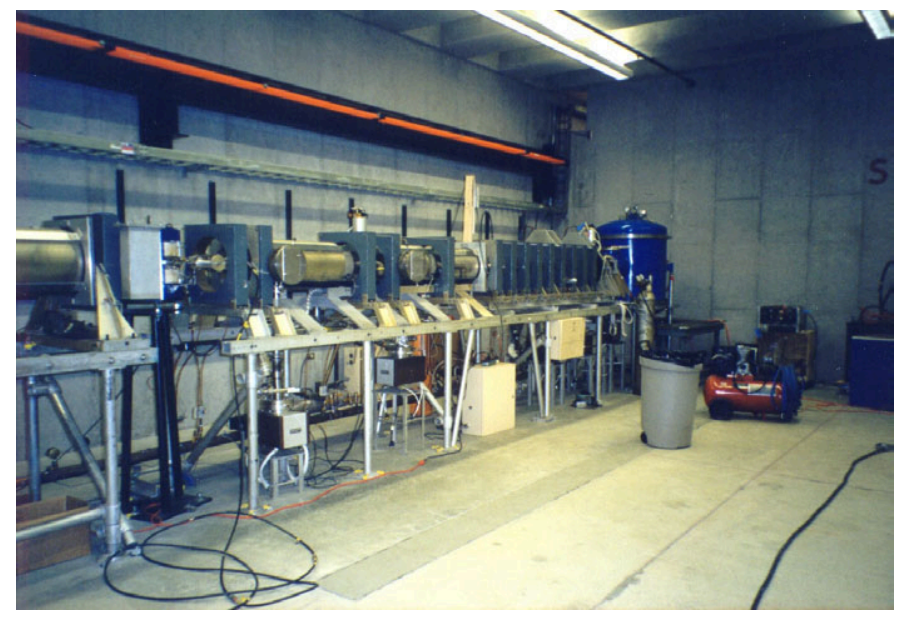

Figure 3. L-Band electron LINAC at the Idaho Accelerator Center.

\footnotetext{
${ }^{\text {a }}$ FLUENTAL is a trademark of The Technical Research Centre of Finland.
} 


\section{CURRENT PROGRESS}

The new experimental apparatus, which is now assembled and ready to operate, features a much more prototypical system geometry, having the irradiation point on an axis at right angles to the electron beam axis. The significantly higher power of the L-Band LINAC will permit neutron spectral measurements with much smaller experimental uncertainties. Furthermore, the rightangle geometry will permit a more realistic measurement of the photon content of the neutron source at the irradiation point. Control of photon contamination to acceptable levels at the irradiation point is crucial to the success of the overall concept. In addition, experimental optimization studies leading to the design of a full-scale device will also be greatly facilitated by the next prototype.

Figure 4 shows the partially-completed experimental neutron production and filtering assembly. The accelerator is on the other side of the concrete shielding wall in the background of the photograph. Electrons from the accelerator are directed down an evacuated drift tube that passes through a hole in the wall. A tungsten target is placed at the end of the drift tube at the point where it is flush with the outside surface of the wall. A cylindrical tank of heavy water is then positioned with its curved surface tangent to the wall, adjacent to the accelerator target, as shown in Figure 4. Hence, the bremsstrahlung photons produced in the target impinge radially onto the immediately adjacent tank. The previously-described block of FLUENTAL filtering material, now with the $40-\mathrm{cm}$ dimension aligned parallel to the filtered beam axis, perpendicular to the tank face, is also shown in Figure 4.

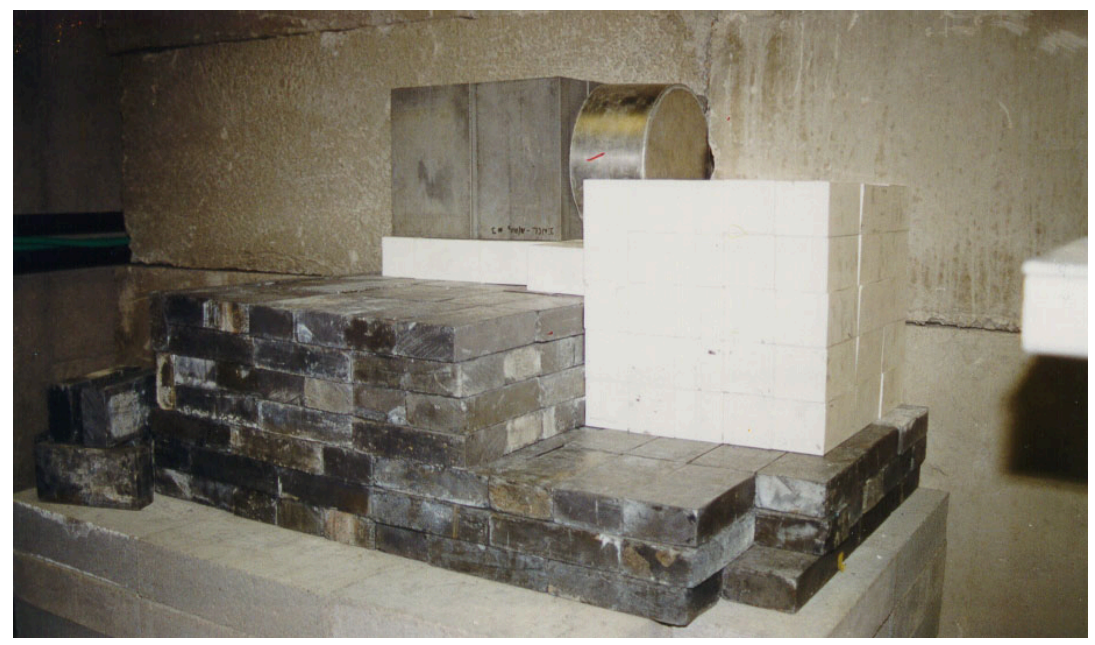

Figure 4. Partially-assembled neutron production and filtering assembly at the Idaho Accelerator Center L-band LINAC Facility. 


\section{FUTURE WORK}

Figure 5 shows the completed filtering assembly, surrounded by an aluminum oxide and lead reflector, with bismuth gamma shielding blocks placed on the downstream face of the FLUENTAL neutron filtering regions. Initial measurements of the neutron spectrum produced by this assembly are scheduled for early 2001 . The data obtained from these initial experiments will be used to design a comprehensive series of computational and experimental parameter studies to be conducted during the remainder of 2001. These studies will be designed to characterize the neutron spectral performance of the device as a function of electron energy, and to measure the gamma contamination level at the irradiation point, per unit useful neutron flux. Activation foils will be used to characterize the neutron flux in these measurements. Gamma radiation measurements will be performed using a calibrated ion chamber. All theoretical computations to support the measurements will be performed using the ITS $^{4}$ and MCNP ${ }^{5}$ codes.

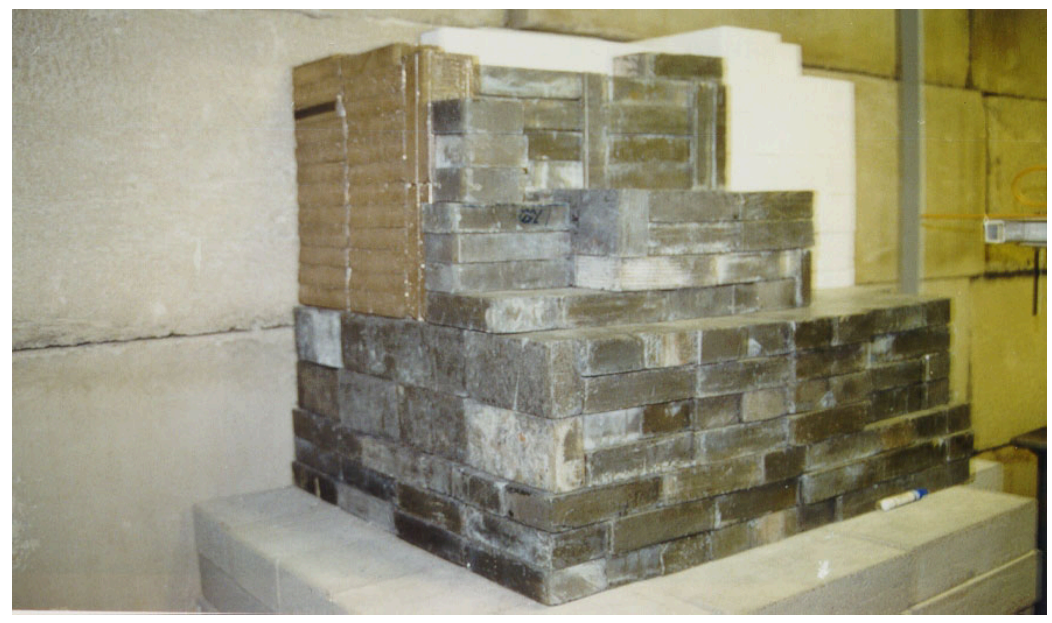

Figure 5. Completed neutron filtering assembly for photoneutron source experiments.

\section{REFERENCES}

1. Nigg, D.W., Mitchell, H.E., Yoon, W.Y., Harker, Y.D., Jones, J.L., “An Accelerator-Based Epithermal Photoneutron Source for BNCT," In: Mishima Y (ed), Proc. 6th Int. Symp. on NCT, Kobe, Japan, 1994, Plenum Press, NY.

2. Nigg, D.W., Mitchell, H.E., Harker, Y.D., Harmon, J.F., "Experimental Investigation of Filtered Epithermal Photoneutron Beams for BNCT", In: Larsson, et al. (eds.), Advances in Neutron Capture Therapy, Volume I, Medicine and Physics, Elsevier Science BV, 1997, pp 477-481. 
3. Yoon, et al., "Accelerator Based Neutron Source for Boron Neutron Capture Therapy and Method”, US Patent 5,903,622, May 11, 1999.

4. Hablieb, J.A. et. al., "ITS- The Integrated Tiger Series of Coupled Electron/Photon Transport Codes", SAND84-05873, Sandia National Laboratory, November, 1984.

5. Briesmeister JF, MCNP - A General Monte Carlo Code for Neutron and Photon Transport, 1986, LA-7396 (Rev 2). 


\title{
RELEASE OF FREE IONS BY FLUENTAL ${ }^{\text {TM }}$ MATERIAL IMMERSED IN WATER
}

\author{
D.D. Siemer ${ }^{1}$, D.W. Nigg ${ }^{1}$, P. Hiismäki ${ }^{2}$, S. Autry-Conwell ${ }^{3}$ \\ 1. Idaho National Engineering and Environmental Laboratory, Idaho Falls, ID. \\ 2. VTT Chemical Technology, Technical Research Centre of Finland, Helsinki, Finland. \\ 3. University of California, Davis, CA.
}

\section{INTRODUCTION}

The Technical Research Centre of Finland (VTT) has been a leader in the development of technology for advanced research reactor based epithermal neutron beam facilities useful in Boron Neutron Capture Therapy (BNCT) research and clinical applications. Their own facility ${ }^{1}$, located at the $250 \mathrm{~kW}$ FiR 1 research reactor installation in Otaniemi, near Helsinki, was brought into full operation in 1998. FiR 1 is a standard TRIGA ${ }^{\mathrm{TM}}$ research reactor of the Mark-II design, produced by the General Atomics Company, La Jolla, California, USA. This facility served as a test bed for a patented, high-efficiency, filter/moderator material with a composition of $69 \%$ $\mathrm{AlF}_{3}, 30 \% \mathrm{Al}$, and $1 \% \mathrm{LiF}$, developed by $\mathrm{VTT}^{2}$ especially for the purpose of producing a highquality epithermal neutron beam from standard, low power, research reactors. This material (trade name FLUENTAL $\left.{ }^{\mathrm{TM}}\right)^{\mathrm{a}}$ is fabricated by hot isostatic pressing (HIP) mixtures of those powders into high-density $\left(\sim 3 \mathrm{~g} / \mathrm{cm}^{3}\right)$ blocks. It was used to construct a $63-\mathrm{cm}$ thick neutron filter/moderator in the large horizontal access port to produce the original FiR 1 epithermalneutron beam. Measurements of the neutronic performance of the beam by the Finnish group ${ }^{3,4}$ and by collaborators from the Idaho National Engineering and Environmental Laboratory $\left(\right.$ INEEL) ${ }^{5}$ validated the VTT design calculations, which had predicted a beam having a particularly high intensity per MW of reactor power, with minimal fast-neutron and gamma components.

The successful development and demonstration of the FLUENTAL material has stimulated interest in its use in the construction of other epithermal-neutron facilities worldwide, with three applications now underway in the US. Some early experimental work conducted by the INEEL, using a photoneutron source driven by an electron accelerator ${ }^{6}$, showed that FLUENTAL material should also perform well in that particular application, but the experimental uncertainties in the early work were rather large because of the low intensity of the available neutron source. New measurements using a higher-powered electron accelerator to reduce the experimental uncertainties are currently underway ${ }^{7}$. In addition, an assembly composed of FLUENTAL blocks serves as the primary neutron moderating filtering component in the new epithermal neutron beam facility nearing completion at the Washington State University (WSU) research reactor center ${ }^{8}$. Finally, the University of California at Davis (UCD) is currently constructing a sophisticated thermal/epithermal neutron beam at the former McClellan Air Force

\footnotetext{
${ }^{\text {a }}$ FLUENTAL is a trademark of The Technical Research Centre of Finland.
} 
Base TRIGA research reactor, which recently became a part of $\mathrm{UCD}^{9}$. Several specialized FLUENTAL components will be installed in the beamline of this facility.

Because the FLUENTAL material contains fluorine in a potentially soluble form, there has been some safety-related interest in the consequences of the hypothetical situation where FLUENTAL neutron filtering components installed in a reactor environment might somehow become directly exposed to the reactor coolant, possibly releasing free fluoride, a corrosive agent, into the coolant. At WSU, the FLUENTAL filter/moderator blocks are installed outside of the reactor tank, lessening this concern considerably. However, at UCD, there is an in-tank block composed of FLUENTAL material that is positioned between the graphite reflector surrounding the reactor core and the inside surface of the vessel wall. Although the in-tank FLUENTAL insert at UCD will be encapsulated in aluminum, with leak detectors installed, it was still deemed necessary for regulatory compliance purposes to measure the fluoride leach rate from the FLUENTAL material prior to installation in the reactor environment. Measurements of this type were originally conducted by VTT (Appendix A), and some confirmatory independent measurements were recently performed by INEEL in support of an overall UCD/INEEL collaboration for design, construction and testing of the new UCD beam facility. This article documents the results of the INEEL study.

\section{METHODS AND MATERIALS}

The INEEL leach study was done to supplement data gathered by VTT using a version of procedure MCC-101S (Appendix A). That protocol invokes one-time exposure of a specimen of known geometric surface area to the leachant (in this case, distilled water), followed by determination of how much of the component of interest ends up in the leachate. The test used at INEEL was the ANS/ANSI-16.1 (Measurement of the Leachability of Solidified Low-Level Radioactive Wastes by a Short-Term Test Procedure, 1986). It generates estimates of the mobility of individual components within specimens that have been fully immersed in water. Mobilities are expressed in terms of effective bulk diffusion constants, D, in units of $\mathrm{cm}^{2} / \mathrm{s}$. Saturation is prevented by periodically replacing the leach water. Three samples of FLUENTAL material were tested. Two samples, denoted as "VTT \#4" and "VTT \#6", contained approximately $0.33 \%$ and $0.25 \%$ by weight $\mathrm{LiF}$, rather than the nominal $1 \%$. The third, referred to as "VTT-square", contained the nominal $1 \% \mathrm{LiF}$ by weight.

The leach specimens were sawed from the original samples using a power hacksaw. These specimens were cut into simple shapes, two of which were short right circular cylinders (rather like large coins), and one was a rectangular prism, so that their geometric surface areas could be readily calculated. The as-cut surfaces were then brought to a uniform degree of surface finish by polishing with \#600 sandpaper (the same treatment specified by the MCC-101S protocol). After polishing, the specimens were vigorously wiped with tissues to remove dust. To assure that the leachant had free access to the entire surface of the specimen, the bottoms of the polypropylene bottles used as the leach vessels were dimpled. Because VTT's study suggested that the absolute amount of material apt to be leached from unirradiated FLUENTAL material would be quite low, in order to generate leachates with sufficient analyte in them for accurate quantitation, only 
enough leach water was used to completely cover the specimens (the standard version of the ANS 16.1 employs a leachant volume to specimen area (V/A) ratio of $10 \mathrm{~cm}-\mathrm{V} / \mathrm{A}$ ratios used for this work ranged from 0.55 to $0.66 \mathrm{~cm}$.) Leaching was done at a slightly elevated (i.e., "conservative") temperature of $47^{\circ} \mathrm{C}$ (vs the recommended $17.5-27.5^{\circ} \mathrm{C}$ ) by placing the bottles in a convection oven. Leachates were analyzed using an inductively coupled plasma atomic emission spectrometer for the cations, and a suppressed ion chromatograph for the anions. The leachates did not contain significant ( $>1 \mathrm{ppm}$ ) amounts of other common anions (e.g., nitrate, chloride, etc.) or cations (e.g., potassium, sodium, or calcium). Relevant data is presented in Table 1.

Table 1. Raw leach data for FLUENTAL specimens.

\begin{tabular}{|c|c|c|c|c|c|c|c|c|c|c|c|c|}
\hline Material & \multicolumn{4}{|c|}{ VTT \#4 } & \multicolumn{4}{|c|}{ VTT \#6 } & \multicolumn{4}{|c|}{ VTT-square } \\
\hline Surface area, $\mathrm{cm}^{2}$ & \multicolumn{4}{|c|}{18.2} & \multicolumn{4}{|c|}{15.0} & \multicolumn{4}{|c|}{31.2} \\
\hline Sample mass, $\mathrm{g}$ & \multicolumn{4}{|c|}{7.9} & \multicolumn{4}{|c|}{9.1} & \multicolumn{4}{|c|}{23.5} \\
\hline $\begin{array}{l}\text { Conductivity }(\mu \mathrm{S} / \mathrm{cm}) \\
\text { and concentrations } \\
(\mathrm{ppm}) \text { of analytes in } \\
\text { leachate }\end{array}$ & Cond & $\mathrm{F}$ & $\mathrm{Li}$ & $\mathrm{Al}$ & Cond & $\mathrm{F}$ & $\mathrm{Li}$ & $\mathrm{Al}$ & Cond & $\mathrm{F}$ & $\mathrm{Li}$ & $\mathrm{Al}$ \\
\hline Rinsate $(\sim 1 \mathrm{~min})$ & 25 & 4.3 & 0.7 & 1.7 & 32 & 4.8 & 0.8 & 1.4 & 28 & 5.9 & 1.2 & 1.4 \\
\hline $1^{\text {st }}$ interval, $1.83 \mathrm{hr}$. & 108 & 12.6 & 6.9 & 1.3 & 74 & 7.0 & 3.4 & 0.5 & 94 & 27 & 6.5 & 6.6 \\
\hline $2^{\text {nd }}$ interval, $5.25 \mathrm{hr}$. & 69 & 5.3 & 4.5 & 0.3 & 44 & 1.8 & 2.2 & 0.2 & 46 & 9.5 & 3.5 & 2.1 \\
\hline $3^{\text {rd }}$ interval, $17 \mathrm{hr}$. & 72 & 5.3 & 4.8 & 0.2 & 58 & 1.9 & 3.0 & 0.2 & 70 & 10.3 & 5.7 & 1.7 \\
\hline $4^{\text {th }}$ interval, $24 \mathrm{hr}$. & 37 & 2.5 & 2.9 & 0.2 & 38 & 1.6 & 2.4 & 0.1 & 51 & 5.9 & 4.0 & 1.3 \\
\hline $5^{\text {th }}$ interval, $121 \mathrm{hr}$. & 56 & 7 & 3.0 & 2.2 & 82 & 2.8 & 4.0 & 0.2 & 147 & 8.2 & 9.8 & 5.2 \\
\hline
\end{tabular}

Note: All of the leachates smelled like hydrogen sulfide and all had measureable ( $>1 \mathrm{ppm})$ concentrations of sulfate in them. pHs ranged from a low of about 5.5 up to about 6.8.

The ANS/ANSI 16.1 protocol translates this type of data to effective diffusion constants (D) as follows:

$$
\mathrm{D}=\pi^{*} \mathrm{~T} *\left(\mathrm{Fi} /(\Delta \mathrm{t})_{\mathrm{n}}\right)^{2} *(\mathrm{~V} / \mathrm{S})^{2}
$$

where

$\mathrm{D}=$ effective bulk diffusivity of a component during the interval, $\mathrm{cm}^{2} / \mathrm{sec}$

$\mathrm{Fi}=$ the fraction of a component leached from the specimen during interval " $\mathrm{n}$ "

$\mathrm{V}=$ volume of the specimen, $\mathrm{cm}^{3}$

$\mathrm{S}=$ geometric surface area of the specimen, $\mathrm{cm}^{2}$

$\mathrm{T}=$ the interval's "mean time" $=\left[0.5 *\left(\mathrm{t}^{1 / 2}+\mathrm{t}^{1 / 2}{ }_{\mathrm{n}-1}\right)\right]^{2}$, where $t_{n}=$ leach interval " $n$ " (seconds). 
When the total quantities of fluoride and aluminum ions initially present in these specimens are used to calculate the fractions leached (Fi) during each interval, the data in Table 1 translate to those in Table 2.

Table 2. Effective mobilities of fluoride, lithium, and aluminum ions based upon total initial makeup values.

\begin{tabular}{|c|c|c|c|c|c|c|c|c|c|}
\hline Specimen & \multicolumn{3}{|c|}{ VTT\#4 } & \multicolumn{3}{c|}{ VTT \#6 } & \multicolumn{3}{c|}{ VTT-square } \\
\hline Mobility (- $\left.\log _{10} \mathrm{D}\right)$ & $\mathrm{F}$ & $\mathrm{Li}$ & $\mathrm{Al}$ & $\mathrm{F}$ & $\mathrm{Li}$ & $\mathrm{Al}$ & $\mathrm{F}$ & $\mathrm{Li}$ & $\mathrm{Al}$ \\
\hline $1^{\text {st }}$ interval, $1.83 \mathrm{hr}$. & 14.5 & 9.6 & 15.8 & 14.9 & 9.8 & 16.4 & 13.7 & 10.5 & 14.2 \\
\hline $2^{\text {nd }}$ interval, $5.25 \mathrm{hr}$. & 15.2 & 9.9 & 17.0 & 16.0 & 10.1 & 17.2 & 14.6 & 11.0 & 15.2 \\
\hline $3^{\text {rd }}$ interval, $17 \mathrm{hr}$. & 15.7 & 10.3 & 17.8 & 16.4 & 10.3 & 17.7 & 15.0 & 11.0 & 15.8 \\
\hline $4^{\text {th }}$ interval, $24 \mathrm{hr}$. & 16.3 & 10.7 & 17.8 & 16.5 & 10.3 & 17.9 & 15.4 & 11.2 & 16.0 \\
\hline $5^{\text {th }}$ interval, $121 \mathrm{hr}$. & 16.3 & 11.6 & 16.6 & 17.0 & 11.3 & 18.5 & 16.1 & 11.4 & 15.7 \\
\hline$\sum$ Fraction leached & $8.6 \mathrm{E}-5$ & $3.2 \mathrm{E}-2$ & $2.5 \mathrm{E}-5$ & $3.4 \mathrm{E}-5$ & $2.3 \mathrm{E}-2$ & $6.3 \mathrm{E}-6$ & $1.0 \mathrm{E}-4$ & $9.3 \mathrm{E}-3$ & $6.9 \mathrm{E}-5$ \\
\hline "leach index" & 15.6 & 10.4 & 17.0 & 16.1 & 10.4 & 17.5 & 15.0 & 11.0 & 15.4 \\
\hline
\end{tabular}

Note: All of the specimens initially contained $\sim 48 \mathrm{wt} \% \mathrm{~F}^{-}$and $\sim 21 \mathrm{wt} \% \mathrm{Al}^{+++}$. The initial lithium concentrations were $0.089 \mathrm{wt} \%$ in VTT \#4, $0.067 \mathrm{wt} \%$ in VTT \#6, and $0.27 \mathrm{wt} \%$ in VTT-square.

The rate of accumulation of ionic solutes in the fifth-interval (121 hour) leachates was monitored by periodically measuring their electrical conductivities, shown in Table 3.

Table 3. Conductivity of the fifth-interval leachates as a function of time.

\begin{tabular}{|c|c|c|c|}
\hline \multirow{2}{*}{ Time } & VTT\#4 & VTT \#6 & VTT-square \\
\cline { 2 - 4 } & Conductivity $\mu \mathrm{S} / \mathrm{cm}$ & Conductivity $\mu \mathrm{S} / \mathrm{cm}$ & Conductivity $\mu \mathrm{S} / \mathrm{cm}$ \\
\hline $2.66 \mathrm{hr}$. & 5.7 & 6.1 & 5.7 \\
\hline $18 \mathrm{hr}$. & 21.8 & 23.3 & 30 \\
\hline $27 \mathrm{hr}$. & 25.7 & 30.4 & 40.8 \\
\hline $121 \mathrm{hr}$. & 56.1 & 82.0 & 147 \\
\hline
\end{tabular}

\section{DISCUSSION}

What does all of this mean?

The CRC Handbook lists the solubility (see Appendix A) of $\mathrm{AlF}_{3}$ in room-temperature water as $5.59 \mathrm{~g} /$ liter, and that of LiF 2.7 as g/liter. These figures correspond to fluoride concentrations of 3790 and $2130 \mathrm{ppm}$, respectively. The highest single fluoride concentration observed in any of the leachates generated by the INEEL tests was $27 \mathrm{ppm}$, and most of them were an order of magnitude lower. Total fluoride leached during the entire duration of these tests (169 hours, 7+ days) ranged from $\sim 10 \mu \mathrm{g} / \mathrm{cm}^{2}$ for VTT \#6 to $20 \mu \mathrm{g} / \mathrm{cm}^{2}$ from VTT-square. Two specimens 
leached by VTT (Appendix A) using the (in some respects less rigorous ${ }^{\mathrm{a}}$ ) MCC-101 protocol lost only 6 and $8 \mu \mathrm{g} / \mathrm{cm}^{2}$ of fluoride. In no case was more than about $0.012 \%$ of the total fluoride solubilized.

Consequently, the primary conclusion to draw from these studies is that the FLUENTAL material does a rather effective job of encapsulating the salts that go into it.

If the fluoride Ds in Table II are recalculated, with the assumption that the only source of leachable fluoride is LiF, they increase by factors of $10^{4.59}$ for VTT \#4, $10^{4.84}$ for VTT\#6, and $10^{3.62}$ for VTT-square. Since these numbers are rather similar to the lithium Ds observed for the same specimens, this suggests (but does not prove) that the assumption that the only source of leachable fluoride is LiF may be right. If so, then only a rather small fraction of the total fluoride in FLUENTAL material is potentially leachable.

The primary assumptions of the ANS/ANSI 16.1 protocol are that: 1) the rate at which a constituent leaches is determined by the rate at which it can diffuse from the interior of the specimen to its surface; and 2) the specimen is absolutely uniform. If these assumptions hold, the leach rate will be inversely proportional to the square root of time, and the Ds observed for all leach intervals will be the same. As is often the case with real materials, experimental results suggest that leaching is not that simple.

First, the apparent diffusivities of all components during the initial leach intervals were greater than those seen during later intervals. In physical terms, this means that the surfaces of these specimens are more "leachable" than are their interiors. Of course, this is to be expected of materials comprised of a physically compacted (HIP) mixture of salts with powdered metal. Since the particles possess finite sizes, a freshly cut specimen exposes the interiors of surface salt grains to the leachant. This "washout" would (and does) enhance the leachrate/apparent mobility of analytes during the initial leach intervals of the ANS/ANSI 16.1 test.

However, if only the surface of the FLUENTAL were leachable, the Ds observed for subsequent leach intervals would drop to approximately zero. While Ds do indeed decrease to rather small figures $\left(<10^{-11} \mathrm{~cm}^{2} / \mathrm{s}\right)$, leaching doesn't completely stop. The conductivity versus time numbers generated for the fifth-interval leachates (Table III) corroborate this. This means that the salts in a chunk of FLUENTAL material do have a finite chance of being mobilized (leached) if it is accidentally breached.

How much chance?

One way to get some feeling for what these "D numbers" mean is to compare them to the figures generated by materials for which the ANS/ANSI 16.1 protocol was originally devised, i.e., lowlevel radioactive waste forms (often concrete-based). The "waste acceptance criterion" for such

\footnotetext{
${ }^{a}$ Less rigorous because the specimens were initially subjected to a much more rigorous pre-leach washing procedure, leaching is done at $\sim 20^{\circ} \mathrm{C}$ rather than $47^{\circ} \mathrm{C}$, and the volume of leach water used per unit surface area of the sample was less.
} 
materials is generally set at $<10^{-6} \mathrm{~cm}^{2} / \mathrm{s}$. Consequently, FLUENTAL material Ds, ranging from $\sim 10^{-17} \mathrm{~cm}^{2} / \mathrm{s}$ for $\mathrm{Al}^{+++}$to $\sim 10^{-10} \mathrm{~cm}^{2} / \mathrm{s}$ for $\mathrm{Li}^{+}$, indicate that its components are much less leachable than are toxic/radioactive constituents of materials deemed acceptable for land-disposal.

After initial "washout" (first two days worth of exposure) has occurred, fluoride leach rates from all of the specimens were under one microgram $/ \mathrm{cm}^{2} /$ day. Since breaching of the aluminum that will sheath bulk FLUENTAL in actual in-tank applications in the US is apt to expose only a small area of the material to a relatively huge volume of water, it is difficult to envision a scenario in which the fluoride concentration of reactor water-so exposed would reach even one part-per-million. Even it that were to happen, it is then equally difficult to envision any serious consequence because: 1) fluorine is too reactive to exist in any form other than fluoride ions under such conditions (it won't be present as HF or elemental fluorine gas); 2) fluoride ions are not particularly corrosive to the materials from which reactors are normally manufactured; and 3) neutrons do not convert fluoride to anything that can cause problems if circulated throughout the reactor's heat exchange system.

The observations that hydrogen sulfide accumulated in the headspace of the leach vessels and sulfate could be detected in the leachates (the maximum $\mathrm{SO}_{4}{ }^{--}$concentration observed was 4.8 ppm) means that the FLUENTAL material also contains some sulfur.

\section{REFERENCES}

1. I. Auterinen, et al., "Metamorphosis of a 35 Years Old TRIGA Reactor into a Modern BNCT Facility", In: Proceedings of the Eighth International Symposium on Neutron Capture Therapy, Plenum Press, New York (In Publication).

2. I. Auterinen, P Hiismäki, T Serén, T. Seppälä, "Creating an Epithermal-Neutron Field for BNCT Using a TRIGA Reactor and an Aluminum Fluoride Composite as Neutron Moderator", In: Proceedings of the 1998 ANS Radiation Protection and Shielding Division Topical Conference, Technologies for the New Century, April 19-23, 1998, Nashville, Tennessee, USA, ANS 1998, Vol. 2, pp 77-83.

3. T. Serén, et al., "Spectral Characterization of the Neutron Field at the Improved Finnish Epithermal BNCT Facility", In: Proceedings of the Eighth International Symposium on Neutron Capture Therapy, Plenum Press, New York (In Publication).

4. T. Serén, et al., "A Tale of Two Beams - Comparison of the Radiation Fields at the BMRR and FiR Epithermal BNCT Facilities", Proceedings of the $11^{\text {th }}$ Nordic-Baltic Conference on Biomedical Engineering, Tallinn, Estonia, June, 1999 (In Publication).

5. D.W. Nigg, et al., "Collaborative Neutronic Performance Characterization of the FiR 1 Clinical Epithermal-Neutron Beam Facility for BNCT", In: J.R. Venhuizen (ed.), INEEL BNCT Research Program Annual Report 1998, INEEL/EXT-99-00293, April 1999. 
6. D.W. Nigg, H.E. Mitchell, Y.D. Harker, J. Frank Harmon, "Experimental Investigation of Filtered Epithermal Neutron Beams for BNCT", In: B. Larsson et al. (Editors), Advances in Neutron Capture Therapy, Volume I- Medicine and Physics, Elsevier Science BV, Amsterdam, 1997.

7. D.W. Nigg, et al., "Advanced Proof of Principal Experiments for Filtered Epithermal Photoneutron Beams", In: J.R. Venhuizen (ed.), INEEL BNCT Annual Report for 2000, INEEL/EXT-01-00204, March 2000.

8. J.R. Venhuizen, et al., "Progress on Construction of an Epithermal Neutron Beam for Preclinical BNCT Research at Washington State University", In J.R. Venhuizen (ed.), INEEL BNCT Annual Report for 2000, INEEL/EXT-01-00204, March 2001.

9. S. Autry-Conwell et al., "University of California Davis Comprehensive Neutron Capture Therapy Program", Proceedings of the Ninth International Symposium on Neutron Capture Therapy for Cancer, October 2-6, 2000, Osaka, Japan. 
APPENDIX A

VTT Leach Test Documentation 


\section{The outcome of the study of solubility in water of FLUENTAL ${ }^{\mathrm{TM}}$ as such and as irradiated three} weeks in the central thimble of FiR 1 TRIGA reactor, in 1996.

\section{Purpose}

The purpose of the study was to assess the integrity of FLUENTAL ${ }^{\mathrm{TM}}$, when exposed to

a) room temperature water

b) reactor in core irradiation in water.

\section{Samples}

Six samples of dimensions $15 \mathrm{~mm} \times 25 \mathrm{~mm} \times 3 \mathrm{~mm}$ and of $1980 \mathrm{~mm}^{2}$ total surface area were cut from FLUENTAL ${ }^{\mathrm{TM}}$ and polished with 600-grit abrasive paper in compliance with MCC-101S standard. The samples were then cleaned with acetone, dried and each placed in a quartz ampoule (i.d. $20 \mathrm{~mm}$, o.d. 25 $\mathrm{mm}$ and length $100 \mathrm{~mm}$ ) with $9 \mathrm{ml}$ ion exchanged, filtered water, sufficient for immersing the sample. The ampoules were loaded and closed by fusing September $20^{\text {th }} 1996$.

\section{Irradiation procedure}

Three of the samples were stored at room temperature as reference samples. The other three were placed in the central thimble of FiR 1, at about 40 degrees centigrade for three weeks. The accumulated neutron fluence and gamma dose were estimated to be

$\begin{array}{ll}\text { Total thermal neutron fluence } & 2.2 \times 10^{18} \mathrm{n} / \mathrm{cm}^{2} \\ \text { Total fast neutron fluence } & 2.7 \times 10^{18} \mathrm{n} / \mathrm{cm}^{2} \\ \text { gamma dose } & 55 \mathrm{MGy}\end{array}$

\section{Weight change}

After three days cooling all the six ampoules were opened. One of the irradiated ampoule exploded, due to mechanical problems, when opening, and the water was partially lost. There was clear over pressure in the irradiated samples, probably due to the radiolysis of water. No loss of weight of any of the samples was observed. Rather a slight increase of weight was observed, probably due to some adsorption of water.

\section{Analysis of fluoride in water}

Fluoride content of the leaching water was analysed by ion chromatography (FINAS T44/Al/95).

The results are given in Table 1.

Otakaari 3 A, Espoo

P.O. Box 1404

FIN-02044 VTT, Finland
Tel. +35894561

$\mathrm{Fax}+35894566390$

Http://www.vtt.fi/ 
Table 1 (letter $\mathrm{V}$ refers to the unirradiated and letter $\mathrm{A}$ to the irradiated samples)

\begin{tabular}{|l|l|l|}
\hline Sample & Fluoride [mg/l] & Comment \\
\hline $0 \quad 24.9 .1996$ & $<0.05$ & zero sample, no FLUENTAL ${ }^{\mathrm{TM}}$ \\
\hline 1.V 23. 9. 1996 & 14 & \\
\hline 1.A 24.10.1996 & 77 & The exploded ampoule \\
\hline 2.V 23.10.1996 & 18 & \\
\hline 2.A 24.10.1996 & 280 & \\
\hline 3.V 23.10.1996 & 18 & \\
\hline 3.A 23.10.1996 & 210 & \\
\hline
\end{tabular}

\section{Considerations}

The hypothesis is that the metal aluminium matrix, formed by the HIP process, serves as a leaching barrier, which prevents the exposure of all but the fluoride grains at the very surface to the immersion water. In order to test this hypothesis, it had been necessary that one set of samples had contained just the constituent powders without any HIP. However, The CRC Handbook provides the value $5.59 \mathrm{~g} /$ litre for the saturation solubility of aluminium fluoride into water and $2.7 \mathrm{~g} /$ litre for the lithium fluoride. When converted to the fluoride ion mass only, these saturation concentrations are $1.26 \mathrm{~g} /$ litre and 1.97 g/litre.

The highest measured fluoride concentrations are at the level $10 \ldots 20 \%$ of these saturation values supporting the barrier hypothesis. Exposure to reactor core irradiation clearly increases the leaching response. This may be due to the neutron induced reaction in lithium- 6 nuclei.

The measured fluoride concentrations suggest that the total delivery of fluoride ions/ $\mathrm{cm}^{2}$ from FLUENTAL $^{\mathrm{TM}}$ into water is $0.1 \mathrm{mg} / \mathrm{cm}^{2}$, when exposed to the given dose of reactor core irradiation. However, further studies are needed, with and without lithium fluoride at different irradiation doses, before the picture is clear. 
factors as materials, respository design, waste paskage design, and wate loading. The combinations specified in MCC-101 are intended to produce baseline data for which considerable confidence will be established by extensive testing; Other data can then be related to these baseline data through commonality of test conditions and similarity of corrosion mechanisms to increase confidenee in otherwise isolated measurements.

\subsection{TEST SPECIMEN PREPARATION}

\subsection{Test Material Characterization}

Deterinine the following characterization data for the test material.

1. Chemical composition: alloying elements and important impurity elements.

2. Heat-treating conditions
a) temperature
b) times
c) atinosphere
d) cooling rates.

3. Grain size in the longitudinal and long- and short-transverse directions reported as average grain diameter ( $\mathrm{m}$ ).

4. Microstructural details such as types and sizes of second phases. This information may be determined with optical microscopy, XRD, or TEM techniques.

5. Room-temperature hardness obtained on duplicate specimens with the appropriate Rockwell scale for the material being evaluated.

\subsection{Test Specimen Details.}

Four replicate rectangular test specimens, each with a surface area greater than $6 \mathrm{~cm}^{2}$, are specified for use in this test method. The ratio of edge area to the total specimen surface area must not be greater than $10 \%$. Finish the specimens by abrading with 600-grit SiC paper on all surfaces.

In addition to the four replicate specimens with the specified 600-gritabraded surfaces finish, which are mandatory for the benchmark tests, other material conditions such as mill finish, as-fabricated, or as-welded are acceptable

\begin{tabular}{|c|c|c|}
\hline & & SUBMITTED FOR \\
\hline OATE & PAGE & MRE APPROVAL \\
\hline 4-15-85 & $101-14$ & \\
\hline
\end{tabular}


for testing provided that the pretest surface is characterized by optical (up to $500 x$ ) and scanning electron (up to 5000x) microscopy.

clean test specimens before testing using the following procedure.

1. After final machining, remove gross contamination of the specimen using a mild detergent or organic solvent. Following this cleaning, specimens will receive: 1 ultrasonic wash in water for at least 5 min; 1 ultrasonic wash in an organic solvent for at least $5 \mathrm{~min}$, followed by drying at $40^{\circ} \mathrm{C}$ for $1 \mathrm{~h}$.

2. After cleaning and drying, handle specimens with gloves or clean manipulators. Store specimens in a manner that prevents contamination.

Use a minimum of four replicate specimens for a given test and material condition. Three replicates are required for weight-change measurements; the other is used for metallographic sectioning and evaluation of corrosion products.

\subsection{PROCEOURE}

\subsection{Quality Assurance}

This procedure inust conform to all applicable quality assurance requirements of the laboratory perfonning the test.

\subsection{Test Sequence}

The test consists of immersing four specimens for each material condition in a test solution for each of the time-temperatures used. The test apparatus consists of a closed test vessel provided with heaters, recorders, and control apparatus for maintaining temperature. The steps for conducting a corrosion test are as follows:

1. Prepare and document preparation of the test solution as described in Section 7. Prepare the test specimens according to section 8 . Start the test within $24 \mathrm{~h}$ of loading the test specimens in the test vessel.

2. Calibrate all instrunents before and after each test. The devices for which calibrations are required and the method of calibration are listed in Table 1, Section 6.4.

\begin{tabular}{|l|r|r|}
\hline DATE & PAGE & MRB APPROVAL \\
$4-15-85$ & $101-15$ & \\
\hline
\end{tabular}


